DOE/EIA-0552(85-91)

Distribution Category UC-950

\title{
Changes in Energy Intensity in the Manufacturing Sector 1985-1991
}

\author{
September 1995
}

Energy Information Administration

Office of Energy Markets and End Use

U.S. Department of Energy

Washington, DC 20585 


\section{Contacts}

General information about Energy Information Administration (EIA) data on energy consumption can be obtained from Lynda T. Carlson, Director of the Energy End Use and Integrated Statistics Division (EEUISD) (202-586-1112).

General information regarding the contents of this publication can be obtained from Dwight K. French, Chief of the Transportation and Industrial Branch (202-586-1126), or Mark A. Schipper, Survey Manager for the Manufacturing Energy Consumption Survey (202-586-1136; Internet MSCHIPPE@EIA.DOE.GOV). Michael J. Margreta (202-5862327; Internet MMARGRET@EIA.DOE.GOV) is the contact for estimation, analysis, and table preparation. Hattie Ramseur (202-586-1124) is the contact for related energy consumption publications. The FAX number for all EEUISD personnel is 202-586-0018.

EIA maintains the Electronic Publishing System (EPUB) to allow the general public to access electronically the tables found in this report and many of EIA's statistical reports. EPUB can be accessed on (202) 586-2557 with communication settings: baud rate of 300-19200, no parity, 8 data bits, 1 stop bit, full duplex, and terminal type (ANSI, ANSI-BBS, VTI00, etc.). EIA also maintains a Home Page (http://www.eia.doe.gov) on the Internet for easy electronic access to EIA reports.

As part of the EIA's mission to provide meaningful data, the consumption surveys welcome comments from our customers. If you have any suggestions on how to make the data in this report more useful to your needs, please contact Mark A. Schipper, Survey Manager, at 202-586-1136, FAX or Internet at the address below.

If you have any data or report-related requirements or suggestions for any of the other EIA consumption surveys, please contact the appropriate survey manager directly, or use the address below.

Commercial Buildings Energy Consumption Survey (CBECS): Martha Johnson, Survey Manager, at 202-586-1135 (Internet: MJOHNSON@EIA.DOE.GOV).

Residential Energy Consumption Survey (RECS): Wendel Thompson, Survey Manager, at 202-5861119 (Internet: WTHOMPSO@EIA.DOE.GOV).

Residential Transportation Energy Consumption Survey (RTECS): Ron Lambrecht, Survey Manager, at 202-586-4962 (Internet: RLAMBREC@EIA.DOE.GOV).

You are encouraged to provide your comments to the survey managers. Your feedback is important to us.

EI-63, Mail Stop 2G-090

1000 Independence Avenue, SW

Washington, DC 20585

FAX: 202-586-0018

Internet: MSCHIPPE@EIA.DOE.GOV 


\section{DISCLAIMER}

This report was prepared as an account of work sponsored by an agency of the United States Government. Neither the United States Government nor any agency thereof, nor any of their employees, make any warranty, express or implied, or assumes any legal liability or responsibility for the accuracy, completeness, or usefulness of any information, apparatus, product, or process disclosed, or represents that its use would not infringe privately owned rights. Reference herein to any specific commercial product, process, or service by trade name, trademark, manufacturer, or otherwise does not necessarily constitute or imply its endorsement, recommendation, or favoring by the United States Government or any agency thereof. The views and opinions of authors expressed herein do not necessarily state or reflect those of the United States Government or any agency thereof. 


\section{DISCLAIMER}

Portions of this document may be illegible in electronic image products. Images are produced from the best available original document. 


\section{Contents}

Page

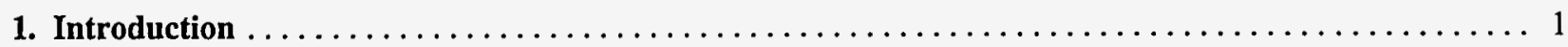

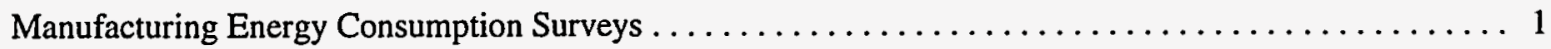

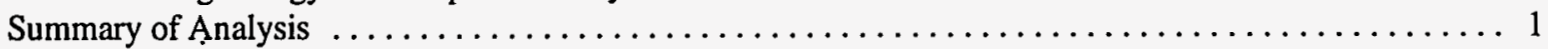

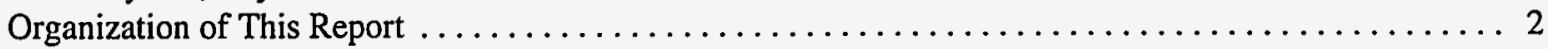

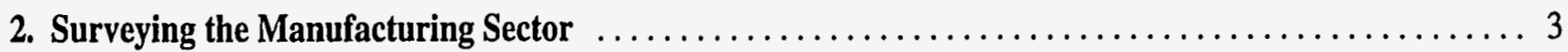

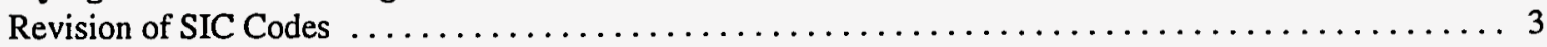

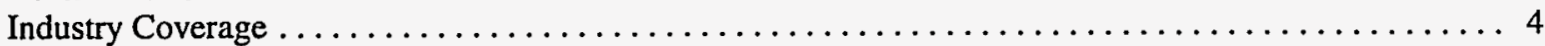

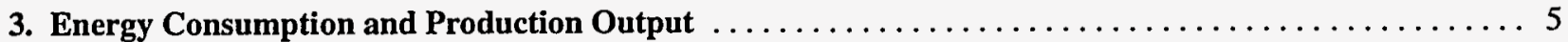

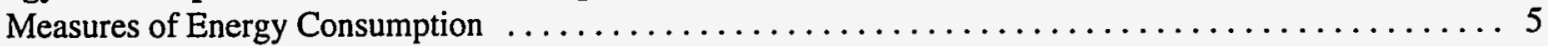

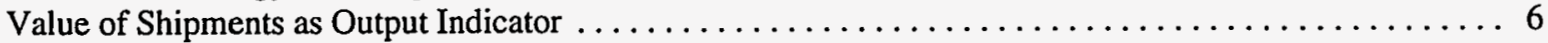

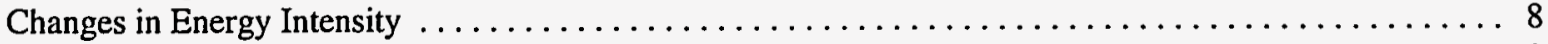

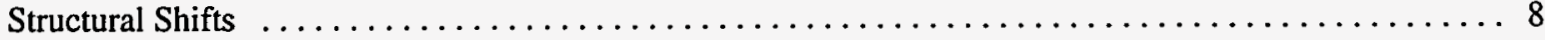

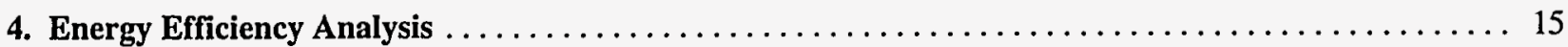

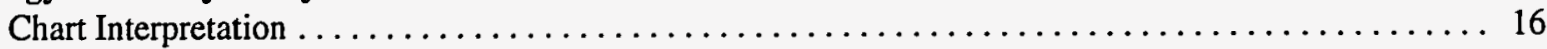

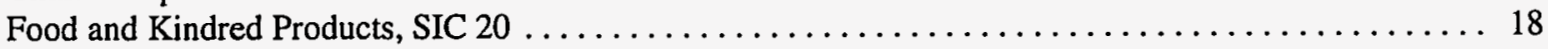

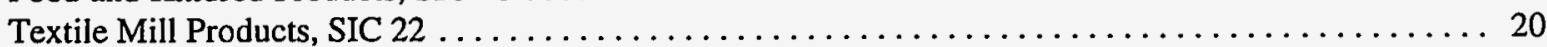

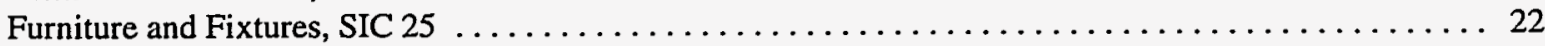

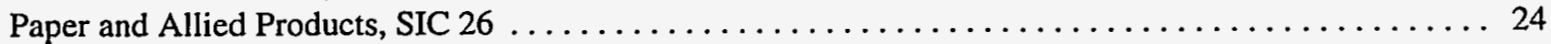

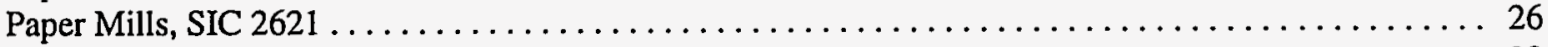

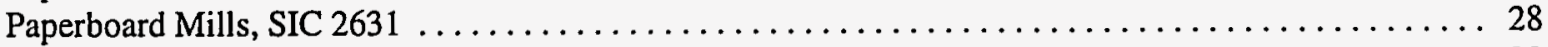

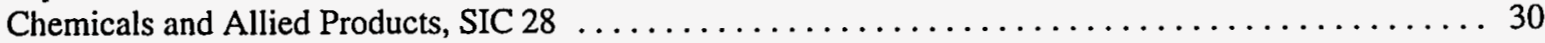

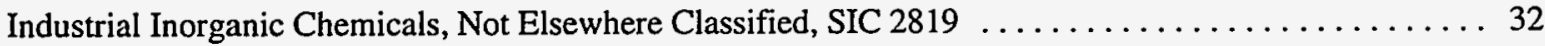

Plastics Materials, Synthetic Resins, and Nonvulcanizable Elastomers, SIC $2821 \ldots \ldots \ldots \ldots \ldots \ldots$

Industrial Organic Chemicals, Not Elsewhere Classified, SIC $2869 \ldots \ldots \ldots \ldots \ldots \ldots \ldots \ldots \ldots$

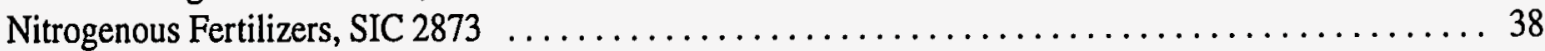

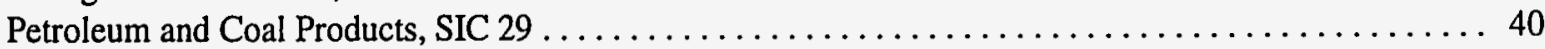

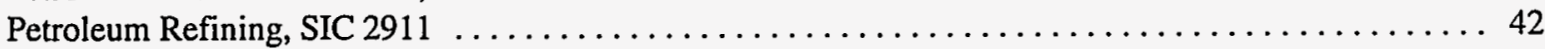

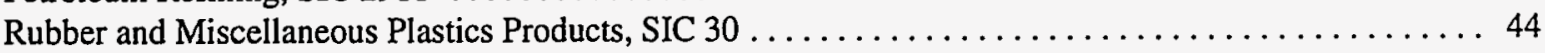

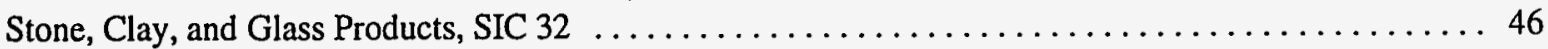

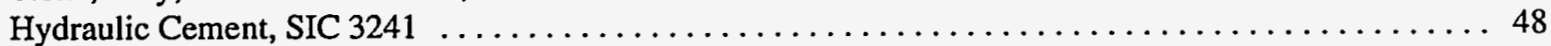

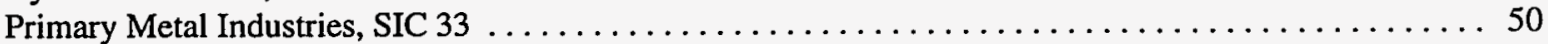

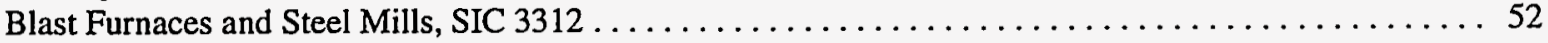

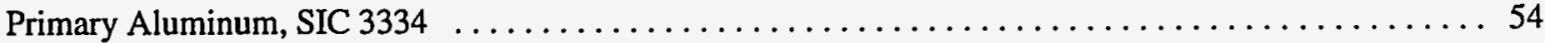

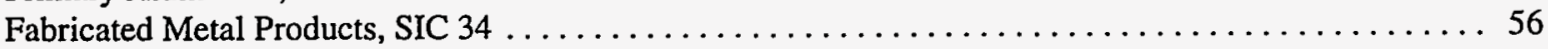

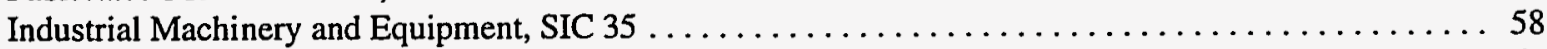

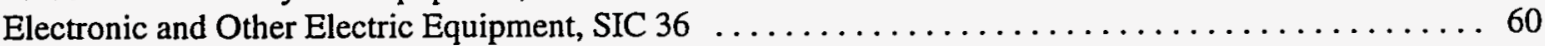

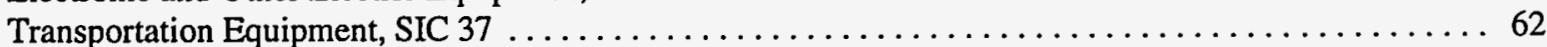

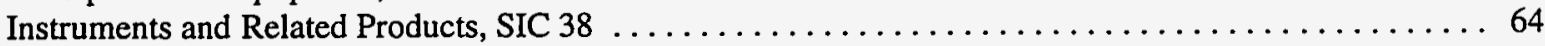

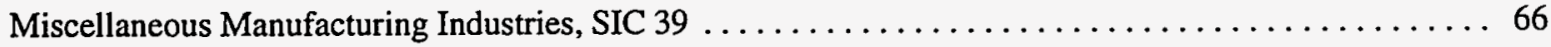

Appendices

A. Survey Design, Implementation, and Estimates $\ldots \ldots \ldots \ldots \ldots \ldots \ldots \ldots \ldots \ldots \ldots \ldots \ldots \ldots \ldots \ldots \ldots \ldots \ldots$

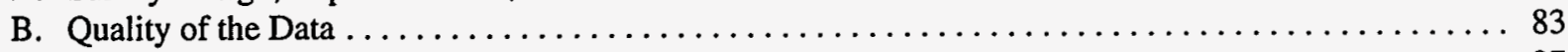

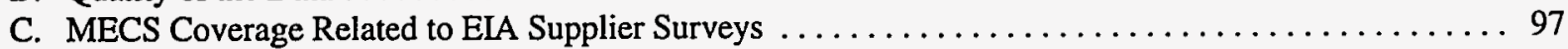

D. Descriptions of Manufacturing Groups and Selected Industries $\ldots \ldots \ldots \ldots \ldots \ldots \ldots \ldots \ldots \ldots \ldots$

E. Related EIA Publications on Energy Consumption $\ldots \ldots \ldots \ldots \ldots \ldots \ldots \ldots \ldots \ldots \ldots \ldots \ldots \ldots \ldots \ldots \ldots$

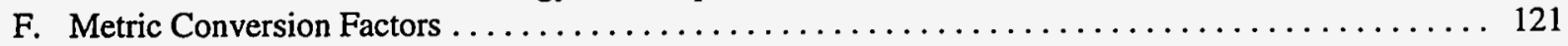

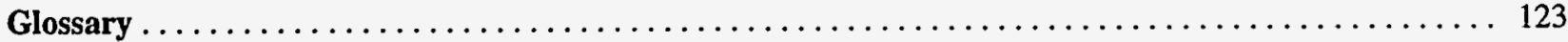




\section{Tables}

1. Primary Energy Intensity of Offsite-Produced Energy in Major Manufacturing Groups, 1985, 1988, and

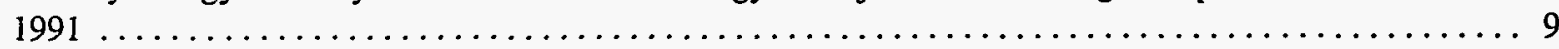

2. Primary Energy Intensity of Total Inputs of Energy in Major Manufacturing Groups, 1985, 1988, and 1991

3. Site Energy Intensity of Offsite-Produced Energy in Major Manufacturing Groups and Selected

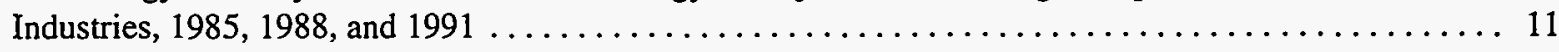

4. Site Energy Intensity of Total Inputs of Energy in Major Manufacturing Groups and Selected

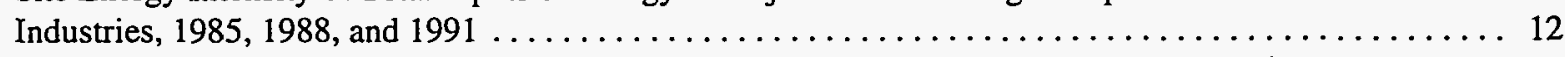

5. Site Energy Intensity of Offsite-Produced Energy (Structurally Adjusted) in Major Manufacturing

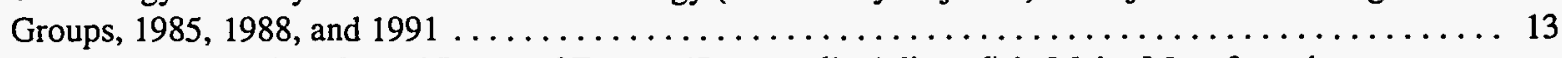

6. Site Energy Intensity of Total Inputs of Energy (Structurally Adjusted) in Major Manufacturing

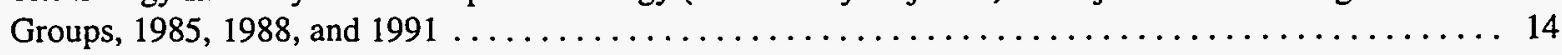

B1. Relative Standard Errors for Primary Energy Intensity of Offsite-Produced Energy in Major Manufacturing

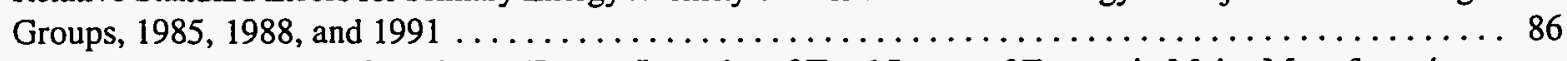

B2. Relative Standard Errors for Primary Energy Intensity of Total Inputs of Energy in Major Manufacturing

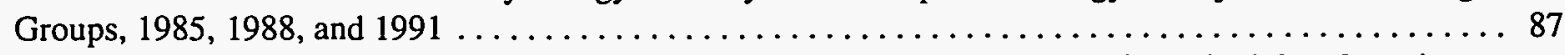

B3 Relative Standard Errors for Site Energy Intensity of Offsite-Produced Energy in Major Manufacturing

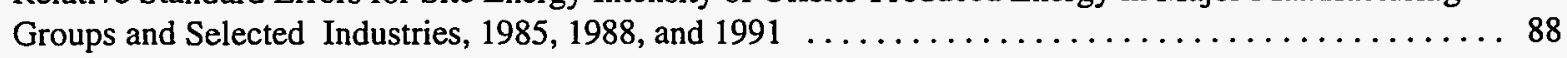

B4. Relative Standard Errors for Site Energy Intensity of Total Inputs of Energy in Major Manufacturing

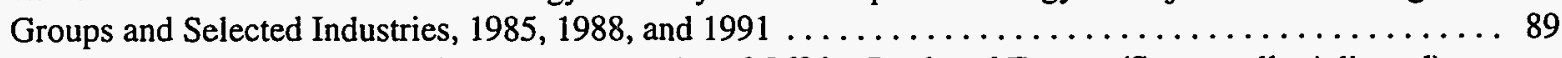

B5. Relative Standard Errors for Site Energy Intensity of Offsite-Produced Energy (Structurally Adjusted)

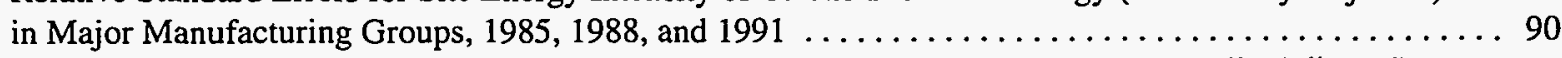

B6. Relative Standard Errors for Site Energy Intensity of Total Inputs of Energy (Structurally Adjusted)

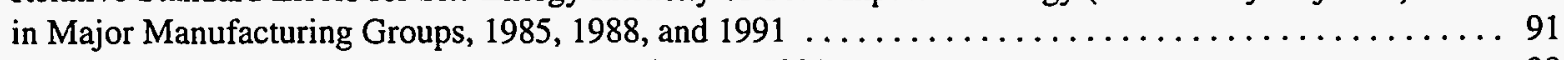

C1. Comparison of EIA Energy Consumption Estimates, $1991 \ldots \ldots \ldots \ldots \ldots \ldots \ldots \ldots \ldots \ldots \ldots . \ldots 8$

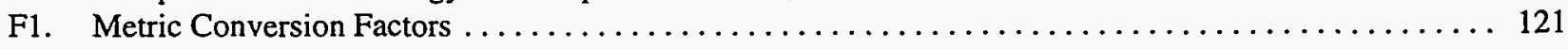




\section{Illustrations}

Figure 4.1. Interpretation of Output and Offsite-Produced Energy Consumption Indices for the Manufacturing Sector, 1977 Through 1991 ...................................... 16

Figure 4.2. Interpretation of Site Energy Intensities for the Manufacturing Sector, 1985-1991 . . . . . . . . 16

Figure 4.3. Output and Offsite-Produced Energy Consumption Indices for SIC 20, 1977 Through $1991 \ldots \ldots 19$

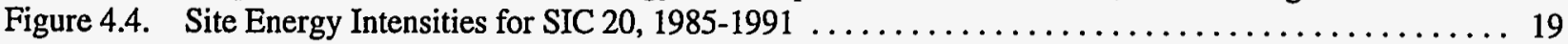

Figure 4.5. Output and Offsite-Produced Energy Consumption Indices for SIC 22, 1977 Through $1991 \ldots \ldots 21$

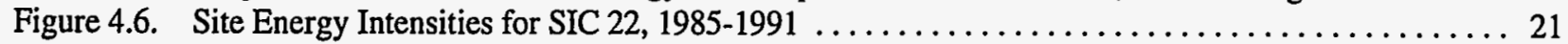

Figure 4.7. Output and Offsite-Produced Energy Consumption Indices for SIC 25, 1977 Through $1991 \ldots \ldots 23$

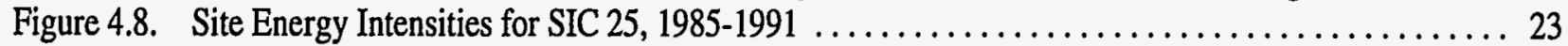

Figure 4.9. Output and Offsite-Produced Energy Consumption Indices for SIC 26, 1977 Through $1991 \ldots \ldots 25$

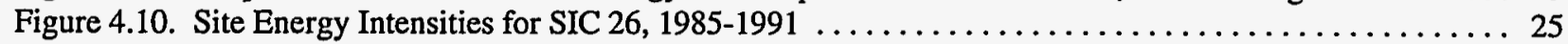

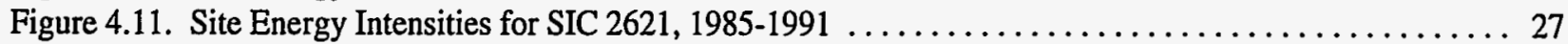

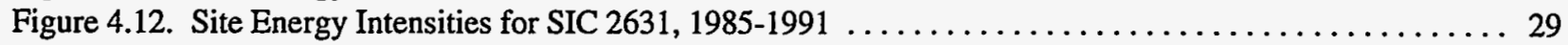

Figure 4.13. Output and Offsite-Produced Energy Consumption Indices for SIC 28, 1977 Through $1991 \ldots \ldots 31$

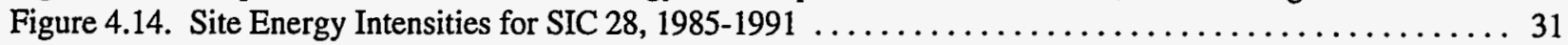

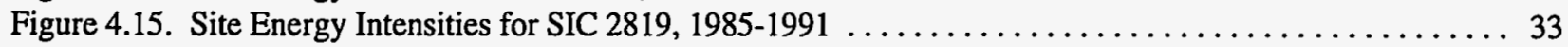

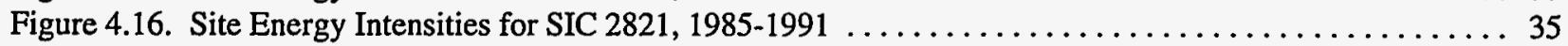

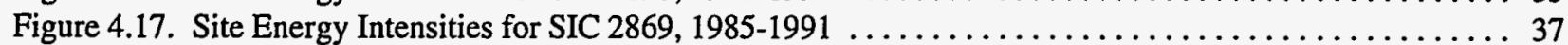

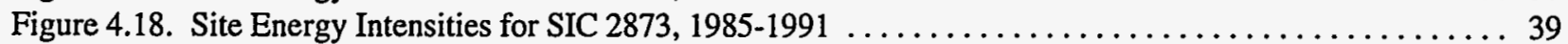

Figure 4.19. Output and Offsite-Produced Energy Consumption Indices for SIC 29, 1977 Through $1991 \ldots \ldots 41$

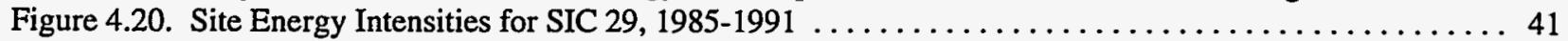

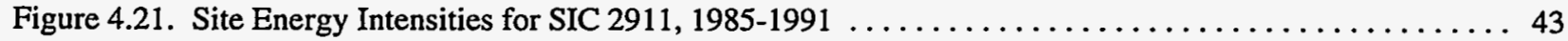

Figure 4.22. Output and Offsite-Produced Energy Consumption Indices for SIC 30, 1977 Through $1991 \ldots \ldots 45$

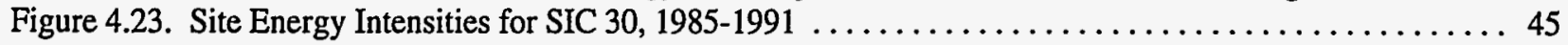

Figure 4.24. Output and Offsite-Produced Energy Consumption Indices for SIC 32, 1977 Through 1991 . . . . 47

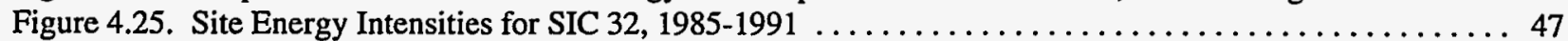

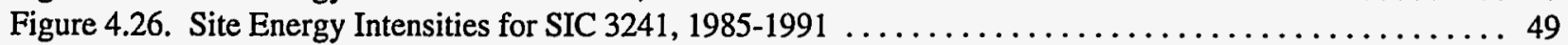

Figure 4.27. Output and Offsite-Produced Energy Consumption Indices for SIC 33, 1977 Through $1991 \ldots \ldots 51$

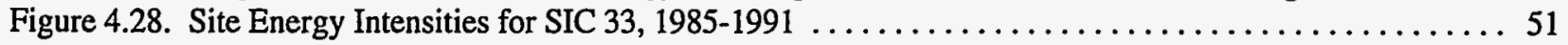

Figure 4.29. Site Energy Intensities for SIC 3312, 1985-1991 $\ldots \ldots \ldots \ldots \ldots \ldots \ldots \ldots \ldots \ldots \ldots \ldots \ldots$

Figure 4.30. Site Energy Intensities for SIC 3334, 1985-1991 ....................... 55

Figure 4.31. Output and Offsite-Produced Energy Consumption Indices for SIC 34, 1977 Through $1991 \ldots \ldots 57$

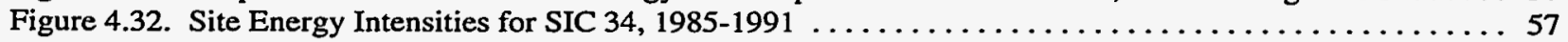

Figure 4.33. Output and Offsite-Produced Energy Consumption Indices for SIC 35, 1977 Through 1991 . . . . 59

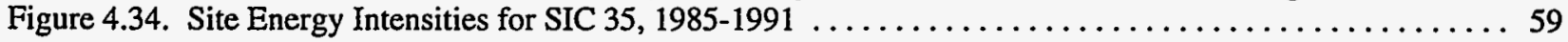

Figure 4.35. Output and Offsite-Produced Energy Consumption Indices for SIC 36, 1977 Through $1991 \ldots \ldots 61$

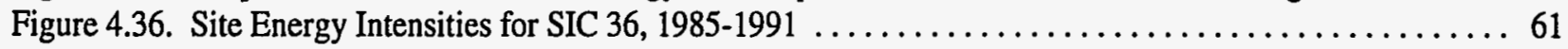

Figure 4.37. Output and Offsite-Produced Energy Consumption Indices for SIC 37, 1977 Through $1991 \ldots \ldots 63$

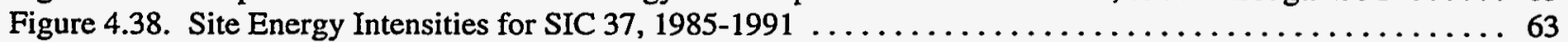

Figure 4.39. Output and Offsite-Produced Energy Consumption Indices for SIC 38, 1977 Through $1991 \ldots \ldots 65$

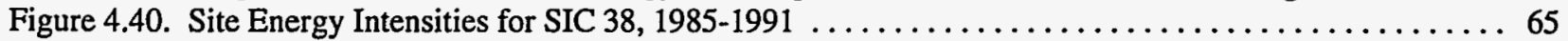

Figure 4.41. Output and Offsite-Produced Energy Consumption Indices for SIC 39, 1977 Through $1991 \ldots \ldots 67$

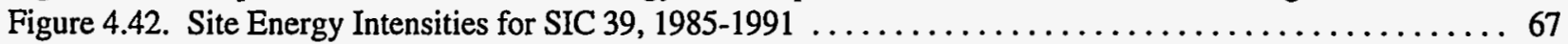


To provide an historical context for energy usage in the manufacturing sector, Figures ES1 and ES2 provide indices of energy prices and energy intensities.

Figure ES1. History of U.S. Industrial Energy Price Indices for Selected Energy Sources, 1970 Through 1992

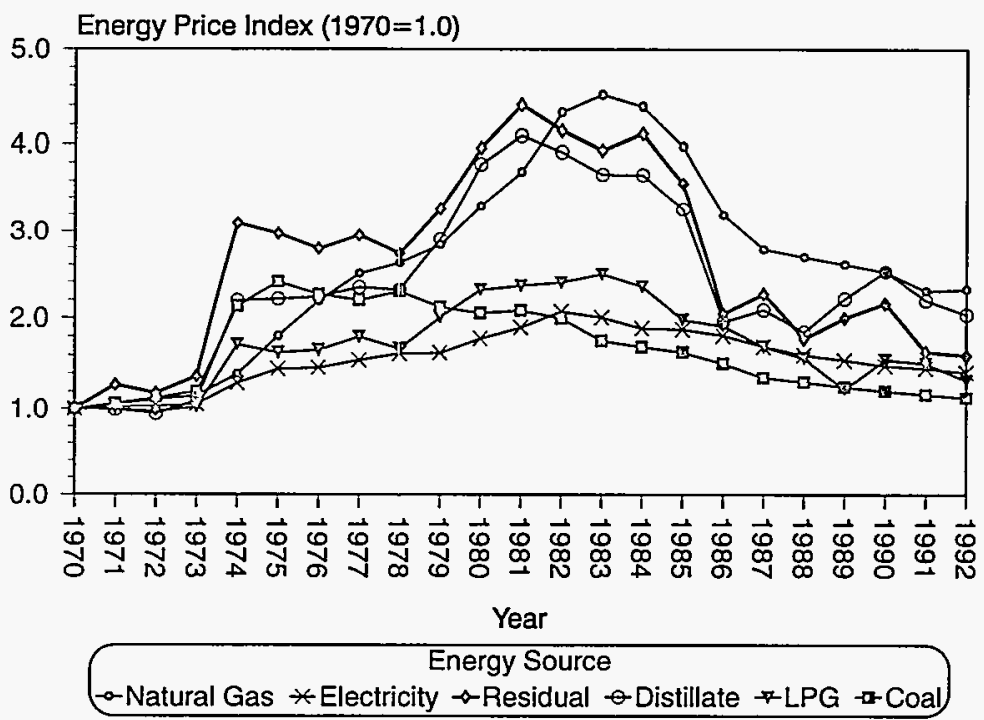

Source: Energy Information Administration, 1992 State Energy Price and Expenditure Report.

For years 1977-1981 in Figure ES2, intensities are derived from energy consumption collected by the Annual Survey of Manufactures, conducted by the Bureau of the Census. For 1985, 1988, and 1991, the MECS collected energy consumption. For 1982, 1983, 1984, 1986, 1987, 1989, and 1990, energy consumption was computed via data interpolation. See "The Concept of Energy Intensity" in Appendix A for a more detailed description on the derivation of energy intensity. See Derived Annual Estimates of Manufacturing Energy Consumption 1974-1988, DOE/EIA$0555(92) / 3$ for a more detailed description on data interpolation. This report will concentrate on the MECS collections of energy data in years 1985,1988 , and 1991.

Figure ES2. History of Energy Intensity of Offsite-Produced Energy in Total U.S. Manufacturing , 1977 Through 1991

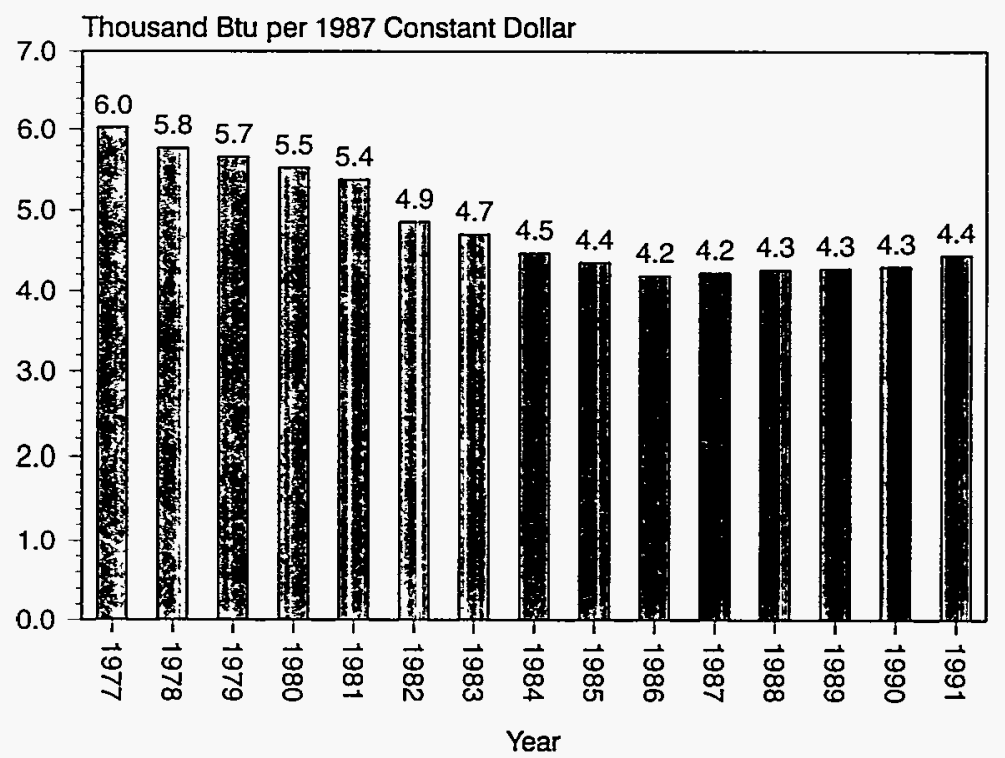

Source: Energy Information Administration, Manufacturing Energy Consumption Surveys and Bureau of the Census, Annual Survey of Manufactures. 


\section{Executive Summary}

In 1991, the manufacturing sector, on average, consumed more energy per value of shipments than in either 1988 or 1985, showing an increase in purchased energy intensity of four percent from 1988 to 1991 . This increased energy requirement is a function of a myriad of internal and external factors. Among the numerous internal factors that could influence energy intensity are changes in manufacturers' internal mix of products produced during these years, and changes in the technologies and processes used to produce them. Economic conditions represent one of the most influential external factors. At one time, cost control had been cited as one of the most common business incentives for investing in projects to manage energy usage. Now however, this stimulus has been lessened due to the steady decline in energy prices (Figure ES1), the end of the 1991 Persian Gulf War, and the continuing weakness of the Organization of Petroleum Exporting Countries (OPEC).

Changes in Energy Intensity in the Manufacturing Sector, 1985-1991 presents statistics about changes in energy consumption per constant dollar of value of shipments. The report is based on the 1991 Manufacturing Energy Consumption Survey (MECS), and is the third publication associated with that survey. ${ }^{1}$ The 1991 MECS is the third survey conducted, with earlier surveys gathering information on 1985 and 1988 energy consumption patterns. The information in this report continues the data series ${ }^{2}$ on changes in energy intensity based on information collected by the two earlier surveys.

Past manufacturing surveys did not collect information relating to the potential causes of changes in energy efficiency. The 1991 survey, however, provides a cross-sectional view of the energy-management activities and general technologies in existence at manufacturing establishments, and it estimates the effects of changes in product mix (structural shift). With the completion of the 1994 survey, trends relating those factors to energy efficiency may begin to be revealed.

In this report, energy intensity is defined as the ratio of energy consumption per unit of output. Output is measured as the constant dollar of value of shipments and receipts, and two measures of energy consumption are presented in British thermal units (Btu): Offsite-Produced Energy and Total Inputs of Energy. A decrease in energy intensity from one period to another suggests an increase in energy efficiency, and vice versa.

Energy efficiency can be defined and measured in various ways. Certain concepts of energy efficiency, especially those limited to equipment efficiencies, cannot be measured over time using changes in energy-intensity ratios. While improved energy efficiency will tend to reduce energy intensity, it is also true that a change in energy intensity can be due to factors unrelated to energy efficiency. For this report, energy intensity is used as a surrogate measure for energy efficiency, based on industry knowledge and current methodological analyses.

Data for the MECS were collected on an establishment-by-establishment basis and reported based on the Standard Industry Classification (SIC) system. For more information on SIC, see Chapter 2.

\section{Key Findings}

- In 1991, manufacturers required more Offsite-Produced Energy than in either of the earlier survey years, 4.44 thousand Btu for each constant dollar value of shipments. In 1985, manufacturers required 4.35 thousand Btu of Offsite-Produced Energy for every constant dollar value of shipments. This energy requirement decreased to 4.26 thousand Btu in 1988.

- Offsite-Produced Energy efficiency decreased for seven major manufacturing groups between 1985 and 1991. Eight major groups had increases in Offsite-Produced Energy efficiency between 1985 and 1991.

\footnotetext{
'Energy Information Administration, Development of the 1991 Manufacturing Energy Consumption Survey, DOE/EIA-0555(92)/2, Washington DC, 1992; Energy Information Administration, Manufacturing Energy Consumption Survey: Consumption of Energy, 1991, DOE/EIA-0512(91), Washington DC, 1994.

${ }^{2}$ Energy Information Administration, Manufacturing Energy Consumption Survey: Changes in Energy Efficiency, 1980-1985, DOE/EIA0516(85), Washington, DC, 1990; Energy Information Administration, Manufacturing Energy Consumption Survey: Changes in Energy Intensity in the Manufacturing Sector 1980-1988, DOE/EIA-0552(80-88), Washington, DC, 1991.
} 
- Shifts in product mix account for most of the changes in energy efficiency in five major manufacturing groups.

- Likewise in 1991, manufacturers required more Total Inputs of Energy than in either of the earlier survey years, 6.15 thousand Btu for each constant dollar value of shipments. In 1985, manufacturers required 6.06 thousand Btu of Total Inputs for every constant dollar value of shipments. This energy requirement decreased to 5.96 thousand Btu in 1988.

- Energy efficiency based on Total Inputs of Energy decreased for seven major manufacturing groups between 1985 and 1991. Energy efficiency for two major groups remained essentially unchanged through the same period. Six major groups had increases in Total Inputs of Energy efficiency between 1985 and 1991.

- To improve energy efficiency, manufacturing establishments participated in various demand-side management (DSM) and other energy-management programs. From 1989 through 1991, their activities and percent of participation, expressed in terms of Total Inputs of Energy used by participating establishments, were as follows: improving the efficiency of steam production (32 percent); improving the efficiency of process heating (34 percent); improving the efficiency of process refrigeration ( 15 percent); installing or retrofitting motors to achieve better energy efficiency ( 36 percent); improving the efficiency of facility heating, ventilation, and air conditioning (HVAC) systems (23 percent); and, improving the efficiency of facility lighting ( 36 percent). 


\section{Introduction}

After the 1973 oil embargo, industry and Government joined forces to encourage the efficient use of energy, but the incentive for these efforts decreased as more energy became available and the price of energy declined. Early conservation programs focused on awareness of consumption and inexpensive methods to minimize waste. Today, manufacturers can choose early replacement of equipment or alterations in major production processes in order to bring about significant improvements in energy efficiency.

The focus of this report is on intensity of energy use, measured by energy consumption relative to constant dollar shipments of manufactured products. This report explicitly relates changes in energy intensity to efficiency, while being cognizant that there are structural and behavioral effects enmeshed in those measures of energy efficiency. Although this report is similar in scope to earlier reports on changes in intensity, it contains significant differences. Specifically, this report:

- Separates the changes in energy intensity into changes caused by the different product mix (structural shift) in 1988 and 1991, compared with 1985.

- Includes primary electricity in changes in intensity.

- Discusses ten of the most energy-intensive industries (e.g., paper mills, nitrogenous fertilizers) in addition to 15 major industry groups (e.g., food, chemicals, petroleum).

- Includes intensities based on the 1987 SIC definitions. Earlier reports used the 1972 SIC definitions. All charts showing historical energy consumption and value of shipments data use the 1972 SIC definitions through 1986.

- Examines energy intensity/efficiency based on Total Inputs of Energy for heat, power, and electricity generation (including byproduct and waste products) as well as Offsite-Produced Energy.

\section{Manufacturing Energy Consumption Surveys}

The Manufacturing Energy Consumption Survey (MECS) is the Congressionally mandated data collection that provides statistics for this report. Section 310(a) of the 1986 Omnibus Budget Reconciliation Act (Public Law 99-509, as amended) directs the Energy Information Administration to conduct the survey at least every 3 years.

The MECS focuses on consumption of various energy sources by U.S. manufacturers. It also collects establishment information such as fuel-switching capability and onsite fuel storage capabilities. Additional data collected by the 1991 survey include establishment size, energy-management activities, end uses of energy, and technologies in place.

\section{Summary of Analysis}

Data collected by the 1991 MECS clearly indicate the energy intensities of manufacturing establishments are no longer declining. In contrast, for the years between 1985 and 1988, the manufacturing sector's energy requirements declined for every constant dollar value of shipments. This reduction in energy use came about through a variety of methods, including improved technology and maintenance. The relatively high price of energy in the mid 1980's (Figure ES1) fostered the implementation of efficiency programs.

Between 1988 and 1991, however, this trend was reversed and energy requirements increased for each constant dollar value of shipments. Two economic reasons are among the causes for most manufacturers' minimized investments in energy conservation. One reason is that manufacturers spend only about 5 percent of their total cost of materials on purchased fuels and electricity. Consequently, manufacturers might reduce manufacturing inputs more effectively by reducing the costs of labor or raw materials. A second reason is that all capital projects, whether or not they involve energy use, compete for funds based upon speed of payback. Industry analyst and manufacturers themselves generally 
agree that for capital projects undertaken voluntarily, the payback must be no longer than 2 years. Because most energy sources are readily available and reasonably inexpensive, at present, it difficult for manufacturers to justify investments in energy-efficient technologies or activities.

Energy efficiency is important in the manufacturing sector for reasons other than these, however. Energy efficiency helps industry become more competitive by cost-effectively shifting from waste management to resource efficiency and pollution prevention. MECS data indicate manufacturers' continued interest in minimizing energy consumption. In addition to installing energy-efficient equipment whenever possible, manufacturers also are working with electric and natural gas utilities to minimize waste and reduce energy requirements. The most common type of energy-management program identified by the MECS is the energy audit. Energy audits identify both large and small changes in equipment and procedures that will reduce energy requirements. In partnership with utilities, manufacturers also take advantage of special rate schedules offered. Such rate schedules as time-of-use or interruptible service allow the manufacturer to control energy costs.

Economic stagnation may adversely affect energy efficiency in a number of ways. Energy prices and availability determine the incentives for investing in projects that manage energy use. During times of economic growth, capacity expansion for expanding market may increase the penetration of new technologies. In times of economic recessions, however, slower rates of energy-efficient improvements may result.

\section{Organization of This Report}

This introductory chapter is followed by a chapter discussing the Standard Industrial Classification (SIC) system, which explains how the system identifies and classifies manufacturing establishments. Also discussed are the impacts the 1987 SIC revision had on data collected for each MECS, and how this revision is handled for longitudinal (i.e., cross-year) comparisons.

Discussions of two measures of energy consumption and manufacturing output are the focus of the third chapter. That chapter defines changes in energy intensity and includes six tables that illustrate the effects of using different definitions. Also included in that chapter is a discussion of structural shifts in production and how these shifts affect measurement of energy intensity.

The fourth chapter contains SIC-specific information on energy intensities for each of the 15 major manufacturing groups considered in this report, along with the ten industries that consume the most energy. That chapter begins with samples of the charts included in the discussions and their interpretation. Following these chapters are six appendices:

- Appendix A, "Survey Design, Implementation, and Estimate," presents detailed information on the MECS survey design, implementation and estimates, and technical information on the calculation of estimates.

- Appendix B, "Quality of the Data," discusses the quality of the survey data.

- Appendix C, “MECS Coverage Related to EIA Supplier Surveys," compares MECS coverage with supplier surveys conducted by the Energy Information Administration.

- Appendix D, 'Description of Major Manufacturing Groups and Selected Industries," includes a description of the major industrial groups and selected industries covered by this report.

- Appendix E, "Related EIA Publications on Energy Consumption," lists related energy consumption publications for readers interested in earlier MECS publications or consumption reports for other sectors.

- Appendix F, “Metric Conversion Factors," presents metric conversion factors.

These appendices are followed by a glossary of statistical and engineering terms used in this report. 


\section{Surveying the Manufacturing Sector}

The manufacturing sector consists of establishments that use mechanical or chemical processes to transform material or substances into new products. An establishment is usually at a single physical location and is often called a plant, factory, or mill. It ordinarily uses power-driven machines and equipment for handling materials. Its products may be final products that consumers will purchase, such as an automobile or a chair, or they may be goods for use by other manufacturers, such as parts for automobile engines or rolls of upholstery fabric. A manufacturing establishment may also assemble parts or perform blending operations.

The Federal Office of Management and Budget (OMB) developed procedures for classifying manufacturing and nonmanufacturing establishments into industry classes. These procedures are known as the Standard Industrial Classification (SIC) system. Each industry class consists of establishments that produce similar types of good or services.

Establishments that fall into SIC categories 20 (Food and Kindred Products) through 39 (Miscellaneous Manufacturing Industries) make up the manufacturing sector. Each of these two-digit major groups is further separated into three-digit industry groups and four-digit industries based on their primary products. For example, SIC 325 (Structural Clay Products) is one of nine industry groups in SIC 32 (Stone, Clay, Glass, and Concrete Products). SIC 3253 (Ceramic Wall and Floor Tile) and SIC 3255 (Clay Refractories) are two of the four-digit industries that make up SIC 325.

The MECS is an establishment-based survey and uses the SIC definition to identify separate establishments. This report is the first on energy intensities to include information on the ten four-digit industries that consume the most energy.

\section{Revision of SIC Codes}

OMB maintains and periodically updates the SIC system to ensure the classification system remains up-to-date, accurately reflecting current economic activities. Revisions consist of adding new categories as well as removing or combining old categories. Examples include creating separate categories for electronic computers and computer storage devices, and combining categories for primary lead, primary zinc, and other primary nonferrous metals into a single category. The latest SIC revision was completed in 1987.

SIC code revisions to industry groups and industries within a major group are reflected in changes in the third or fourth digit of a code. Moving industries from one major group to another causes changes in the first two digits. The 1987 version of the SIC codes was the basis for selecting establishments for both the 1988 and 1991 surveys, while the 1985 MECS was selected under the previous version (1972). Estimates involving establishments that were reclassified at the level of the third or fourth digit but remained in the same two-digit major industry group are comparable with 1985 and 1988 estimates. However, when revisions moved establishments from one major group to another, the estimates are not comparable.

Energy consumption and value of shipments estimates are calculated for each SIC as though the 1987 SIC system were in effect for the 1985 and 1988 surveys.

The only exception to this are the SIC-specific charts identifying energy consumption and value of shipments over time.

\section{Energy-Intensity Ratios Based on 1987 Definitions of Industry}

The Standard Industrial Classification system underwent a major revision in 1987, resulting in several industries being redefined. The MECS estimates of energy consumption-Total Inputs of Energy and Offsite-Produced Energy-and the Annual Survey of Manufactures (ASM) estimates of value of shipments for 1988 and 1991 conform to the revised industry classifications. The corresponding estimates for 1985 were based on the 1972 classification system.

Calculating the changes in energy intensity for major groups requires comparability between the base and end-year estimates. Accordingly, the 1985 estimates of energy consumption, value of shipments, and energy-intensity ratios were re-estimated using the 1987 classification system. The adjustments could not be applied to the data in the index charts. Thus, all index estimates appearing in this report for years preceding 1987 are based on the 1972 classification system, while 1988 and later year estimates are based on the 1987 classification system. 
In other words, each SIC includes the same industries and industry groups up through 1986. At this point, depending on how the revision affected the make-up of the two-digit major group, industries might have been either added or removed for 1987 through 1991 . The SIC-specific discussions included in this report identify any changes in the twodigit major group that resulted from the 1987 SIC modifications.

Changes between two-digit SIC categories must be considered when comparing data presented in this publication with data presented in earlier reports. For this report, all data for 1985 and 1988 conform to the 1987 SIC definitions. Because of these recalculations, direct comparison between this report and the reports associated with the 1985 and 1988 surveys is neither advisable nor possible.

\section{Industry Coverage}

The MECS is a nationally representative sample of manufacturing establishments classified by SIC codes 20 through 39. In addition to these major manufacturing groups, SIC codes 01-07 (Agriculture), SIC codes 15-17 (Construction), and SIC codes 10-14 (Mining Activities) are outside the scope of the survey.

The EIA constructed the MECS questionnaire and designed the sampling plan. The Census Bureau conducted the survey, assuring that each MECS response is covered by the same confidentiality provisions as apply to all Census Bureau data collections (Section 9, Title 13 of the U.S. Code). Response is mandatory. Only sworn Census agents have access to individual survey responses.

The sample design allows attachment of economic data obtained by other agencies (e.g., Census Bureau, Bureau of Economic Analysis). This matching is possible on an establishment-by-establishment basis. Data for this report include economic information for a specific establishment and energy consumption data for that same establishment. TheBureau of the Census and the Bureau of Economic Analysis (BEA) provide economic data. These data combine to provide the information required to develop energy-intensity estimates.

The MECS selects from the entire manufacturing sector through its relationship with the Census of Manufactures (CM) and Annual Survey of Manufactures (ASM) conducted by the Bureau of the Census. Appendix A provides further details on this relationship. The sizes of the sample for the three MECS are as follows:

- 1991 -- 16,054 mailed questionnaires

- 1988 -- 12,065 mailed questionnaires

- 1985 -- 11,684 mailed questionnaires

This report, like earlier reports, omits five manufacturing groups. Earlier reports omitted these groups because data were not available for the time frame of interest (1985-1991). These groups are:

- SIC 21 - Tobacco Products

- SIC 23 - Apparel

- SIC 24 - Lumber and Wood Products

- SIC 27 - Printing and Publishing

- SIC 31 - Leather Products 


\section{Energy Consumption and Production Output}

\section{Measures of Energy Consumption}

This report presents information on two measures of energy consumption: (1) Total Inputs of Energy for Heat, Power, and Electricity Generation, and (2) Offsite-Produced Energy for Heat, Power, and Electricity Generation. Both measures provide specific information on how manufacturing establishments use energy.

Total Inputs of Energy for Heat, Power, and Electricity Generation is the more comprehensive measure of energy consumption. For the first time, this report includes intensities based on this measure of consumption. This measure:

- Includes all final uses of energy sources-produced either onsite or offsite-to produce heat and power, and to generate electricity.

- Includes net electricity, net steam and net industrial hot water (see glossary for further descriptions).

- Excludes energy sources used as raw material or for other nonfuel uses (e.g., coal used as an input to produce coke or wood used to make furniture).

Consumption of Offsite-Produced Energy for Heat, Power, and Electricity Generation is a more limited measure of energy consumption collected by the MECS. This measure:

- Includes all energy sources purchased or transferred from offsite and consumed onsite to produce heat and power and to generate electricity.

- Excludes all energy produced onsite and consumed as fuel.

- Excludes energy sources used as raw material or for other nonfuel purposes.

Previous reports used one energy measure-Offsite-Produced Energy consumption for heat, power, and electricity generation. This measure continues the Census Bureau series of purchased fuels and electricity energy data. When compared with Total Inputs of Energy measures, it shows how dependent particular industry groups are on energy purchased or transferred from offsite sources. For example, the Paper and Allied Products Industry (SIC 26) consumed 22.32 thousand Btu for every constant dollar value of output in 1991 . Of this total consumption, only 13.90 thousand Btu came from Offsite-Produced Energy. Much of the remainder of the energy consumed was in the form of pulping liquor, a combustible byproduct of the pulping process.

\section{Evaluation of Electricity Consumption}

Electricity consumption can be expressed in terms of either

- physical units, most commonly kilowatthours (kWh), or

- a common thermal unit, most commonly British thermal units (Btu).

The physical unit is meant to give a clear understanding of the amount of a particular energy source being used, while the thermal unit is a measure of convenience used to aggregate or compare various energy sources measured in different physical units. Converting $\mathrm{kWh}$ of electricity to Btu is not a trivial issue, because the amount of input energy needed to create a kWh of electricity is far greater than the amount of useful energy in the $\mathrm{kWh}$ at its point of use. Therefore, meaningful conversions of electricity use from $\mathrm{kWh}$ to Btu can be given in terms of:

- Site (point-of-use) electricity, at the universal value of $3,412 \mathrm{Btu} / \mathrm{kWh}$. This value is useful to engineers, energy managers, and others trying to improve energy efficiency.

- Primary electricity, at a value that reflects the content of the energy inputs used to produce the electricity. This rate is most useful to policymakers and analysts who are considering global resources and environmental issues.

\section{(Continued on next page)}


This report also includes information on manufacturing energy intensity when the primary conversion factor for electricity is used rather than the site conversion factor. This measure of consumption includes the amounts of energy required by electricity generators to produce electricity consumed by manufacturers, and the amount of electricity lost in transmission and not available to the establishment.

Different conversion factors for each year are used to calculate primary electricity. These conversion factors are 10,447 Btu per kilowatthour ( $\mathrm{kWh}$ ) for $1985,10,324$ Btu/kWh for 1988, and 10,352 Btu/kWh for 1991. Differences in conversion factors indicate different mixes of energy used to generate the electricity (e.g., natural gas, coal, and nuclear). Tables 1 and 2 show changes in primary intensity associated with energy consumption. These provide statistics on OffsiteProduced Energy and Total Inputs of Energy, respectively.

Earlier intensity reports calculate changes in intensity based upon the amount of electricity actually consumed at the establishment site. The conversion factor for this electricity remains a constant $3,412 \mathrm{Btu} / \mathrm{kWh}$. This constant conversion factor represents the amount of energy actually available to the user. Tables 3 and 4 give statistics for changes in OffsiteProduced and Total Inputs of site energy intensity, respectively. Data from these tables provided input to the SIC-specific discussions on energy intensity changes.

\section{Evaluation of Electricity Consumption (Continued)}

For convenience and consistency, the factor used in this report to convert electricity use to primary electricity is $10,447 \mathrm{Btu} / \mathrm{kWh}$ for $1985,10,324 \mathrm{Btu} / \mathrm{kWh}$ for 1988 , and $10,352 \mathrm{Btu} / \mathrm{kWh}$ for 1991. This factor represents the average energy input to the generation process for fossil-fuel utility plants in the United States in 1991, as given in EIA's Monthly Energy Review (August 1994). However, the reader should understand that the true conversion values for the range of electricity estimates in this report is unknown. Applying the single value to the range of electricity estimates in this report provides only a rough approximation of primary electricity because:

- For some type of utility energy inputs-hydroelectric, wood/waste, wind, and solar (thermal or photovoltaic), there is no generally accepted conversion rate.

- The fossil-fueled, nuclear, and geothermal generation processes have known but different conversion rates, so the overall conversion rate for these energy sources is a function of their mix.

A particular problem with manufacturing is that industries tend to be clustered much more than households and businesses in general. The electricity-intensive industries, such as aluminum, are concentrated in areas with inexpensive electricity, usually hydropower-generated. Thus, the accuracy of the overall conversion factor given above varies across industry groups.

Estimates of primary electricity using this conversion factor should thus be treated with caution. They should be considered rough alternative measures to site energy as indicators of the importance of electricity as a manufacturing energy source.

\section{Value of Shipments as Output Indicator}

The calculation of changes in intensity requires a measure of production output for each SIC. One possible measure is the number of physical units produced; however, physical quantities are not the best measure for two reasons. First, most manufacturing establishments produce more than a single product line. For example, in SIC 22 (Textiles) a single establishment may produce not only bedspreads, but also tablecloths and dishcloths. Because these are different products, with different process steps and energy requirements, summing them to a single measure of total output is not possible. For the same reason, it is not possible to sum the physical outputs of all industries to obtain an estimate of total manufacturing sector output.

Second, summing different products into a single output indicator might be appropriate if information on energy consumption associated with each product line were available, but manufacturers rarely, if ever, monitor and record energy data by product or process. This information could suggest the use of a particular production process, possibly affecting their competitive status. An associated difficulty is that the MECS and ASM obtain data by establishments, 
not by products. Combining information from different sources would be nearly impossible if product rather than a controllable economic variable represented output.

Value of shipments is the output measure used to calculate energy intensity. Summing value of shipments both across and between SIC categories provides output measures for each SIC and for the manufacturing sector as a whole. Value of shipments is also the production measure used by the Census Bureau when assigning establishments into a particular SIC category. Use of this measure further assures consistency between the MECS and the ASM.

A potential competing output measure is value added (see glossary). If the goal were to calculate the total output of the entire manufacturing sector, value added would be the appropriate economic measure to use because it does not duplicate economic inputs as does value of shipments. The duplication inherent in the value of shipments is not an important consideration when calculating changes in intensity. The purpose is not to compare the energy-intensity ratios between industries, but rather, to compare ratios at different points in time for each manufacturing group. For further details see Appendix A.

Using value of shipments as an output indicator also has drawbacks. One problem is that the product values change over time. Inflation can cause these changes. Rising values of shipments over time are not necessarily associated with increased production but instead could reflect general price increases that affect all products and services to varying degrees.

The value of shipments estimate used in the calculation of energy-intensity ratios is adjusted for fluctuations in product value over time. Using BEA price deflators at the industry level, each individual establishment's value of shipments for 1985,1988 , and 1991 is adjusted to

\section{An Example of Structural Shift}

Consider a manufacturing economy composed of only two subsectors: A and B. Subsector A is characterized as an energyintensive subsector, while B is less energy intensive. In 1985, production from subsector $A$ was 100 units, with a corresponding consumption of 500 thousand Btu, resulting in an energy intensity of the 5 thousand Btu per unit of output. For the same year, subsector $B$ also produced 100 units while consuming 200 thousand $B$ tu, resulting in an energy intensity of 2 thousand Btu per unit of output.

In this economy, then, manufacturers produced a total of 200 units of goods and consumed a total of 700 thousand Btu, yielding an energy intensity of 3.5 thousand Btu per unit of output. Subsector $A$ and subsector $B$ each represented 50 percent of all manufacturing output.

Six years later, in 1991, this fictional manufacturing economy responds to the current production demand. Instead of an equal share of manufacturing output, each subsector has accordingly realigned their production shares. The total output remains at 200 units, but subsector $B$ now represents 80 percent ( 160 units) of the manufacturing economy, with $A$ supplying the remaining 20 percent (40 units). Although production shares have undergone realignment, energy intensities for subsectors $A$ and $B$ remain unchanged, which means that energy intensities for $A$ and $B$ are 5 and 2 thousand Btu per unit of output, respectively. However, aggregation of $A$ and $B$ to the manufacturing level results in an energy intensity of 2.6 thousand Btu per unit of output-200 thousand Btu from A and 320 thousand Biu from B to produce 200 units of goods. Direct comparison of 1985 ratio with the 1991 unadjusted manufacturing energy-intensity ratio shows an improvement in energy efficiency of 26 percent-apparently a dramatic improvement in efficiency.

In this illustration, rather than improving energy efficiency through plant improvements or other means, the manufacturing economy has structurally shifted towards less energy-intensive products. To adjust for such shifts, end-year intensities are re-estimated with the base-year (1985) production mix. Since each subsector's energy intensities are unchanged, the manufacturing economy's adjusted 1991 energy intensity is also unchanged, illustrating that energy efficiency was stagnant ( 0 percent) over the past 6 years. Thus, the entire improvement in energy efficiency ( 26 percent) is due to the effect of structural shift within the manufacturing economy since 1985. 
represent 1987 constant dollars. ${ }^{3}$ By adjusting for changes in price of goods, aggregate output measures of value of shipments are made comparable over the time periods of interest.

Further, re-estimation of value of shipments statistics is required to ensure comparability with estimates of energy consumption. Rather than adjust the value of shipment estimates provided by the ASM, this report uses the direct estimates of value of shipments from the MECS sample, which required a 100 percent matching of each individual MECS establishments with their corresponding ASM value of shipments. Direct estimation of both consumption and value of shipments statistics from each of the MECS samples results in comparable energy-intensity ratios.

A second problem with using value of shipments as an output measure is that, over time, the contribution of each SIC to total output may vary. This variation can occur within and between two-digit groups. What might at first glance appear to be an increase or decrease in energy intensity could, in fact, be simply a response to changing demand for particular products. Structural shift is the term that describes these changes in relative importance. (See box for more discussion of structural shift.)

To estimate structural shifts, EIA developed a third set of intensities for each SIC for both Offsite-Produced and Total Inputs of Energy consumption, which are presented in Tables 5 and 6 . The structurally adjusted intensity change is based on the assumption that no structural shift occurred since 1985, and that the same mix of output was available in 1988 and 1991 as in 1985.

\section{Changes in Energy Intensity}

Manufacturers are in the business of producing physical units of output for consumption by end users or other manufacturers. One goal of production is to consume as few inputs as possible to produce a quality output. Specifically, if energy requirements are reduced relative to output, each unit of output has become less energy intensive. This improvement is an increase in energy efficiency.

This report presents the percent changes in energy intensity from 1985 to 1988,1988 to 1991 , and 1985 to 1991 . This information is presented for only 15 of the 20 two-digit major groups. Sample sizes for earlier surveys were not sufficient to produce representative estimates for the remaining 5 two-digit major groups or ten four-digit industries. This report includes 1985 and 1988 survey data recalculated to include all establishments in their 1987 SIC classification. This recalculation precludes comparisons between published reports but provides a solid basis for the analysis of product mix change.

Like previous reports, this report calculates changes in intensity as the difference between the energy requirements per constant dollar value of shipments for one period and those for an earlier period. The energy-intensity ratios included in Tables 1 through 6 provide the information to calculate the changes in intensity. These ratios indicate Btu consumption (in thousands) for each constant dollar of output. A percent change in efficiency that is positive indicates an increase in energy efficiency, whereas a negative percent change indicates a decrease in energy efficiency.

It is important not to compare changes in intensity between different SICs but instead to compare the changes within an individual SIC. The output from one manufacturing establishment is often used as an input by another establishment. To some extent, the value of shipments of the second seller duplicates that of the first seller. For this reason, the sum of individual SIC value of shipments will not result in the value of shipments for the entire manufacturing sector.

\section{Structural Shifts}

Energy intensity is a product of both the efficiency of the manufacturing process and the type and volume of products being produced. Over time, new products (e.g., personal computers, compact discs) become available and replace older technology (e.g., typewriters, phonograph records). Analysis of structural shift identifies this change in demand, and the impact it has on manufacturing establishments. Energy consumption by an establishment or major group changes

${ }^{3}$ U.S. Department of Commerce, Bureau of Economic Analysis, National Income and Wealth Division. 
in response to increased (or decreased) demand for products. For the first time, this report identifies the importance these changes in relative output have on energy intensity. Tables 5 and 6 identify Offsite-Produced and Total Inputs of Energy intensities adjusted for structural shift.

Appendix A provides a mathematical description of how structurally adjusted energy-intensity ratios are derived. As the 1988 or 1991 unadjusted intensities are applied to the original 1985 output distribution of the three-digit group, the result is the amount of energy that would be required to produce the same distribution of 1985 product, but with 1988 or 1991 energy intensities. If an adjusted intensity is less than the unadjusted intensity for that same year, this indicates a movement within the two-digit group toward more energy-intensive products over time. At the same time, if the adjusted intensity is greater than the unadjusted intensity, movement within the group was toward less energy intensive products. Comparison of unadjusted and adjusted percent changes in energy intensity indicates how much of the unadjusted change was due to changes in efficiency and how much was due to structural shifts within manufacturing.

Table 1. Primary Energy Intensity of Offsite-Produced Energy in Major Manufacturing Groups, 1985, 1988, and $1991^{\mathrm{a}}$

\begin{tabular}{|c|c|c|c|c|c|c|c|}
\hline \multirow[b]{2}{*}{$\begin{array}{c}\text { SIC } \\
\text { Code } \\
\end{array}$} & \multirow[b]{2}{*}{ Major Group } & \multicolumn{3}{|c|}{$\begin{array}{c}\text { Energy-Intensity Ratios } \\
\text { (thousand Btu/constant } \\
\text { dollar) }\end{array}$} & \multicolumn{3}{|c|}{$\begin{array}{c}\text { Change in } \\
\text { Energy Efficiency } \\
\text { (percent) }\end{array}$} \\
\hline & & 1985 & 1988 & 1991 & $\begin{array}{c}1985- \\
1988 \\
\end{array}$ & $\begin{array}{c}1988- \\
1991 \\
\end{array}$ & $\begin{array}{l}1985- \\
1991 \\
\end{array}$ \\
\hline 20 & Food and Kindred Products & 3.45 & 3.84 & 3.64 & -11.22 & 5.10 & -5.55 \\
\hline 21 & Tobacco Products & NA & NA & NA & NA & NA & NA \\
\hline 22 & Textile Mill Products & 7.75 & 7.92 & 8.19 & -2.30 & -3.34 & -5.72 \\
\hline 23 & Apparel and Other Textile Products & NA & NA & NA & NA & NA & NA \\
\hline 24 & Lumber and Wood Products & NA & NA & NA & NA & NA & NA \\
\hline 25 & Furniture and Fixtures $\ldots$. & 2.35 & 2.56 & 2.42 & -9.08 & 5.47 & -3.11 \\
\hline 26 & Paper and Allied Products & 15.78 & 14.66 & 17.97 & 7.08 & -22.56 & -13.88 \\
\hline 27 & Printing and Publishing & NA & NA & NA & NA & NA & NA \\
\hline 28 & Chemicals and Allied Products & 16.68 & 15.23 & 15.71 & 8.73 & -3.20 & 5.81 \\
\hline 29 & Petroleum and Coal Products & 9.57 & 9.56 & 10.03 & 0.09 & -4.96 & -4.87 \\
\hline 30 & Rubber and Misc. Plastic Products & 5.63 & 5.69 & 5.24 & -1.06 & 7.93 & 6.96 \\
\hline 31 & Leather and Leather Products & NA & NA & NA & NA & NA & NA \\
\hline 32 & Stone, Clay, and Glass Products & 19.28 & 20.27 & 21.59 & -5.13 & -6.50 & -11.96 \\
\hline 33 & Primary Metal Industries & 22.84 & 21.70 & 22.16 & 5.02 & -2.13 & 2.99 \\
\hline 34 & Fabricated Metal Products $\quad \ldots .$. & 3.58 & 3.79 & 3.77 & -6.06 & 0.66 & -5.35 \\
\hline 35 & Industrial Machinery and Equipment & 2.21 & 2.03 & 1.88 & 7.90 & 7.48 & 14.80 \\
\hline 36 & Electronic and Other Electric Equipment & 2.36 & 2.44 & 2.17 & -3.76 & 11.33 & 8.00 \\
\hline 37 & Transportation Equipment & 1.81 & 1.70 & 1.77 & 6.24 & -4.09 & 2.40 \\
\hline 38 & Instruments and Related Products & 1.87 & 1.72 & 1.67 & 7.91 & 2.73 & 10.42 \\
\hline \multirow[t]{2}{*}{39} & Misc. Manufacturing Industries & 2.22 & 2.18 & 2.01 & 1.76 & 7.83 & 9.45 \\
\hline & Total $\quad \ldots \ldots \ldots \ldots \ldots \ldots \ldots \ldots \ldots \ldots$ & 6.40 & 6.20 & 6.48 & 3.11 & -4.54 & -1.29 \\
\hline
\end{tabular}

aPrimary energy includes electricity at the Btu equivalent of the generating plant. It includes line losses and does not reflect the actual amount of electricity available to the plant for use.

$N A=$ Not available. Data are included in higher-level totals.

Note: Positive percent change indicates a decrease in energy intensity and an increase in energy efficiency. Negative percent change indicates an increase in energy intensity and a decrease in energy efficiency.

Source: Energy Information Administration, Manufacturing Consumption of Energy 1991, DOE/EIA-0512(91), Washington, DC, 1994, Manufacturing Energy Consumption Survey: Consumption of Energy, 1988, DOE/EIA-0512(88), Washington, DC, 1991, and Manufacturing Energy Consumption Survey: Consumption of Energy, 1985, DOEJEIA-0512(85), Washington, DC, 1988. 
Table 2. Primary Energy Intensity of Total Inputs of Energy in Major Manufacturing Groups, 1985, 1988, and $1991^{\mathrm{a}}$

\begin{tabular}{|c|c|c|c|c|c|c|c|}
\hline \multirow[b]{2}{*}{$\begin{array}{l}\text { SIC } \\
\text { Code }\end{array}$} & \multirow[b]{2}{*}{ Major Group } & \multicolumn{3}{|c|}{$\begin{array}{c}\text { Energy-Intensity Ratios } \\
\text { (thousand Btu/constant } \\
\text { dollar) }\end{array}$} & \multicolumn{3}{|c|}{$\begin{array}{c}\text { Change in } \\
\text { Energy Efficiency } \\
\text { (percent) }\end{array}$} \\
\hline & & 1985 & 1988 & 1991 & $\begin{array}{c}1985- \\
1988 \\
\end{array}$ & $\begin{array}{c}1988- \\
1991 \\
\end{array}$ & $\begin{array}{l}1985- \\
1991\end{array}$ \\
\hline 20 & Food and Kindred Products & 3.64 & 3.96 & 3.71 & -8.79 & 6.13 & -2.12 \\
\hline 21 & Tobacco Products & NA & NA & NA & NA & NA & NA \\
\hline 22 & Textile Mill Products $\ldots .$. & 7.75 & 7.92 & 8.21 & -2.15 & -3.72 & -5.94 \\
\hline 23 & Apparel and Other Textile Products & NA & NA & NA & NA & NA & NA \\
\hline 24 & Lumber and Wood Products & NA & NA & NA & NA & NA & NA \\
\hline 25 & Furniture and Fixtures & 2.56 & 2.82 & 3.08 & -10.08 & -8.98 & -19.97 \\
\hline 26 & Paper and Allied Products & 23.53 & 21.85 & 26.01 & 7.13 & -19.03 & -10.54 \\
\hline 27 & Printing and Publishing & NA & NA & NA & NA & NA & NA \\
\hline 28 & Chemicals and Allied Products & 17.72 & 16.27 & 16.99 & 8.18 & -4.47 & 4.08 \\
\hline 29 & Petroleum and Coal Products $\ldots$ & 22.16 & 24.43 & 23.43 & -10.25 & 4.10 & -5.73 \\
\hline 30 & Rubber and Misc. Plastic Products & 5.64 & 5.70 & 5.26 & -1.12 & 7.69 & 6.65 \\
\hline 31 & Leather and Leather Products & NA & NA & NA & NA & NA & NA \\
\hline 32 & Stone, Clay, and Glass Products & 19.59 & 20.35 & 21.90 & -3.87 & -7.64 & -11.81 \\
\hline 33 & Primary Metal Industries & 30.43 & 28.15 & 28.37 & 7.52 & -0.79 & 6.79 \\
\hline 34 & Fabricated Metal Products & 3.58 & 3.79 & 3.76 & -5.84 & 0.73 & -5.07 \\
\hline 35 & Industrial Machinery and Equipment & 2.19 & 2.01 & 1.87 & 7.93 & 6.98 & 14.36 \\
\hline 36 & Electronic and Other Electric Equipment & 2.35 & 2.44 & 2.16 & -3.97 & 11.45 & 7.93 \\
\hline 37 & Transportation Equipment & 1.77 & 1.68 & 1.80 & 5.30 & -7.07 & -1.40 \\
\hline 38 & Instruments and Related Products & 1.84 & 1.73 & 1.68 & 6.32 & 2.80 & 8.94 \\
\hline \multirow[t]{2}{*}{39} & Misc. Manufacturing Industries & 2.28 & 2.19 & 2.01 & 3.92 & 8.36 & 11.96 \\
\hline & Total . & 8.05 & 7.82 & 8.13 & 2.81 & -3.92 & -1.00 \\
\hline
\end{tabular}

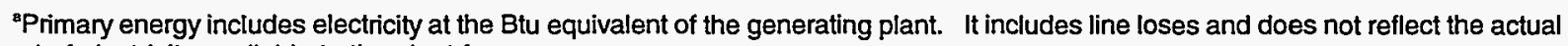
amount of electricity available to the plant for use.

$\mathrm{NA}=$ Not available. Data are included in higher-level totals.

Note: Positive percent change indicates a decrease in energy intensity and an increase in energy efficiency. Negative percent change indicates an increase in energy intensity and a decrease in energy efficiency.

Source: Energy Information Administration, Manufacturing Consumption of Energy 1991, DOE/EIA-0512(91), Washington, DC, 1994, Manufacturing Energy Consumption Survey: Consumption of Energy, 1988, DOE/EIA-0512(88), Washington, DC, 1991, and Manufacturing Energy Consumption Survey: Consumption of Energy, 1985, DOE/EIA-0512(85), Washington, DC, 1988. 
Table 3. Site Energy Intensity of Offsite-Produced Energy in Major Manufacturing Groups and Selected Industries, 1985,1988 , and $1991^{\mathrm{a}}$

\begin{tabular}{|c|c|c|c|c|c|c|c|}
\hline \multirow[b]{2}{*}{$\begin{array}{l}\text { SIC } \\
\text { Code }\end{array}$} & \multirow[b]{2}{*}{ Major Group and Industry } & \multicolumn{3}{|c|}{$\begin{array}{c}\text { Energy-Intensity Ratios } \\
\text { (thousand Btu/constant } \\
\text { dollar) }\end{array}$} & \multicolumn{3}{|c|}{$\begin{array}{l}\text { Change in } \\
\text { Energy Efficiency } \\
\text { (percent) }\end{array}$} \\
\hline & & 1985 & 1988 & 1991 & $\begin{array}{c}1985- \\
1988\end{array}$ & $\begin{array}{c}1988- \\
1991\end{array}$ & $\begin{array}{c}1985- \\
1991\end{array}$ \\
\hline 20 & Food and Kindred Products & 2.53 & 2.79 & 2.64 & -10.07 & 5.27 & -4.27 \\
\hline 21 & Tobacco Products & NA & NA & NA & NA & NA & NA \\
\hline 22 & Textile Mill Products & 4.49 & 4.54 & 4.67 & -1.12 & -2.87 & -4.02 \\
\hline 23 & Apparel and Other Textile Products & NA & NA & NA & NA & NA & NA \\
\hline 24 & Lumber and Wood Products ... & NA & NA & NA & NA & NA & NA \\
\hline 25 & Furniture and Fixtures $\ldots \ldots \ldots \ldots$ & 1.37 & 1.48 & 1.39 & -8.24 & 6.07 & -1.67 \\
\hline 26 & Paper and Allied Products . & 12.27 & 11.29 & 13.90 & 7.97 & -23.09 & -13.28 \\
\hline 2621 & Paper Mills & 24.27 & 23.22 & 26.63 & 4.31 & -14.66 & -9.71 \\
\hline 2631 & Paperboard Mills ......... & 36.31 & 33.89 & 39.47 & 6.65 & -16.47 & -8.72 \\
\hline 27 & Printing and Publishing $\ldots \ldots \ldots \ldots$ & NA & NA & NA & NA & NA & NA \\
\hline 28 & Chemicals and Allied Products ..... & 11.85 & 11.28 & 11.55 & 4.80 & -2.34 & 2.58 \\
\hline 2819 & Industrial Inorganic Chemicals, nec & 19.08 & 19.68 & 21.14 & -3.13 & -7.41 & -10.77 \\
\hline 2821 & Plastics Materials and Resins . ............ & 10.22 & 10.42 & 9.80 & -1.97 & 6.00 & 4.14 \\
\hline 2869 & Industrial Organic Chemicals, nec... & 22.66 & 19.75 & 21.01 & 12.82 & -6.40 & 7.25 \\
\hline 2873 & Nitrogenous Fertilizers $\ldots \ldots \ldots \ldots \ldots \ldots$ & 79.89 & 90.60 & 111.64 & -13.41 & -23.22 & -39.75 \\
\hline 29 & Petroleum and Coal Products .... & 7.63 & 7.83 & 8.33 & -2.60 & -6.41 & -9.18 \\
\hline 2911 & Petroleum Refining $\ldots \ldots \ldots \ldots \ldots$ & 7.75 & 7.87 & 8.63 & -1.30 & -9.60 & -11.02 \\
\hline 30 & Rubber and Misc. Plastic Products & 3.04 & 3.05 & 2.62 & -0.48 & 14.31 & 13.90 \\
\hline 31 & Leather and Leather Products ..... & NA & NA & NA & NA & NA & NA \\
\hline 32 & Stone, Clay, and Glass Products ........... & 15.52 & 16.39 & 17.35 & -5.61 & -5.82 & -11.76 \\
\hline 3241 & Hydraulic Cement $\ldots \ldots \ldots \ldots$ & 81.04 & 78.06 & 86.89 & 3.68 & -11.32 & -7.22 \\
\hline 33 & Primary Metal Industries $\ldots \ldots \ldots \ldots$ & 13.84 & 13.66 & 13.40 & 1.31 & 1.89 & 3.18 \\
\hline 3312 & Blast Furnaces and Steel Mills ....... & 22.32 & 23.21 & 21.96 & -3.97 & 5.37 & 1.61 \\
\hline 3334 & Primary Aluminum.$\ldots \ldots \ldots \ldots$ & 45.21 & 41.11 & 37.94 & 9.07 & 7.72 & 16.09 \\
\hline 34 & Fabricated Metal Products ......... & 2.18 & 2.33 & 2.24 & -6.84 & 3.82 & -2.76 \\
\hline 35 & Industrial Machinery and Equipment ......... & 1.20 & 1.10 & 1.00 & 7.84 & 9.04 & 16.17 \\
\hline 36 & Electronic and Other Electric Equipment & 1.15 & 1.21 & 1.05 & -4.83 & 12.94 & 8.74 \\
\hline 37 & Transportation Equipment ............... & 1.04 & 0.97 & 1.00 & 6.78 & -2.68 & 4.28 \\
\hline 38 & Instruments and Related Products & 1.05 & 0.91 & 0.89 & 13.21 & 2.53 & 15.41 \\
\hline \multirow[t]{2}{*}{39} & Misc. Manufacturing Industries . ........... & 1.25 & 1.27 & 1.08 & -1.45 & 14.87 & 13.64 \\
\hline & 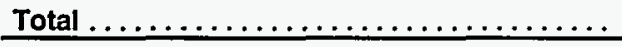 & 4.35 & 4.26 & 4.44 & 2.05 & -4.08 & -1.95 \\
\hline
\end{tabular}

"Site energy includes only those Btu available to the establishment. It specifically includes electricity available for the manufacturing establishment (3,412 Blu/kWh).

$N A=$ Not available. Data are included in higher-level totals.

Note: Positive percent change indicates a decrease in energy intensity and an increase in energy efficiency. Negative percent change indicates an increase in energy intensity and a decrease in energy efficiency.

Source: Energy Information Administration, Manufacturing Consumption of Energy 1991, DOE/ElA-0512(91), Washington, DC, 1994, Manufacturing Energy Consumption Survey: Consumption of Energy, 1988, DOE/EIA-0512(88), Washington, DC, 1991, and Manufacturing Energy Consumption Survey: Consumption of Energy, 1985, DOE/EIA-0512(85), Washington, DC, 1988. 
Table 4. Site Energy Intensity of Total Inputs of Energy in Major Manufacturing Groups and Selected Industries, 1985, 1988, and $1991^{\mathrm{a}}$

\begin{tabular}{|c|c|c|c|c|c|c|c|}
\hline \multirow[b]{2}{*}{$\begin{array}{l}\text { SIC } \\
\text { Code }\end{array}$} & \multirow[b]{2}{*}{ Major Group and Industry } & \multicolumn{3}{|c|}{$\begin{array}{c}\text { Energy-Intensity Ratios } \\
\text { (thousand Btu/constant } \\
\text { dollar) }\end{array}$} & \multicolumn{3}{|c|}{$\begin{array}{l}\text { Change in } \\
\text { Energy Efficiency } \\
\text { (percent) }\end{array}$} \\
\hline & & 1985 & 1988 & 1991 & $\begin{array}{r}1985- \\
1988 \\
\end{array}$ & $\begin{array}{c}1988- \\
1991 \\
\end{array}$ & $\begin{array}{c}1985- \\
1991 \\
\end{array}$ \\
\hline 20 & Food and Kindred Products . & 2.73 & 2.93 & 2.73 & -7.31 & 6.96 & 0.16 \\
\hline 21 & Tobacco Products & NA & NA & NA & NA & NA & NA \\
\hline 22 & Textile Mill Products ........ & 4.50 & 4.52 & 4.69 & -0.71 & -3.64 & -4.37 \\
\hline 23 & Apparel and Other Textile Products & NA & NA & NA & NA & NA & NA \\
\hline 24 & Lumber and Wood Products & NA & NA & NA & NA & NA & NA \\
\hline 25 & Furniture and Fixtures ... & 1.59 & 1.74 & 2.04 & -10.03 & -17.06 & -28.81 \\
\hline 26 & Paper and Allied Products ... & 20.17 & 18.78 & 22.32 & 6.90 & -18.84 & -10.63 \\
\hline 2621 & Paper Mills...$\ldots \ldots \ldots$ & 38.18 & 36.50 & 41.42 & 4.40 & -13.47 & -8.48 \\
\hline 2631 & Paperboard Mills ...... & 64.25 & 59.43 & 62.34 & 7.51 & -4.90 & 2.98 \\
\hline 27 & Printing and Publishing..... & NA & NA & NA & NA & NA & NA \\
\hline 28 & Chemicals and Allied Products & 13.16 & 12.57 & 13.13 & 4.50 & -4.43 & 0.26 \\
\hline 2819 & Industrial Inorganic Chemicals, nec & 21.41 & 20.70 & 21.67 & 3.29 & -4.66 & -1.21 \\
\hline 2821 & Plastics Materials and Resins ....... & 13.62 & 11.47 & 10.75 & 15.78 & 6.31 & 21.09 \\
\hline 2869 & Industrial Organic Chemicals, nec........ & 26.91 & 23.43 & 26.77 & 12.93 & -14.25 & 0.52 \\
\hline 2873 & Nitrogenous Fertilizers . . . . . . . . & 80.63 & 94.09 & 112.62 & -16.69 & -19.69 & -39.66 \\
\hline 29 & Petroleum and Coal Products ....... & 20.36 & 22.86 & 21.87 & -12.25 & 4.33 & -7.39 \\
\hline 2911 & Petroleum Refining $\ldots \ldots \ldots \ldots \ldots \ldots$ & 21.54 & 24.09 & 23.45 & -11.85 & 2.67 & -8.85 \\
\hline 30 & Rubber and Misc. Plastic Products ...... & 3.05 & 3.06 & 2.64 & -0.55 & 13.83 & 13.36 \\
\hline 31 & Leather and Leather Products .......... & NA & NA & NA & NA & NA & NA \\
\hline 32 & Stone, Clay, and Glass Products ... & 15.84 & 16.50 & 17.67 & -4.16 & -7.14 & -11.59 \\
\hline 3241 & Hydraulic Cement & 84.09 & 79.58 & 91.49 & 5.36 & -14.96 & -8.78 \\
\hline 33 & Primary Metal Industries .... & 21.54 & 20.20 & 19.66 & 6.21 & 2.67 & 8.71 \\
\hline 3312 & Blast Furnaces and Steel Mills & 45.46 & 42.73 & 40.93 & 6.00 & 4.22 & 9.97 \\
\hline 3334 & Primary Aluminum & 45.23 & 41.02 & 37.75 & 9.30 & 7.97 & 16.53 \\
\hline 34 & Fabricated Metal Products . . . . . . . . & 2.19 & 2.34 & 2.24 & -6.61 & 3.99 & -2.35 \\
\hline 35 & Industrial Machinery and Equipment ....... & 1.19 & 1.10 & 1.00 & 7.88 & 8.63 & 15.83 \\
\hline 36 & Electronic and Other Electric Equipment & 1.15 & 1.21 & 1.05 & -5.11 & 13.09 & 8.64 \\
\hline 37 & Transportation Equipment & 1.03 & 0.97 & 1.04 & 5.92 & -7.99 & -1.60 \\
\hline 38 & Instruments and Related Products ....... & 1.04 & 0.92 & 0.89 & 11.83 & 2.77 & 14.27 \\
\hline \multirow[t]{2}{*}{39} & Misc. Manufacturing Industries . . . . . . . . & 1.31 & 1.28 & 1.11 & 2.47 & 13.31 & 15.46 \\
\hline & Total $\ldots \ldots \ldots \ldots \ldots \ldots \ldots \ldots \ldots$ & 6.06 & 5.96 & 6.15 & 1.70 & -3.35 & -1.60 \\
\hline
\end{tabular}

aSite energy includes only those Btu available to the establishment. It specifically includes electricity available for the manufacturing establishment $(3,412 \mathrm{Btu} / \mathrm{kWh})$.

$\mathrm{NA}=$ Not available. Data are included in higher-level totals.

Note: Positive percent change indicates a decrease in energy intensity and an increase in energy efficiency. Negative percent change indicates an increase in energy intensity and a decrease in energy efficiency.

Source: Energy Information Administration, Manufacturing Consumption of Energy 1991, DOE/EIA-0512(91), Washington, DC, 1994, Manufacturing Energy Consumption Survey: Consumption of Energy, 1988, DOE/EIA-0512(88), Washington, DC, 1991, and Manufacturing Energy Consumption Survey: Consumption of Energy, 1985, DOE/EIA-0512(85), Washington, DC, 1988. 
Table 5. Site Energy Intensity of Offsite-Produced Energy (Structurally Adjusted) in Major Manufacturing Groups, 1985, 1988, and $1991^{\mathrm{a}}$

\begin{tabular}{|c|c|c|c|c|c|c|c|}
\hline \multirow[b]{2}{*}{$\begin{array}{l}\text { SIC } \\
\text { Code }\end{array}$} & \multirow[b]{2}{*}{ Major Group } & \multicolumn{3}{|c|}{$\begin{array}{c}\text { Energy-Intensity Ratios } \\
\text { (thousand Btu/constant dollar) }\end{array}$} & \multicolumn{3}{|c|}{$\begin{array}{c}\text { Change in } \\
\text { Energy Efficiency } \\
\text { (percent) }\end{array}$} \\
\hline & & 1985 & $\begin{array}{c}1988 \\
\text { Adjusted } \\
\end{array}$ & $\begin{array}{c}1991 \\
\text { Adjusted }\end{array}$ & $\begin{array}{l}1985 \\
1988 \\
\end{array}$ & $\begin{array}{l}1988- \\
1991\end{array}$ & $\begin{array}{l}1985- \\
1991 \\
\end{array}$ \\
\hline 20 & Food and Kindred Products & 2.53 & 2.75 & 2.62 & -8.54 & 4.76 & -3.38 \\
\hline 21 & $\ldots \ldots \ldots \ldots \ldots \ldots \ldots$ & NA & NA & NA & NA & NA & NA \\
\hline 22 & Textile Mill Products & 4.49 & 4.50 & 4.64 & -0.20 & -3.13 & -3.34 \\
\hline 23 & Apparel and Other Textile Products & NA & NA & NA & NA & NA & NA \\
\hline 24 & Lumber and Wood Products & NA & NA & NA & NA & NA & NA \\
\hline 25 & Furniture and Fixtures & 1.37 & 1.48 & 1.39 & -8.18 & 6.04 & -1.65 \\
\hline 26 & Paper and Allied Products & 12.27 & 11.08 & 12.99 & 9.66 & -17.17 & -5.85 \\
\hline 27 & Printing and Publishing & NA & NA & NA & NA & NA & NA \\
\hline 28 & Chemicals and Allied Products & 11.85 & 11.40 & 12.18 & 3.84 & -6.84 & -2.75 \\
\hline 29 & Petroleum and Coal Products & 7.63 & 7.83 & 8.40 & -2.58 & -7.25 & -10.02 \\
\hline 30 & Rubber and Misc. Plastic Products & 3.04 & 3.08 & 2.63 & -1.35 & 14.56 & 13.41 \\
\hline 31 & Leather and Leather Products & NA & NA & NA & NA & NA & NA \\
\hline 32 & Stone, Clay, and Glass Products & 15.52 & 16.35 & 17.25 & -5.32 & -5.53 & -11.14 \\
\hline 33 & Primary Metal Industries & 13.84 & 13.33 & 13.00 & 3.68 & 2.49 & 6.09 \\
\hline 34 & Fabricated Metal Products & 2.18 & 2.29 & 2.21 & -4.81 & 3.44 & -1.21 \\
\hline 35 & Industrial Machinery and Equipment & 1.20 & 1.13 & 1.08 & 5.58 & 3.97 & 9.34 \\
\hline 36 & Electronic and Other Electric Equipment & 1.15 & 1.19 & 1.05 & -3.18 & 11.26 & 8.44 \\
\hline 37 & Transportation Equipment & 1.04 & 0.98 & 1.03 & 6.25 & -5.36 & 1.23 \\
\hline 38 & Instruments and Related Products & 1.05 & 1.00 & 0.97 & 5.10 & 2.72 & 7.69 \\
\hline \multirow[t]{2}{*}{39} & Misc. Manufacturing Industries & 1.25 & 1.21 & 1.10 & 3.01 & 9.71 & 12.42 \\
\hline & Total $\ldots \ldots \ldots \ldots \ldots \ldots \ldots \ldots \ldots$ & 4.35 & 4.29 & 4.46 & 1.38 & -3.91 & -2.47 \\
\hline
\end{tabular}

'Site energy includes only those Btu available to the establishment. It specifically includes electricity available for the manufacturing establishment $(3,412 \mathrm{Btu} / \mathrm{kWh})$. For 1988 and 1991, intensities are adjusted to reflect the general product mix of the manufacturing sector in 1985.

NA=Not available. Data are included in higher-level totals.

Note: Positive percent change indicates a decrease in energy intensity and an increase in energy efficiency. Negative percent change indicates an increase in energy intensity and a decrease in energy efficiency.

Source: Energy Information Administration, Manufacturing Consumption of Energy 1991, DOE/EIA-0512(91), Washington, DC, 1994, Manufacturing Energy Consumption Survey: Consumption of Energy, 1988, DOE/EIA-0512(88), Washington, DC, 1991, and Manufacturing Energy Consumption Survey: Consumption of Energy, 1985, DOE/EIA-0512(85), Washington, DC, 1988. 
Table 6. Site Energy Intensity of Total Inputs of Energy (Structurally Adjusted) in Major Manufacturing Groups, 1985, 1988, and $1991^{\mathrm{a}}$

\begin{tabular}{|c|c|c|c|c|c|c|c|}
\hline \multirow[b]{2}{*}{$\begin{array}{l}\text { SIC } \\
\text { Code }\end{array}$} & \multirow[b]{2}{*}{ Major Group } & \multicolumn{3}{|c|}{$\begin{array}{c}\text { Energy-Intensity Ratios } \\
\text { (thousand Btu/constant dollar) }\end{array}$} & \multicolumn{3}{|c|}{$\begin{array}{c}\text { Change in } \\
\text { Energy Efficiency } \\
\text { (percent) }\end{array}$} \\
\hline & & 1985 & $\begin{array}{c}1988 \\
\text { Adjusted } \\
\end{array}$ & $\begin{array}{c}1991 \\
\text { Adjusted } \\
\end{array}$ & $\begin{array}{l}1985- \\
1988 \\
\end{array}$ & $\begin{array}{l}1988- \\
1991\end{array}$ & $\begin{array}{l}1985- \\
1991\end{array}$ \\
\hline 20 & Food and Kindred Products & 2.73 & 2.88 & 2.71 & -5.55 & 6.21 & 1.00 \\
\hline 21 & Tobacco Products & NA & NA & NA & NA & NA & NA \\
\hline 22 & Textile Mill Products & 4.50 & 4.49 & 4.66 & 0.20 & -3.86 & -3.65 \\
\hline 23 & Apparel and Other Textile Products & NA & NA & NA & NA & NA & NA \\
\hline 24 & Lumber and Wood Products & NA & NA & NA & NA & NA & NA \\
\hline 25 & Furniture and Fixtures & 1.59 & 1.74 & 2.04 & -9.52 & -17.62 & -28.82 \\
\hline 26 & Paper and Allied Products & 20.17 & 18.40 & 20.92 & 8.80 & -13.72 & -3.71 \\
\hline 27 & Printing and Publishing & NA & NA & NA & NA & NA & NA \\
\hline 28 & Chemicals and Allied Products & 13.16 & 12.61 & 13.74 & 4.16 & -8.90 & -4.37 \\
\hline 29 & Petroleum and Coal Products & 20.36 & 22.81 & 22.21 & -12.00 & 2.61 & -9.07 \\
\hline 30 & Rubber and Misc. Plastic Products & 3.05 & 3.09 & 2.66 & -1.42 & 14.08 & 12.86 \\
\hline 31 & Leather and Leather Products & NA & NA & NA & NA & NA & NA \\
\hline 32 & Stone, Clay, and Glass Products & 15.84 & 16.45 & 17.57 & -3.88 & -6.81 & -10.96 \\
\hline 33 & Primary Metal Industries & 21.54 & 19.48 & 18.68 & 9.56 & 4.08 & 13.26 \\
\hline 34 & Fabricated Metal Products & 2.19 & 2.29 & 2.21 & -4.58 & 3.61 & -0.80 \\
\hline 35 & Industrial Machinery and Equipment & 1.19 & 1.12 & 1.08 & 5.59 & 3.56 & 8.96 \\
\hline 36 & Electronic and Other Electric Equipment & 1.15 & 1.19 & 1.05 & -3.49 & 11.45 & 8.36 \\
\hline 37 & Transportation Equipment & 1.03 & 0.97 & 1.08 & 5.40 & -11.13 & -5.13 \\
\hline 38 & Instruments and Related Products & 1.04 & 1.00 & 0.97 & 3.48 & 3.00 & 6.37 \\
\hline \multirow[t]{2}{*}{39} & Misc. Manufacturing industries & 1.31 & 1.23 & 1.13 & 6.76 & 7.88 & 14.11 \\
\hline & Total $\ldots \ldots \ldots \ldots \ldots \ldots \ldots \ldots \ldots$ & 6.06 & 5.99 & 6.16 & 1.11 & -2.80 & -1.65 \\
\hline
\end{tabular}

a Site energy includes only those Btu available to the establishment. It specifically includes electricity available for the manufacturing establishment $(3,412 \mathrm{Btu} / \mathrm{kWh})$. For 1988 and 1991 , intensities are adjusted to reflect the general product mix of the manufacturing sector in 1985.

$N A=$ Not available. Data are included in higher-level totals.

Note: A positive percent change indicates a decrease in energy intensity and an increase in energy efficiency. A negative percent change indicates an increase in energy intensity and a decrease in energy efficiency.

Source: Energy Information Administration, Manufacturing Consumption of Energy 1991, DOE/EIA-0512(91), Washington, DC, 1994, Manufacturing Energy Consumption Survey: Consumption of Energy, 1988, DOE/EIA-0512(88), Washington, DC, 1991, and Manufacturing Energy Consumption Survey: Consumption of Energy, 1985, DOE/EIA-0512(85), Washington, DC, 1988. 


\section{Energy Efficiency Analysis}

This chapter contains separate discussions for 15 of the 20 major manufacturing groups, and the ten industries (4-digit SIC codes) that consume the most energy. Discussions of major groups each contain two charts as well as text descriptions of the SIC of interest. The first chart presents indices for Offsite-Produced Energy consumption and 1987 constant dollar value of shipments indices for years between 1977 and 1991, illustrating the general relationship between output and one measure of energy consumption. A second chart displays both adjusted and unadjusted energy-intensity ratios for 1985, 1988, and 1991. With 1985 serving as the base year for structural-shift adjustments, adjusted intensities are shown only for 1988 and 1991 end years. Of the 20 major manufacturing groups, five groups are excluded from these discussions because data on them are unavailable in earlier MECS publications. Discussions of the 4-digit SIC industries display the chart showing energy-intensity ratios along with text description.

Because of the SIC system's revision in 1987, discontinuities may occur in the historical data covering the time periods before and after 1987. Specifically, all charts showing energy-intensity ratios and percent changes in energy efficiency have been re-estimated under the 1987 SIC system, ensuring the comparability of estimates for 1985, 1988, and 1991. However, charts of consumption and output indices for the 1977-1991 time period use both the OMB's 1972 and 1987 SIC system. For those charts, the 1987 definitions are used from 1987 through 1991, while the 1972 definitions are active for years 1977 through 1986. Because earlier MECS efficiency reports employed the 1972 SIC system definition, direct comparison of energy intensities among these publications is impossible.

This report relies on external data sources. Analysis of SIC-specific number of employees, value of shipments, and cost of materials is based on data from Table 2 of the 1985, 1988, and 1991 Annual Survey of Manufactures. ${ }^{4}$ Table 4 from those publications also provides data on cost of purchased fuels and electric energy.

The EIA report, Manufacturing Consumption of Energy, 1991, provides the core data for this report:

- Table A4 provides Total Inputs of Energy for heat, power, and electricity generation.

- Table A5 provides information on Offsite-Produced Energy consumption for heat, power, and electricity generation.

- Table A16 provides electricity demand.

- Table A17 provides components of onsite electricity generation.

- Table A36 gives information on manufacturer's end-use consumption for process, nonprocess, and boiler fuel uses.

- Table A40 shows the participation of manufacturers in programs designed to manage energy consumption.

- Table A44 identifies the existence of general and industry-specific technologies for selected industries. 


\section{Chart Interpretation}

\section{Index Chart}

These charts present indices of 15 years (1977-1991) of historical data of constant-dollar value of shipments and Offsite-Produced Energy consumption, using 1977 as the base year $(1977=100)$ (Figure 4.1). Indexing both energy consumption and corresponding constant dollar value of shipments best illustrates the trends in output and consumption. Taken separately, these two indices track the relative growth rates within the specified major group. Taken together, they reveal trends in energy efficiency. For example, a steady increase in output, coupled with a decline in energy consumption, represents energy efficiency gains. Likewise, steadily rising energy consumption with a corresponding decline in output illustrates energy efficiency losses.

The vertical axis is truncated in these charts to more clearly identify the relationship between energy consumption and output.

The MECS supplied energy consumption data for 1985 , Figure 4.1. Interpretation of Output and Offsite-
Produced Energy Consumption
Indices for the Manufacturing
Sector, 1977 Through 1991

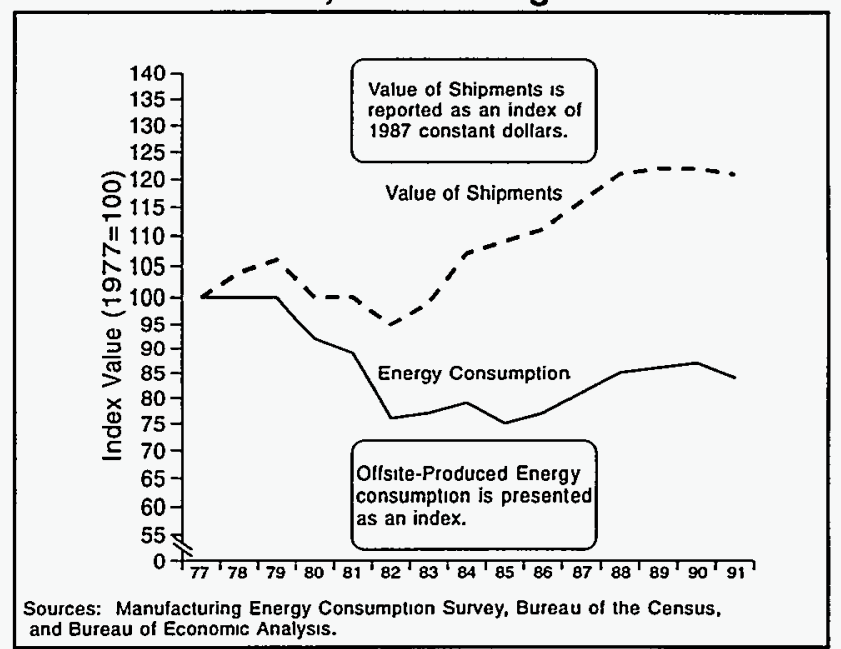
1988 and 1991. Energy consumption data for the intervening years were calculated using the methodology presented in the EIA publication Derived Annual Estimates of Manufacturing Energy Consumption 1974-1988.5 That report used two-way indexing as a means to linearly interpolate between the forward-index and backward-index estimates; that is, the two-way indexed estimate is the weighted average of the estimates obtained by forward and backward indexing, with higher weight given to the closer endpoint year. The Bureau of Economic Analysis (BEA) provided 1987 constant dollar value of shipments data for the period.

\section{Energy Intensity Chart}

The second figure (Figure 4.2) presents both the unadjusted and structurally adjusted energy-intensity ratios, along with the percent change in efficiency, as measured by changes in adjusted energy-intensity ratios. Horizontal bars represent those energy-intensity ratios for both Offsite-Produced Energy and Total Inputs of Energy. The actual ratio for the given year is adjacent to the bar. As appears in Figure 4.2, all estimates for consumption and value of shipments were derived directly from the MECS samples.

Given a base year and end year, the percentage changes in efficiency for both Offsite-Produced and Total Inputs of Energy are displayed adjacent to their respective energy-intensity ratios. Along with the actual percent change, an arrow indicator illustrates the direction of
Figure 4.2. Interpretation of Site Energy Intensities for the Manufacturing Sector, 1985-1991

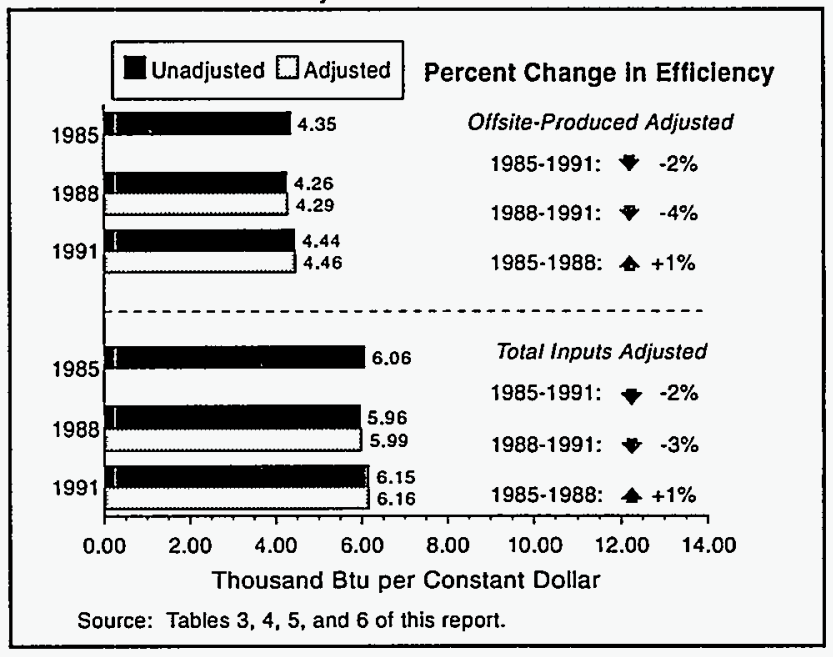




\section{energy efficiency over the specified time period—an upward arrow denotes an improvement in energy efficiency, while a downward arrow denotes a loss in efficiency.}

Both structurally adjusted and unadjusted energy-intensity ratios are shown. ${ }^{6}$ Because 1985 serves as the base year for structural-shift adjustments, energy-intensity ratios adjusted for structural shifts are shown only for 1988 and 1991 end years. If the structurally adjusted ratio is less than the unadjusted ratio, a movement toward more energy-intensive products since 1985 is indicated. Similarly, when the structurally adjusted ratio is more than the unadjusted ratio, a movement since 1985 toward less energy-intensive products is indicated. An absence of movement is indicated by equal adjusted and unadjusted ratios.

Energy-intensity ratios adjusted for structural shifts can provide relatively clean measures of efficiency change (See example on page 7). However, such measures, if they are based only on Offsite-Produced Energy consumption, are incomplete because they ignore the potential impacts of the consumption of Onsite-Produced Energy, such as black liquor, wood chips, petroleum coke, and waste gas. Of the 15.0 quadrillion Btu of Total Inputs of Energy, byproduct consumption accounts for 4.2 quadrillion Btu (28 percent). ${ }^{7}$ If Onsite-Produced Energy sources serve as substitutes for Offsite-Produced Energy sources, a change in the relative amounts of the two sources used could mask changes in energy intensity.

Energy efficiency cannot be inferred directly from changes in energy-intensity ratios. While improved energy efficiency does indicate reduced energy intensity, it is also true that a change in energy intensity can result from factors unrelated to energy efficiency. Energy produced onsite and structural shifts in production mix are two of those factors.

'All MECS surveys are subsampled from the sample for the Annual Survey of Manufacturing (ASM) conducted by the Bureau of the Census. The ASM routinely produces estimates of value of shipments by three-digit manufacturing industry groups. Because of the subsampling procedure used for the MECS, it is possible to replicate those value of shipments estimates by using MECS establishment weights applied to ASM-reported value of shipments for respondents that were in both surveys. If the MECS-weighted estimates of value of shipments were within 10 percent of the ASM estimate for any given three-digit industry group, that group was judged to be sufficiently reliable to assess structural shift. Those estimates with a difference greater than 10 percent were combined until the 10-percent criterion was met. Counting single three-digit industry groups, 83 groups were judged to be sufficiently reliable.

'Energy Information Administration, Manufacturing Consumption of Energy 1991, DOE/EIA-0512(91), December 1994. 


\section{Food and Kindred Products, SIC 20}

The Food and Kindred Products major group is responsible for processing agricultural and marine products into foods and beverages for human consumption. This major group also provides animal feeds as an end product. Both finished products (e.g., crackers, canned or frozen vegetables) and inputs to further home or industry processing (e.g., refined sugar, milled rice) are outputs of this major group. This major group includes nine industry groups (e.g., meat products, dairy products) and 49 industries (e.g., meat packing plants, creamery butter).

In 1991, this major group:

- Employed 1,474,700 workers (9,900 more than in 1988 and 52,200 more than in 1985).

- Shipped $\$ 367.6$ billion of goods ( $\$ 16.1$ billion more than in 1988 and $\$ 66.0$ billion more than in 1985 ), about 14 percent of total manufacturing value of shipments.

- Spent approximately 2 percent of its total cost of materials for fuels and electrical energy.

\section{Use of Energy}

Although the Food and Kindred Products major group consumes a large amount of energy, it is not especially energy intensive. In 1991, this major group:

- Consumed about 9 percent of the Offsite-Produced Energy and about 6 percent of the Total Inputs of Energy for heat, power, and electricity generation in the manufacturing sector.

- Declined in use of Onsite-Produced Energy from 7 percent of Total Inputs in 1985 to 3 percent 1991.

- Used energy in most food establishments mainly to provide steam, hot water, or process heating.

- Reduced energy consumption in recent years by means of incremental improvements to conventional technology, such as waste heat recovery, and the adoption of such process innovations as membrane separations, in place of thermal separations.

\section{Energy Management}

The 1991 MECS represents a first-time collection of manufacturers' participation in energy-management activities. To improve energy efficiency, manufacturing establishments participated in various demand-side management (DSM) and other energy-management programs. ${ }^{8}$ From 1989 through 1991, their activities and percent of participation, expressed in terms of Total Inputs of Energy used by participating establishments, were as follows: improving the efficiency of steam production ( 30 percent); improving the efficiency of process heating ( 31 percent); improving the efficiency of process refrigeration (18 percent); installing or retrofitting motors to achieve better energy efficiency (38 percent); improving the efficiency of facility HVAC systems ( 21 percent); and improving the efficiency of facility lighting (33 percent).

\section{Structural Shifts}

Since 1985, this major group has shifted slightly toward more energy-intensive products, as indicated by a structurally adjusted energy-intensity ratio that is less than the comparable unadjusted ratio. This type of shift occurred in both Offsite-Produced and Total Inputs of Energy (Figure 4.4). 


\section{Impact of 1987 SIC Revision}

The 1987 SIC revision had little impact on the food industry. Changes to the group include reclassifications within the two-digit category, with no industries moving into or out of the two-digit group.

\section{Historical Trends in Energy Consumption and Value of Shipments}

Between 1977 and 1991, the consumption of OffsiteProduced Energy:

- Fell to the lowest point in 1985,8 percent below the 1977 consumption level.

- Increased between 1985 and 1988 before decreasing after 1990.

- Ended 1991 at 3 percent below the 1977 consumption level.

Between 1977 and 1991, the value of shipments (output) for this major group:

- Increased steadily through 1988 , decreased slightly in 1989, then again increased through 1991.

- Ended 1991 at almost 25 percent greater than in 1977.
Figure 4.3. Output and Offsite-Produced Energy Consumption Indices for SIC 20, 1977 Through 1991

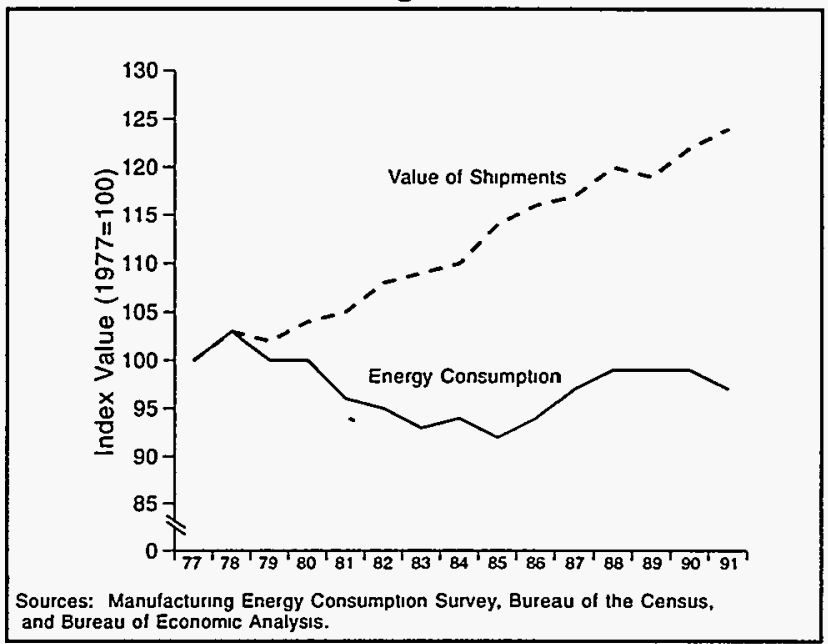

Energy efficiency increased steadily from 1977 through 1985, as evidenced by the two divergent lines that depict falling energy consumption coupled with rising shipment values (Figure 4.3).

\section{Energy Efficiency (Adjusted), 1985-1991}

In the food industries, energy efficiency of OffsiteProduced Energy rebounded with a gain of 5 percent between 1988 and 1991, after a plunge of 9 percent from 1985 to 1988 (Figure 4.4). In the case of Total Inputs of Energy, energy efficiency decreased by 6 percent from 1985 to 1988 , but recovered in the most recent 3-year period with a matching increase.

In the manufacturing sector as a whole, Offsite-Produced Energy efficiency decreased by 4 percent between 1988 and 1991, but increased by 1 percent between 1985 and 1988. Similarly, energy efficiency for Total Inputs of Energy decreased by 3 percent between 1988 and 1991, following an increase of 1 percent between 1985 and 1988.
Figure 4.4. Site Energy Intensities for SIC 20, 1985-1991

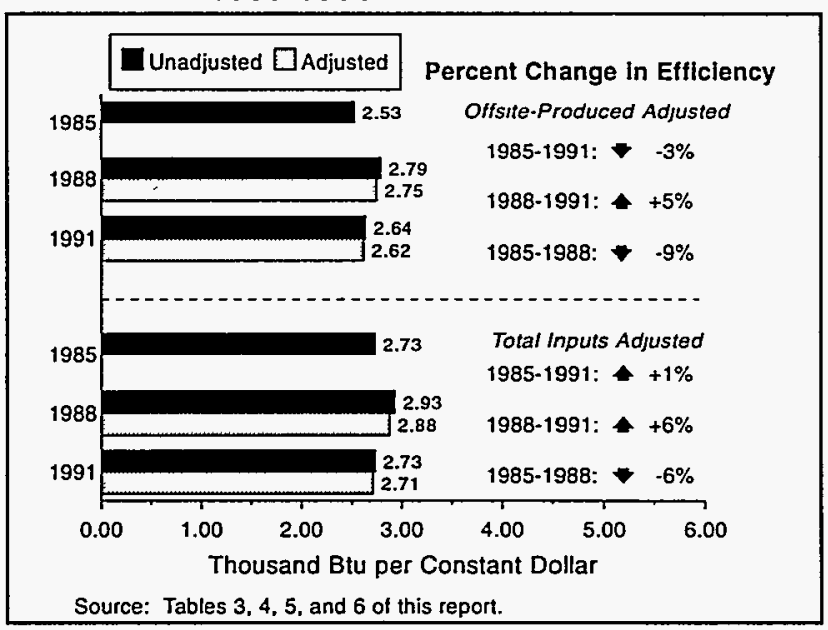




\section{Textile Mill Products, SIC 22}

Establishments in the Textile Mill Products group are engaged in the preparation of fibers and the subsequent manufacture of yarn, thread, braids, twine, and cordage. In addition, these establishments produce goods such as woven fabrics, carpets, knit fabrics, or other finished yarn goods. This major group also produces felt and lace goods, nonwoven fabrics, and various miscellaneous textile products. This group of manufacturers contains nine industry groups (e.g., knitting mills, broadwoven fabric mills, cotton) and 23 industries (e.g., knit outerwear, thread mills).

In 1991, this major group:

- Employed 597,900 workers (70,600 less than in 1988 and 60,500 less than in 1985).

- Shipped $\$ 65.7$ billion of goods ( $\$ 0.9$ billion more than in 1988 and $\$ 12.0$ billion more than in 1985 ), about 2 percent of total manufacturing value of shipments.

- Spent approximately 5 percent of its total cost of materials for fuels and electrical energy.

\section{Use of Energy}

This major group of manufacturers is not an energy-intensive group. In 1991, this group:

- Consumed approximately 3 percent of the Offsite-Produced Energy and about 2 percent of the Total Inputs of Energy for heat, power, and electricity generation in the manufacturing sector.

- Used virtually no Onsite-Produced Energy for heat, power, or electricity generation.

- Used energy mainly for machine drive or as boiler fuel.

\section{Energy Management}

The 1991 MECS represents a first-time collection of manufacturers' participation in energy-management activities. To improve energy efficiency, manufacturing establishments participated in various demand-side management (DSM) and other energy-management programs. ${ }^{9}$ From 1989 through 1991, their activities and percent of participation, expressed in terms of Total Inputs of Energy used by participating establishments, were as follows: improving the efficiency of steam production ( 23 percent); improving the efficiency of process heating (15 percent); improving the efficiency of process refrigeration (10 percent); installing or retrofitting motors to achieve better energy efficiency ( 29 percent); improving the efficiency of facility HVAC systems ( 23 percent); and improving the efficiency of facility lighting (40 percent).

\section{Structural Shifts}

Since 1985, this major group has shifted slightly toward more energy-intensive products, as indicated by a structurally adjusted energy-intensity ratio that is less than the comparable unadjusted ratio. This type of shift occurred in both Offsite-Produced and Total Inputs of Energy (Figure 4.6). 


\section{Impact of 1987 SIC Revision}

The 1987 SIC revision affected this group primarily at the four-digit SIC level. There were no reclassifications into or out of this two-digit SIC group.

\section{Historical Trends in Energy Consumption and Value of Shipments}

Between 1977 and 1991, the consumption of OffsiteProduced Energy by the textile major group:

- Decreased to the lowest point in 1985 , then increased through 1989.

- Ended 1991 at approximately 20 percent below the 1977 level.

Between 1977 and 1991, value of shipments (output) for this group:

- Declined to a low in 1982 , then increased to the highest level in 1989.

- Ended 1991 at approximately 6 percent greater than in 1977.

Except for 1981, energy efficiency increased steadily from 1977 through 1985, as the gap gradually widens between the two lines that depict energy consumption and shipment values (Figure 4.5).

\section{Energy Efficiency (Adjusted), 1985-1991}

In the textile industries, energy efficiency of OffsiteProduced Energy slid by 3 percent between 1988 and 1991, after no change from 1985 to 1988 (Figure 4.6). Energy efficiency for Total Inputs of Energy followed a comparable pattern, down by 4 percent from 1988 to 1991 with no change from 1985 to 1988.

In the manufacturing sector as a whole, Offsite-Produced Energy efficiency decreased by 4 percent between 1988 and 1991, but increased by 1 percent between 1985 and 1988. Similarly, energy efficiency for Total Inputs of Energy decreased by 3 percent between 1988 and 1991, following an increase of 1 percent between 1985 and 1988. 1985-1991

\section{Figure 4.5. Output and Offsite-Produced Energy Consumption Indices for SIC 22, 1977 Through 1991}

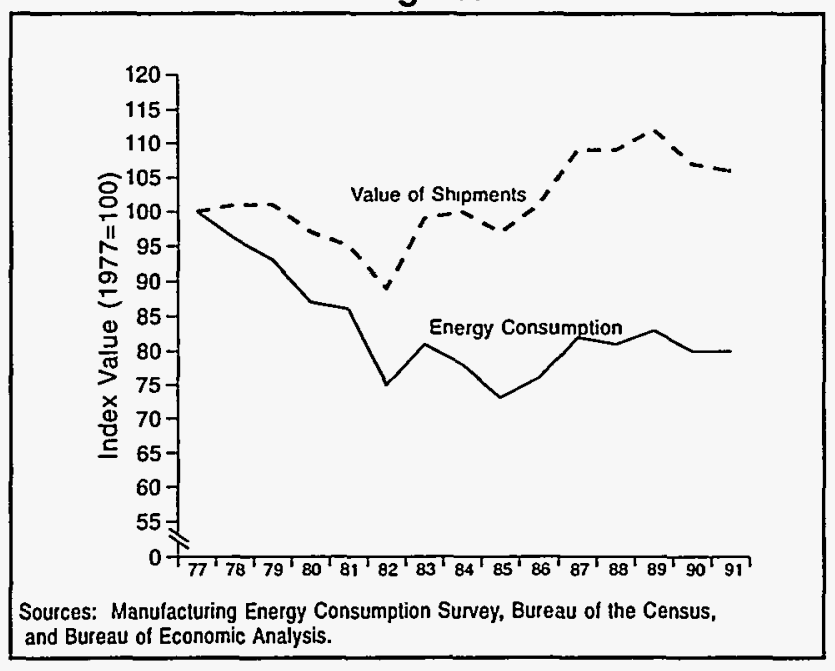
and Bureau of Economic Analysis.

Figure 4.6. Site Energy Intensities for SIC 22,

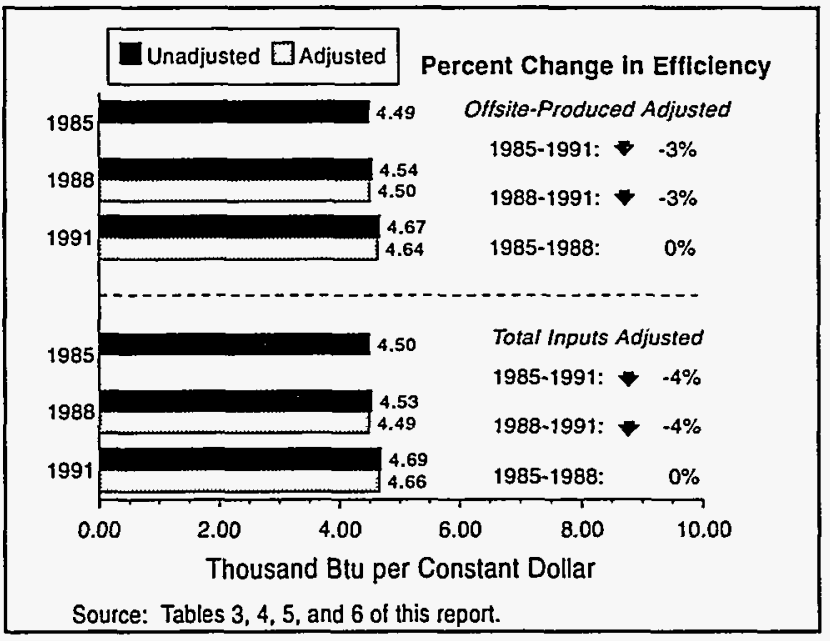




\section{Furniture and Fixtures, SIC 25}

Establishments in the Furniture and Fixtures group produce furniture for households, offices, restaurants, and public buildings. The group also produces office and store fixtures. The major group includes five industry groups (e.g., household furniture, office furniture). These industry groups are separated into 13 industries (e.g., wood television, radio, phonograph, and sewing machine cabinets; drapery hardware, window blinds and shades).

In 1991, the Furniture and Fixtures group:

- Employed approximately 465,700 employees (43,600 less than in 1988 and 6,600 less than in 1985).

- Shipped $\$ 40.0$ billion of goods ( $\$ 0.8$ billion more than in 1988 and $\$ 8.7$ billion more than in 1985 ), about 1 percent of total manufacturing value of shipments.

- Spent approximately 2 percent of its total cost of materials for fuels and electrical energy.

\section{Use of Energy}

This major group of manufacturers consumes very little energy. In 1991, this group:

- Consumed less than one-half of 1 percent of both the Offsite-Produced Energy and the Total Inputs of Energy for heat, power, and electricity generation in the manufacturing sector.

- Increased its use of Onsite-Produced Energy from 15 percent of Total Inputs in 1985 and 1988 to 31 percent in 1991.

- Used byproduct energy sources (i.e., wood chips, bark) for more than one-third of the energy consumed for heat, power, and electricity generation.

\section{Energy Management}

The 1991 MECS represents a first-time collection of manufacturers' participation in energy-management activities. To improve energy efficiency, manufacturing establishments participated in various demand-side management (DSM) and other energy-management programs. ${ }^{10}$ From 1989 through 1991, their activities and percent of participation, expressed in terms of Total Inputs of Energy used by participating establishments, were as follows: improving the efficiency of steam production (12 percent); improving the efficiency of process heating ( 7 percent); improving the efficiency of process refrigeration ( 6 percent); installing or retrofitting motors to achieve better energy efficiency (12 percent); improving the efficiency of facility HVAC systems (16 percent); and improving the efficiency of facility lighting (18 percent).

\section{Structural Shifts}

Since 1985, there have been virtually no structural shifts in either Offsite-Produced or Total Inputs of Energy, as evidenced by a structurally adjusted energy-intensity ratio that matches the comparable unadjusted ratio (Figure 4.8). 


\section{Impact of 1987 SIC Revision}

The 1987 SIC revision affected this group only at the three-digit level. No industries moved into or out of the two-digit group.

\section{Historical Trends in Energy Consumption and Value of Shipments}

Between 1977 and 1991, the consumption of offsiteproduced energy by this group:

- Increased for one year before dropping sharply. In both 1982 and 1985 consumption was 22 percent below the 1977 level.

- Peaked at its highest points in 1978 (5 percent above the 1977 level) and in 1989 (4 percent above the 1977 level).

- Ended 1991 at approximately 87 percent of the 1977 consumption level.

Value of shipments (output) for this group between 1977 and 1991:

- Increased, then dropped through 1982 to 99 percent of the 1977 level, the lowest for this group.
Figure 4.7. Output and Offsite-Produced Energy Consumption Indices for SIC 25, 1977 Through 1991

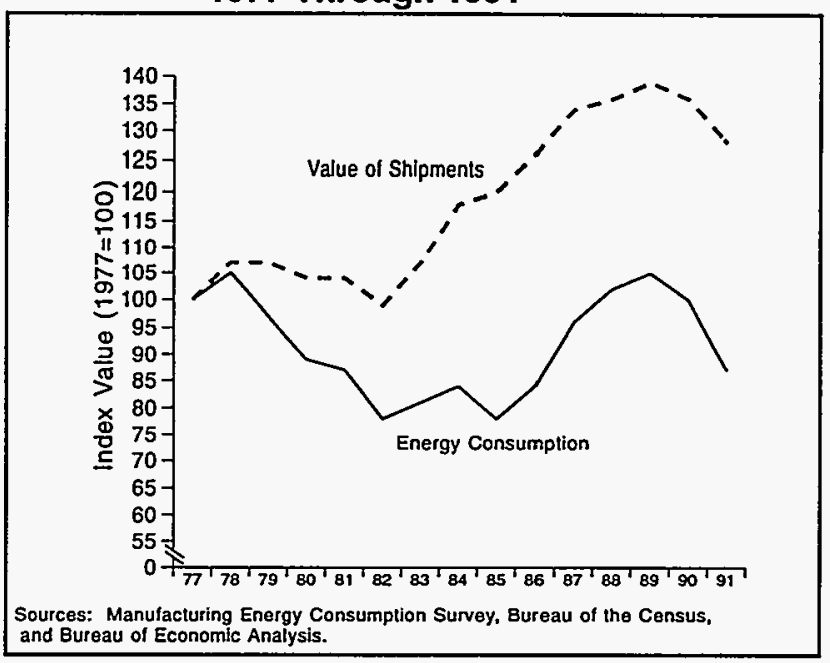

- Increased steadily between 1982 and 1989 before again dropping.

- Ended 1991 at approximately 28 percent greater than in 1977.

Energy efficiency increased consistently from 1977 through 1985 . When value of shipments declined from 1978 to 1982 , consumption dropped even more sharply. Then through 1985, the upswing in shipment values was more noticeable (Figure 4.7).

\section{Energy Efficiency (Adjusted), 1985-1991}

In the furniture industries, energy efficiency of OffsiteProduced Energy recovered with a 6 percent advance from 1988 to 1991, after an 8 percent loss from 1985 to 1988 (Figure 4.8). However, for Total Inputs of Energy, energy efficiency followed a plummet of 10 percent from 1985 to 1988 with an even bigger plunge of 18 percent to 1991. A possible cause of this downslide was increased byproduct consumption of wood chips and bark (25 trillion Btu in 1991, double the 1988 amount).

In the manufacturing sector as a whole, Offsite-Produced Energy efficiency decreased by 4 percent between 1988 and 1991, but increased by 1 percent between 1985 and 1988. Similarly, energy efficiency for Total Inputs of Energy decreased by 3 percent between 1988 and 1991, following an increase of 1 percent between 1985 and 1988 .
Figure 4.8. Site Energy Intensities for SIC 25, 1985-1991

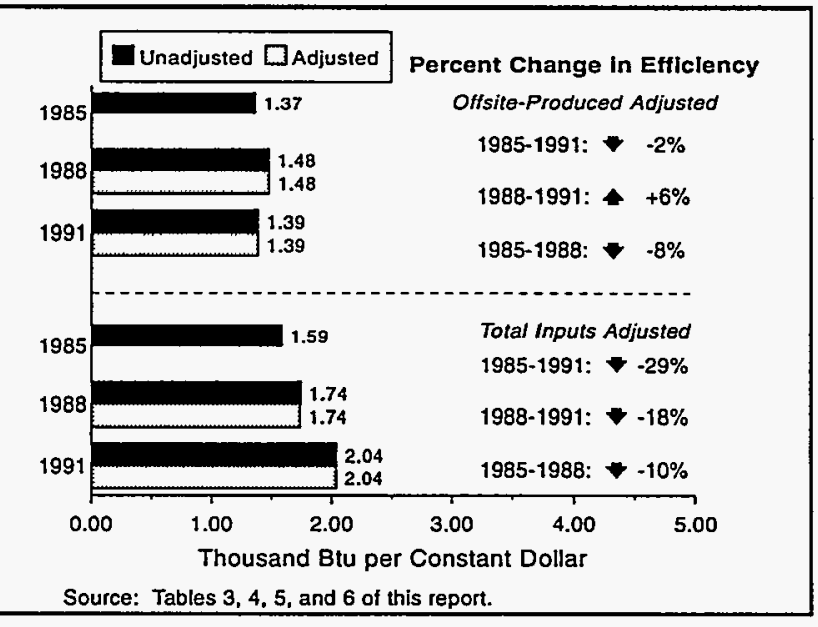




\section{Paper and Allied Products, SIC 26}

Establishments that produce pulp, paper, or both make up the Paper and Allied Products major group. The group also includes establishments that convert paper and paperboard into products such as paper bags, boxes, or envelopes. This major group also includes establishments that manufacture plastic bags. Five industry groups such as pulp mills and paper mills make up this manufacturing group. These are separated into 17 industries (e.g., corrugated and solid fiber boxes; and plastics, foil, and coated paper bags).

In 1991, the Paper and Allied Products group:

- Employed 620,700 employees (1,900 more than in 1988 and 16,800 more than in 1985 ).

- Shipped $\$ 128.8$ billion of goods (\$6.3 billion more than in 1988 and $\$ 35.4$ billion more than in 1985), about 5 percent of total manufacturing value of shipments.

- Spent approximately 8 percent of its total cost of materials for fuels and electrical energy.

\section{Use of Energy}

This major group is the third most energy-intensive manufacturing group. In 1991, this group:

- Consumed approximately 14 percent of the Offsite-Produced Energy and about 16 percent of the Total Inputs of Energy for heat, power, and electricity generation in the manufacturing sector.

- Cogenerated more electricity than any other major group.

- Consumed more Offsite-Produced Energy than any other major groups except the Chemicals and Primary Metals major groups.

- Consumed more Total Inputs of Energy than any other major groups except the Chemicals and Petroleum major groups.

- Used byproduct energy sources, such as pulping liquor, for nearly 50 percent of its total energy requirements for heat, power, and electricity.

- Produced the single largest increase in energy intensity of any 2-digit major group from 1988 to 1991 .

\section{Energy Management}

The 1991 MECS represents a first-time collection of manufacturers' participation in energy-management activities. To improve energy efficiency, manufacturing establishments participated in various demand-side management (DSM) and other energy-management programs. ${ }^{11}$ From 1989 through 1991, their activities and percent of participation, expressed in terms of Total Inputs of Energy used by participating establishments, were as follows: improving the efficiency of steam production ( 39 percent); improving the efficiency of process heating ( 32 percent); improving the efficiency of process refrigeration (12 percent); installing or retrofitting motors to achieve better energy efficiency (44 percent); improving the efficiency of facility HVAC systems ( 23 percent); and improving the efficiency of facility lighting (33 percent).

"Energy Information Administration, Manufacturing Consumption of Energy 1991, DOE/EIA-0512(91), December 1994, Table A40, p. 304. 


\section{Structural Shifts}

Since 1985, this major group has shifted noticeably toward more energy-intensive products, as indicated by a structurally adjusted energy-intensity ratio that is much less than the comparable unadjusted ratio. This type of shift occurred in both Offsite-Produced and Total Inputs of Energy (Figure 4.10).

\section{Impact of 1987 SIC Revision}

The 1987 SIC revision moved some industries from the 1977 SIC 2661 to the major group SIC 24 - Lumber and Wood Products. This revision also moved some industries to new three-digit classifications. The reclassification of establishments to a new two-digit SIC major group does not appear to have significantly affected energy efficiency.

\section{Historical Trends in Energy Consumption and Value of Shipments}

Between 1977 and 1991, the consumption of offsiteproduced energy by the paper and allied products group:

- Declined to a low point in 1982 , then increased steadily through 1991.

- Ended 1991 with consumption approximately 18 percent greater than in 1977.

Between 1977 and 1991, the value of shipments (output) for this group:

- Fluctuated through 1982 before beginning a steady increase through 1991.

- Increased approximately 33 percent above the 1977 level.

Energy efficiency increased modestly from 1977 through 1985 , as evidenced by the two nearly parallel paths that plot energy consumption and shipment values (Figure 4.9).

\section{Energy Efficiency (Adjusted), 1985-1991}

In the pulp and paper industries, energy efficiency of Offsite-Produced Energy dove by 17 percent from 1988 to 1991 , after a 10 percent growth from 1985 to 1988 (Figure 4.10). In the same way, energy efficiency of Total Inputs of Energy fell by 14 percent from 1988 to 1991, following an advance of 9 percent from 1985 to 1988.

In the manufacturing sector as a whole, Offsite-Produced Energy efficiency decreased by 4 percent between 1988 and 1991, but increased by 1 percent between 1985 and 1988. Similarly, energy efficiency for Total Inputs of Energy decreased by 3 percent between 1988 and 1991, after an increase of 1 percent between 1985 and 1988.

\section{Figure 4.9. Output and Offsite-Produced Energy Consumption Indices for SIC 26, 1977 Through 1991}

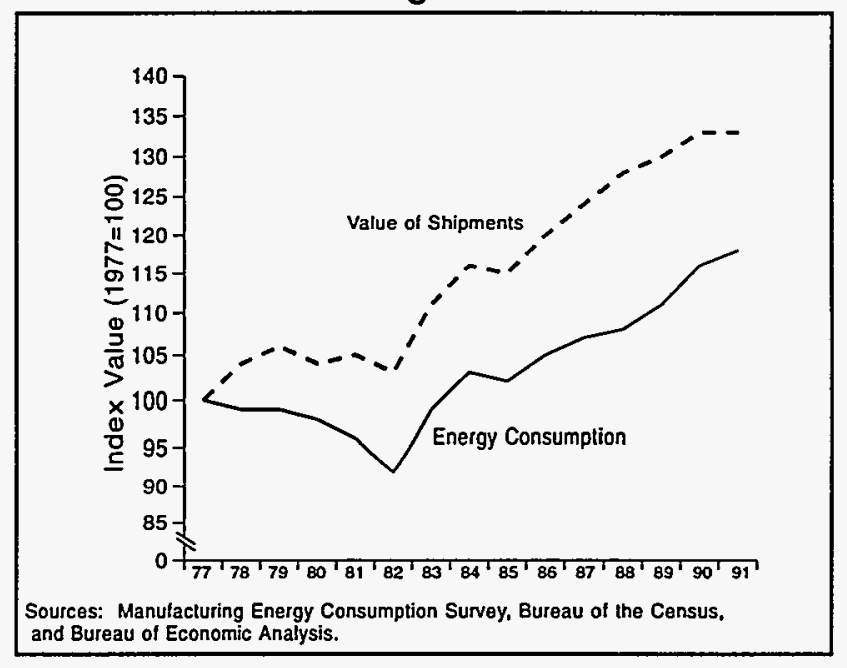

Figure 4.10. Site Energy Intensities for SIC 26, 1985-1991

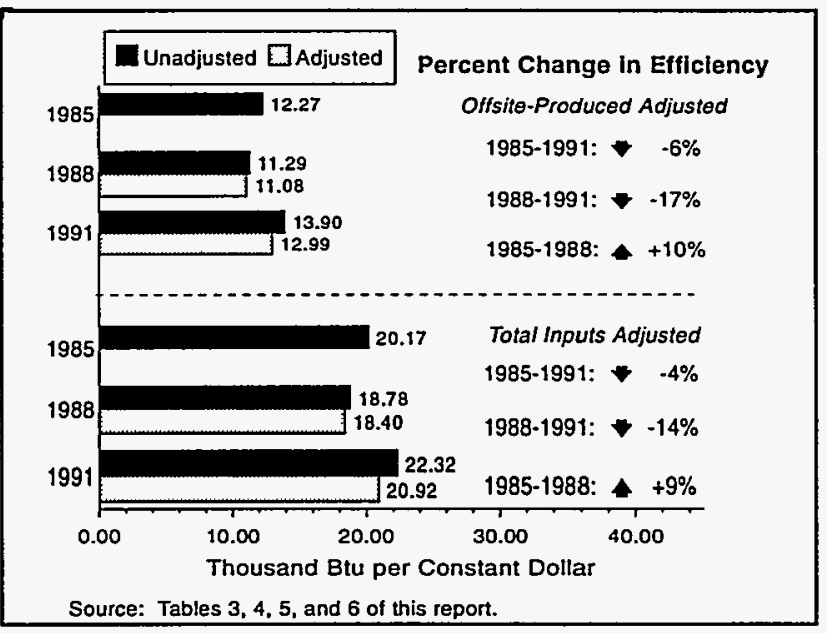




\section{Paper Mills, SIC 2621}

Establishments engaged in the manufacture of paper from wood and other fiber pulp make up this industry. These establishments may also manufacture converted paper products.

In 1991, the Paper Mills industry:

- Employed 130,300 employees (100 less than in 1988 and 1,500 less than in 1985).

- Shipped $\$ 33.3$ billion of goods ( $\$ 0.2$ billion less than in 1988 and $\$ 8.4$ billion more than in 1985), approximately 1 percent of total manufacturing value of shipments.

- Spent approximately 15 percent of its total cost of materials for fuels and electrical energy.

\section{Use of Energy}

The Paper Mills industry is the most energy-consuming subsector of the paper industry. In 1991, this industry:

- Consumed approximately 7 percent of the Offsite-Produced Energy and about 8 percent of the Total Inputs of Energy for heat, power, and electricity generation in the manufacturing sector.

- Consumed approximately 50 percent of both the Total Inputs and the Offsite-Produced Energy used by the Paper and Allied Products major group.

- Used Onsite-Produced Energy for 36 percent of its total fuel needs.

- Used byproduct energy sources for approximately 43 percent of its Total Inputs of Energy for heat, power, and electricity generation.

- Consumed energy mainly as boiler fuel, followed by process heating and machine drive.

- Contributed approximately 60 percent of the Paper and Allied Products major group's cogeneration of electricity.

\section{Energy Management}

The 1991 MECS represents a first-time collection of manufacturers' participation in energy-management activities. To improve energy efficiency, manufacturing establishments participated in various demand-side management (DSM) and other energy-management programs. ${ }^{12}$ From 1989 through 1991, their activities and percent of participation, expressed in terms of Total Inputs of Energy used by participating establishments, were as follows: improving the efficiency of steam production (37 percent); improving the efficiency of process heating ( 36 percent); improving the efficiency of process refrigeration (12 percent); installing or retrofitting motors to achieve better energy efficiency ( 48 percent); improving the efficiency of facility HVAC systems ( 28 percent); and improving the efficiency of facility lighting ( 36 percent).

\section{Structural Shifts}

Data are not available to determine whether structural shifts affected this industry group between 1985 and 1991 . Therefore, there is no adjusted energy-intensity ratio for this industry. 


\section{Impact of 1987 SIC Revision}

The 1987 SIC revision included in this industry part of the 1977 SIC 2661 - Building Paper and Board Mills industry. This revision also removed the 1977 Pulp and Paper Mills, primarily pulp, which is now part of SIC 2611 - Pulp Mills.

\section{Energy Efficiency (Unadjusted), 1985-1991}

In the paper mills industries, energy efficiency of Offsite-Produced Energy dropped by 15 percent from 1988 to 1991 , after a climb of 4 percent from 1985 to 1988 (Figure 4.11). In much the same fashion, energy efficiency of Total Inputs of Energy slid by 13 percent from 1988 to 1991 , following an upturn of 4 percent from 1985 to 1988 .

In the manufacturing sector as a whole, Offsite-Produced Energy efficiency decreased by 4 percent between 1988 and 1991, but increased by 2 percent between 1985 and 1988. Similarly, energy efficiency for Total Inputs of Energy decreased by 3 percent between 1988 and 1991, following an increase of 2 percent between 1985 and 1988.
Figure 4.11. Site Energy Intensities for SIC 2621, 1985-1991

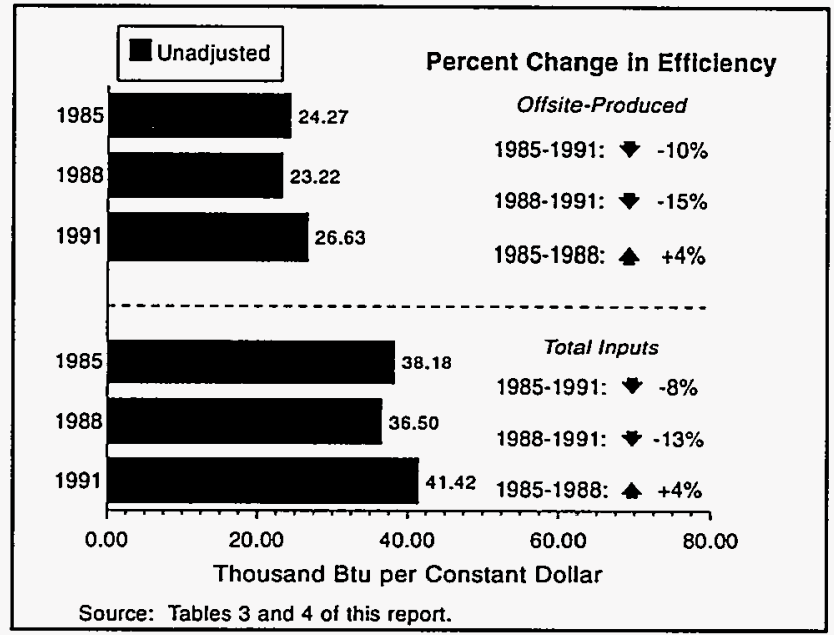




\section{Paperboard Mills, SIC 2631}

Establishments primarily engaged in manufacturing paperboard from wood and other fiber pulp make up the Paperboard Mills industry. These establishments also produce paperboard coated on the paperboard machine, and converted paperboard products. Production processes for paperboard mills are essentially the same as for paper mills. The primary production difference is the thickness of the finished product.

In 1991, the Paperboard Mills industry:

- Employed 50,600 employees (3,000 less than in 1988 and 3,300 less than in 1985).

- Shipped $\$ 15.0$ billion of goods ( $\$ 1.1$ billion less than in 1988 and $\$ 4.5$ billion more than in 1985 ), less than 1 percent of total manufacturing value of shipments.

- Spent approximately 17 percent of its total cost of materials for fuels and electrical energy.

\section{Use of Energy}

In 1991, the Paperboard Mills industry:

- Consumed approximately 5 percent of the Offsite-Produced Energy and 6 percent of the Total Inputs of Energy for heat, power, and electricity in the manufacturing sector.

- Consumed approximately 34 percent of the Offsite-Produced Energy consumed in the Paper and Allied Products major group.

- Supplied approximately 56 percent of its Total Inputs of Energy with byproduct energy.

- Contributed approximately 30 percent of the Paper and Allied Products major group's cogeneration of electricity.

\section{Energy Management}

The 1991 MECS represents a first-time collection of manufacturers' participation in energy-management activities. To improve energy efficiency, manufacturing establishments participated in various demand-side management (DSM) and other energy-management programs. ${ }^{13}$ From 1989 through 1991, their activities and percent of participation, expressed in terms of Total Inputs of Energy used by participating establishments, were as follows: improving the efficiency of steam production ( 46 percent); improving the efficiency of process heating ( 33 percent); improving the efficiency of process refrigeration (13 percent); installing or retrofitting motors to achieve better energy efficiency ( 42 percent); improving the efficiency of facility HVAC systems ( 23 percent); and improving the efficiency of facility lighting ( 27 percent).

\section{Structural Shifts}

Data are not available to determine whether structural shifts affected this industry group between 1985 and 1991 . Therefore, there is no adjusted energy-intensity ratio for this industry. 


\section{Impact of the 1987 SIC Revision}

The 1987 SIC revision removed the 1977 Pulp and Paper Mills, primarily pulp, which is now part of SIC 2611 - Pulp Mills.

\section{Energy Efficiency (Unadjusted), 1985-1991}

In the paperboard mills industries, energy efficiency of Offsite-Produced Energy suffered a downturn of 16 percent from 1988 to 1991, after a boost of 7 percent from 1985 to 1988 (Figure 4.12). Also, energy efficiency of Total Inputs of Energy dipped by 5 percent from 1988 to 1991 , following a gain of 8 percent from 1985 to 1988.

In the manufacturing sector as a whole, Offsite-Produced Energy efficiency decreased by 4 percent between 1988 and 1991, but increased by 2 percent between 1985 and 1988. Similarly, energy efficiency for Total Inputs of Energy decreased by 3 percent between 1988 and 1991, following an increase of 2 percent between 1985 and 1988.
Figure 4.12. Site Energy Intensities for SIC 2631, 1985-1991

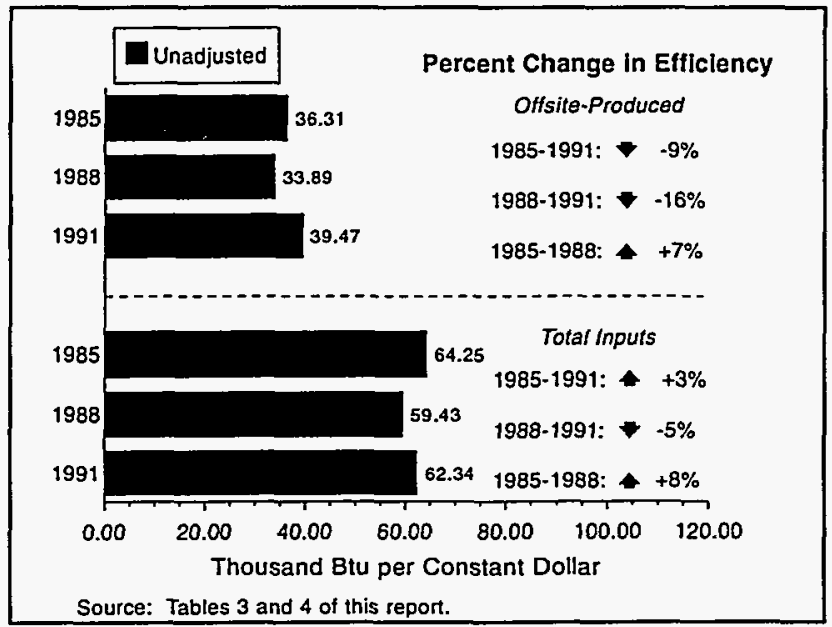




\section{Chemicals and Allied Products, SIC 28}

Establishments in the Chemicals and Allied Products major group produce finished products (e.g., drugs, fertilizers), as well as products used in further manufacturing processes (e.g., plastics, synthetic fibers). Eight industry groups (e.g., industrial inorganic chemicals, drugs) and 29 industries (e.g., alkalies and chlorine, phosphatic fertilizers) make up the Chemical major group.

In 1991, the Chemicals and Allied Products major group:

- Employed 846,400 employees (16,500 more than in 1988 and 20,200 more than in 1985).

- Shipped $\$ 292.3$ billion of goods ( $\$ 32.6$ billion more than in 1988 and $\$ 95.0$ billion more than in 1985 ), about 10 percent of total manufacturing value of shipments.

- Spent approximately 7 percent of its total cost of materials for fuels and electrical energy.

\section{Use of Energy}

The Chemicals and Allied Products major group is the largest consumer of energy in the manufacturing sector. In 1991, this group:

- Consumed about 25 percent of the Offsite-Produced Energy and about 20 percent of the Total Inputs of Energy for heat, power, and electricity generation in the manufacturing sector.

- Satisfied approximately 12 percent of its energy requirements with byproduct energy sources.

- Used energy primarily for boiler fuel and process heating.

- Provided approximately 32 percent of the onsite electricity generation in the manufacturing sector.

\section{Energy Management}

The 1991 MECS represents a first-time collection of manufacturers' participation in energy-management activities. To improve energy efficiency, manufacturing establishments participated in various demand-side management (DSM) and other energy-management programs. ${ }^{14}$ From 1989 through 1991, their activities and percent of participation, expressed in terms of Total Inputs of Energy used by participating establishments, were as follows: improving the efficiency of steam production ( 28 percent); improving the efficiency of process heating ( 33 percent); improving the efficiency of process refrigeration (25 percent); installing or retrofitting motors to achieve better energy efficiency (37 percent); improving the efficiency of facility HVAC systems (20 percent); and improving the efficiency of facility lighting (26 percent).

\section{Structural Shifts}

Since 1985, this major group has shifted notably toward less energy-intensive products, as indicated by a structurally adjusted energy-intensity ratio that is much more than the comparable unadjusted ratio. This type of shift occurred in both Offsite-Produced and Total Inputs of Energy (Figure 4.14). 


\section{Impact of 1987 SIC Revision}

The 1987 SIC revision neither added nor removed industries from this group. Reclassification of some petroleum refining establishments with collocated petrochemical operations as primarily petrochemical (movement from SIC 29 to 28) could explain differences in energy efficiency from earlier publications. This reclassification was the result of data collected on the 1987 Census of Manufactures.

\section{Historical Trends in Energy Consumption and Value of Shipments}

Between 1977 and 1991, the consumption of OffsiteProduced Energy by the Chemicals and Allied Products major group:

- Declined to a low in 1985-1986, then increased through 1990.

- Ended 1991 at approximately 90 percent of the 1977 consumption level.

Between 1977 and 1991, value of shipments (output) for this group:

- Initially declined to a low in 1982 before increasing through 1991.

- Ended 1991 at approximately 31 percent greater than in 1977.

Energy efficiency increased steadily from 1977 through 1985. As energy consumption fell, shipment values descended less sharply from 1977 to 1982, with a marked upswing since 1982 (Figure 4.13).

\section{Energy Efficiency (Adjusted), 1985-1991}

In the chemical industries, energy efficiency of OffsiteProduced Energy dipped by 7 percent between 1988 and 1991, after jumping 4 percent from 1985 to 1988 (Figure 4.14). In the case of Total Inputs of Energy, energy efficiency dropped by 9 percent from 1988 to 1991, following a rise of 4 percent from 1985 to 1988 .

In the manufacturing sector as a whole, Offsite-Produced Energy efficiency decreased by 4 percent between 1988 and 1991, but increased by 1 percent between 1985 and 1988. Similarly, energy efficiency for Total Inputs of Energy decreased by 3 percent between 1988 and 1991, following an increase of 1 percent between 1985 and 1988.
Figure 4.13. Output and Offsite-Produced Energy Consumption Indices for SIC 28, 1977 Through 1991

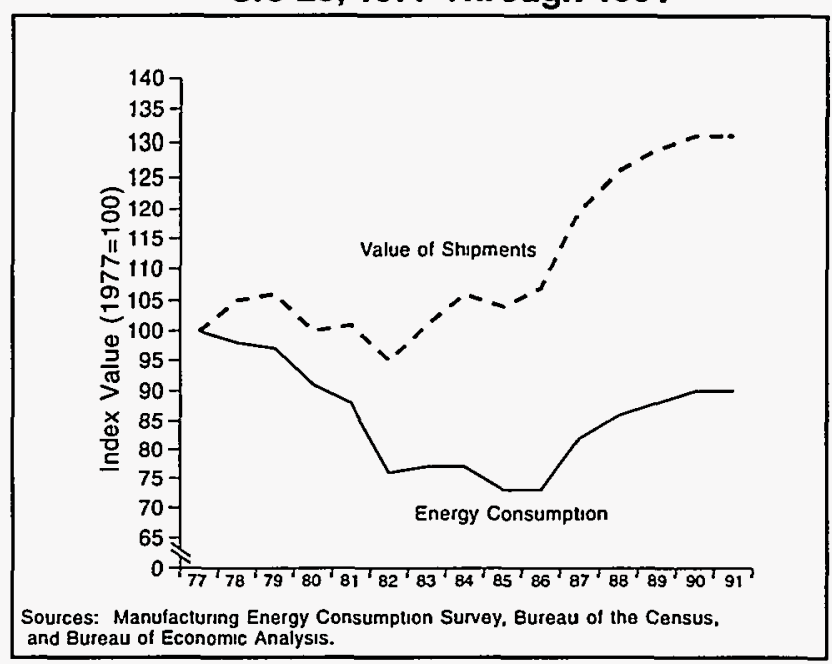

Figure 4.14. Site Energy Intensities for SIC 28, 1985-1991

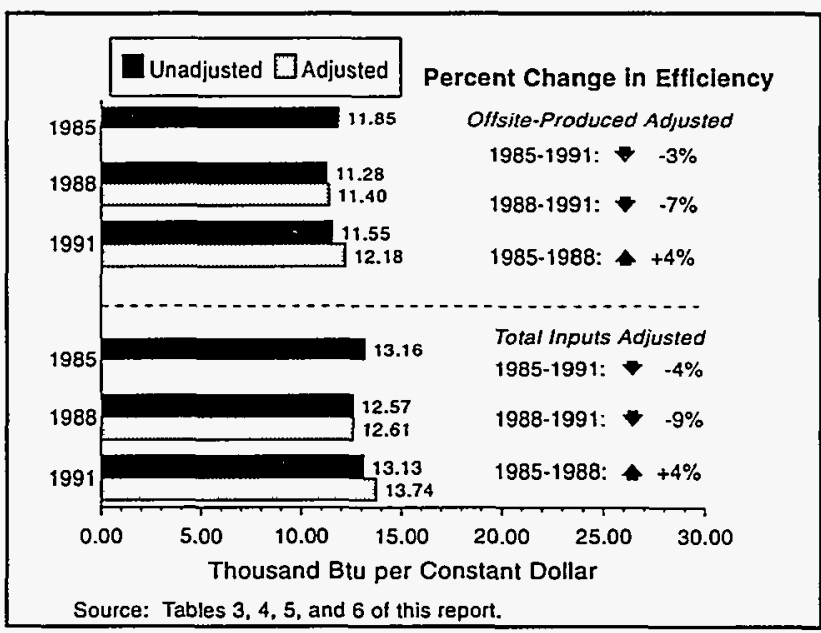




\section{Industrial Inorganic Chemicals, Not Elsewhere Classified, SIC 2819}

In 1991, the Industrial Inorganic Chemicals industry:

- Employed 78,900 employees (6,700 more than in 1988 and 300 more than in 1985).

- Shipped $\$ 17.6$ billion of goods ( $\$ 3.5$ billion more than in 1988 and $\$ 3.9$ billion more than in 1985).

- Spent approximately 18 percent of its total cost of materials for fuels and electrical energy.

\section{Use of Energy}

The Industrial Inorganic Chemicals industry is relatively energy intensive. In 1991, this industry:

- Consumed 3 percent of the Offsite-Produced Energy and 2 percent of the Total Inputs of Energy for heat, power, and electricity generation in the manufacturing sector.

- Contributed approximately 6 percent of the Chemicals and Allied Products major group's value of shipments.

- Consumed approximately 10 percent of both the Offsite-Produced Energy and the Total Inputs of Energy used by the Chemicals and Allied Products major group.

- Consumed more Offsite-Produced Energy than any other Chemical industry except SIC 2869 - Industrial Organic Chemicals.

- Used energy primarily for machine drive.

\section{Energy Management}

The 1991 MECS represents a first-time collection of manufacturers' participation in energy-management activities. To improve energy efficiency, manufacturing establishments participated in various demand-side management (DSM) and other energy-management programs. ${ }^{\text {Is }}$ From 1989 through 1991, their activities and percent of participation, expressed in terms of Total Inputs of Energy used by participating establishments, were as follows: improving the efficiency of steam production ( 40 percent); improving the efficiency of process heating (33 percent); improving the efficiency of process refrigeration (14 percent); installing or retrofitting motors to achieve better energy efficiency (32 percent); improving the efficiency of facility HVAC systems ( 37 percent); and improving the efficiency of facility lighting (39 percent).

\section{Structural Shifts}

Data are not available to determine whether structural shifts affected this industry group between 1985 and 1991 . Therefore, there is no adjusted energy-intensity ratio for this industry.

\section{Impact of 1987 SIC Revision}

The 1987 SIC revision included in this industry part of the 1977 SIC 2869 - Industrial Organic Chemicals, not elsewhere classified.

${ }^{15}$ Energy Information Administration, Manufacturing Consumption of Energy 1991, DOE/EIA-0512(91), December 1994, Table A40, p. 304. 


\section{Energy Efficiency (Unadjusted), 1985-1991}

In the inorganic chemical industries, energy efficiency of Offsite-Produced Energy lost by 7 percent from 1988 to 1991, after another loss of 3 percent from 1985 to 1988 (Figure 4.15). Also, energy efficiency of Total Inputs of Energy dipped by 5 percent from 1988 to 1991, following a gain of 3 percent from 1985 to 1988.

In the manufacturing sector as a whole, Offsite-Produced Energy efficiency decreased by 4 percent between 1988 and 1991 , but increased by 2 percent between 1985 and 1988. Similarly, energy efficiency for Total Inputs of Energy decreased by 3 percent between 1988 and 1991, following an increase of 2 percent between 1985 and 1988.
Figure 4.15. Site Energy Intensities for SIC 2819, 1985-1991

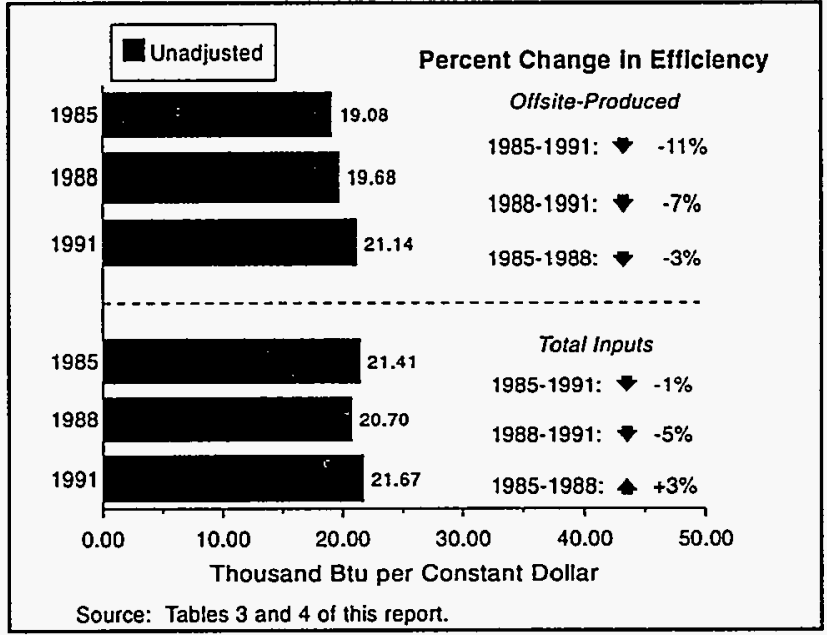




\section{Plastics Materials, Synthetic Resins, and Nonvulcanizable Elastomers, SIC 2821}

In 1991, the Plastics Materials and Resins industry:

- Employed 60,500 employees (2,200 more than in 1988 and 5,100 more than in 1985).

- Shipped $\$ 29.6$ billion of goods ( $\$ 2.5$ billion less than in 1988 and $\$ 9.3$ billion more than in 1985 ), about 10 percent of the Chemicals and Allied Products major group's value of shipments.

- Spent approximately 6 percent of its total cost of materials for fuels and electrical energy.

\section{Use of Energy}

In 1991, the Plastics Materials and Resins industry:

- Consumed approximately 2 percent of both the Offsite-Produced Energy and the Total Inputs of Energy for heat, power, and electricity generation in the manufacturing sector.

- Consumed approximately 10 percent of both the Offsite-Produced Energy and the Total Inputs of Energy used by the Chemicals and Allied Products major group.

- Decreased its use of Onsite-Produced Energy from 25 percent of its Total Inputs in 1985 to 9 percent in 1991.

- Provided approximately 6 percent of the onsite electricity generation in the Chemicals and Allied Products major group.

\section{Energy Management}

The 1991 MECS represents a first-time collection of manufacturers' participation in energy-management activities. To improve energy efficiency, manufacturing establishments participated in various demand-side management (DSM) and other energy-management programs. ${ }^{16}$ From 1989 through 1991, their activities and percent of participation, expressed in terms of Total Inputs of Energy used by participating establishments, were as follows: improving the efficiency of steam production ( 20 percent); improving the efficiency of process heating (18 percent); improving the efficiency of process refrigeration (16 percent); installing or retrofitting motors to achieve better energy efficiency (34 percent); improving the efficiency of facility HVAC systems (16 percent); and improving the efficiency of facility lighting ( 24 percent).

\section{Structural Shifts}

Data are not available to determine whether structural shifts affected this industry group between 1985 and 1991 . Therefore, there is no adjusted energy-intensity ratio for this industry.

\section{Impact of 1987 SIC Revision}

The 1987 SIC revision had no impact on this industry. 


\section{Energy Efficiency (Unadjusted), 1985-1991}

In the plastic material industries, energy efficiency of Offsite-Produced Energy grew by 6 percent from 1988 to 1991 , after slipping by 2 percent from 1985 to 1988 (Figure 4.16). In addition, energy efficiency of Total Inputs of Energy also gained by 6 percent from 1988 to 1991, following a spurt of 16 percent from 1985 to 1988.

In the manufacturing sector as a whole, Offsite-Produced Energy efficiency decreased by 4 percent between 1988 and 1991, but increased by 2 percent between 1985 and 1988. Similarly, energy efficiency for Total Inputs of Energy decreased by 3 percent between 1988 and 1991, following an increase of 2 percent between 1985 and 1988.

\section{Figure 4.16. Site Energy Intensities for SIC 2821,} 1985-1991

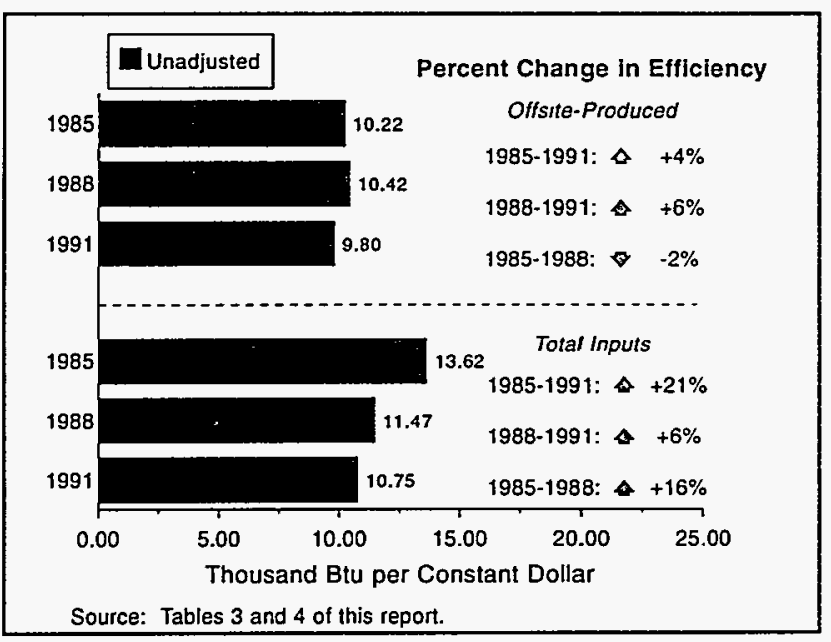




\section{Industrial Organic Chemicals, Not Elsewhere Classified, SIC 2869}

In 1991, the Industrial Organic Chemicals industry:

- Employed 101,000 employees (3,900 more than in 1988 and 4,500 more than in 1985).

- Shipped $\$ 53.1$ billion of goods ( $\$ 4.0$ billion more than in 1988 and $\$ 20.0$ billion more than in 1985 ).

- Spent approximately 8 percent of its total cost of materials for fuels and electrical energy.

\section{Use of Energy}

The Industrial Organic Chemicals industry is the most energy-intensive industry in the Chemicals and Allied Products major group. In 1991, this industry:

- Consumed 35 percent of the Offsite-Produced Energy and nearly 40 percent of the Total Inputs of Energy used by the Chemicals and Allied Products major group.

- Contributed approximately 18 percent of the Chemicals and Allied Products major group's value of shipments and 2 percent of total manufacturing shipments.

- Increased its use of Onsite-Produced Energy from 15 percent of its Total Inputs in 1985 to 21 percent in 1991.

- Provided 52 percent of the onsite electricity generation in the Chemicals and Allied Products major group and 17 percent in the manufacturing sector.

\section{Energy Management}

The 1991 MECS represents a first-time collection of manufacturers' participation in energy-management activities. To improve energy efficiency, manufacturing establishments participated in various demand-side management (DSM) and other energy-management programs. ${ }^{17}$ From 1989 through 1991, their activities and percent of participation, expressed in terms of Total Inputs of Energy used by participating establishments, were as follows: improving the efficiency of steam production ( 32 percent); improving the efficiency of process heating ( 45 percent); improving the efficiency of process refrigeration ( 36 percent); installing or retrofitting motors to achieve better energy efficiency (48 percent); improving the efficiency of facility HVAC systems (19 percent); and improving the efficiency of facility lighting ( 22 percent).

\section{Structural Shifts}

Data are not available to determine whether structural shifts affected this industry group between 1985 and 1991 . Therefore, there is no adjusted energy-intensity ratio for this industry.

\section{Impact of 1987 SIC Revision}

The 1987 SIC revision removed part of this industry (hydrazine) for inclusion in SIC 2819 - Industrial Inorganic Chemicals. 


\section{Energy Efficiency (Unadjusted), 1985-1991}

In the organic chemical industries, energy efficiency of Offsite-Produced Energy dipped by 6 percent from 1988 to 1991 , after a rise of 13 percent from 1985 to 1988 (Figure 4.17). Also, energy efficiency of Total Inputs of Energy slipped by 14 percent from 1988 to 1991, following a gain of 13 percent from 1985 to 1988 .

In the manufacturing sector as a whole, Offsite-Produced Energy efficiency decreased by 4 percent between 1988 and 1991, but increased by 2 percent between 1985 and 1988. Similarly, energy efficiency for Total Inputs of Energy decreased by 3 percent between 1988 and 1991, following an increase of 2 percent between 1985 and 1988.
Figure 4.17. Site Energy Intensities for SIC 2869, 1985-1991

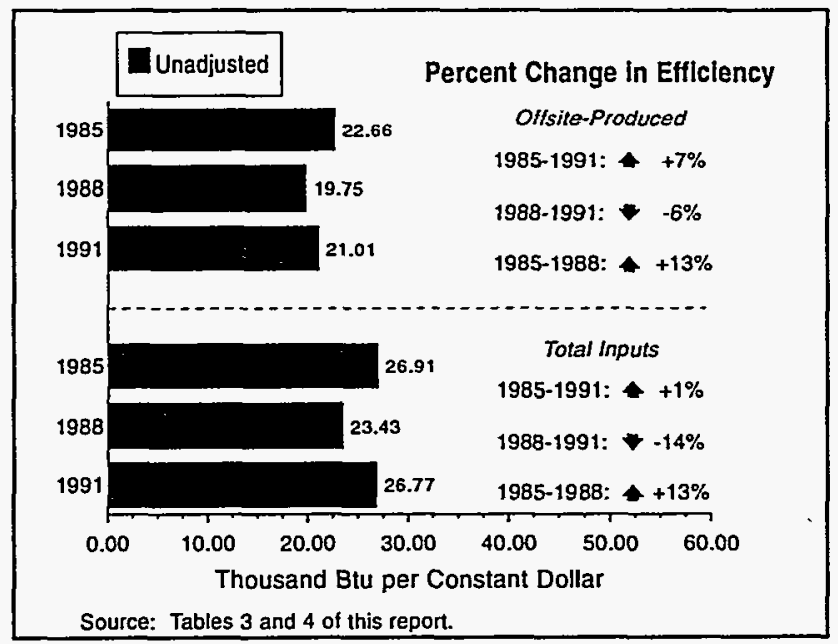




\section{Nitrogenous Fertilizers, SIC 2873}

In 1991, the Nitrogenous Fertilizers industry:

- Employed 7,300 employees (100 more than in 1988 and 1,400 less than in 1985).

- Shipped $\$ 3.2$ billion of goods ( $\$ 0.5$ billion more than in 1988 and $\$ 0.2$ billion less than in 1985), less than 1 percent of total manufacturing value of shipments.

- Spent 24 percent of its cost of materials for fuels and electrical energy.

\section{Use of Energy}

In 1991, the Nitrogenous Fertilizers industry:

- Consumed approximately 3 percent of the Offsite-Produced Energy and 2 percent of the Total Inputs of Energy for heat, power, and electricity generation in the manufacturing sector.

- Consumed approximately 10 percent of the Offsite-Produced Energy and 9 percent of the Total Inputs of Energy used by the Chemicals and Allied Products major group.

- Met essentially 100 percent of its energy requirements with Offsite-Produced Energy.

- Used energy primarily for boiler fuel and process heating.

\section{Energy Management}

The 1991 MECS represents a first-time collection of manufacturers' participation in energy-management activities. To improve energy efficiency, manufacturing establishments participated in various demand-side management (DSM) and other energy-management programs. ${ }^{18}$ From 1989 through 1991, their activities and percent of participation, expressed in terms of Total Inputs of Energy used by participating establishments, were as follows: improving the efficiency of steam production (14 percent); improving the efficiency of process heating ( 20 percent); improving the efficiency of process refrigeration ( 22 percent); installing or retrofitting motors to achieve better energy efficiency (13 percent); improving the efficiency of facility HVAC systems (4 percent); and improving the efficiency of facility lighting ( 9 percent).

\section{Structural Shifts}

Data are not available to determine whether structural shifts affected this industry group between 1985 and 1991 . Therefore, there is no adjusted energy-intensity ratio for this industry.

\section{Impact of 1987 SIC Revision}

The 1987 SIC revision had no impact on this industry. 


\section{Energy Efficiency (Unadjusted), 1985-1991}

In the nitrogenous fertilizer industries, energy efficiency of Offsite-Produced Energy declined by 23 percent from 1988 to 1991 , after a downfall of 13 percent from 1985 to 1988 (Figure 4.18). Furthermore, energy efficiency of Total Inputs of Energy dropped by 20 percent from 1988 to 1991 , following a descent of 17 percent from 1985 to 1988.

In the manufacturing sector as a whole, Offsite-Produced Energy efficiency decreased by 4 percent between 1988 and 1991, but increased by 2 percent between 1985 and 1988. Similarly, energy efficiency for Total Inputs of Energy decreased by 3 percent between 1988 and 1991, following an increase of 2 percent between 1985 and 1988.
Figure 4.18. Site Energy Intensities for SIC 2873, 1985-1991

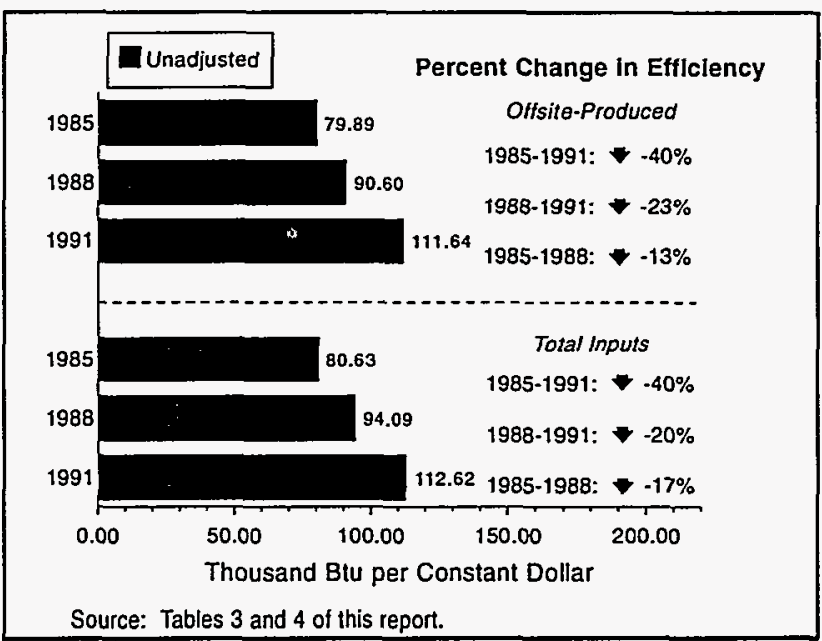




\section{Petroleum and Coal Products, SIC 29}

Outputs of the Petroleum and Coal major group include various refined petroleum products, asphalt paving and roofing materials, and miscellaneous products of petroleum and coal such as lubricating oils and greases. Outputs of this group fall into the general categories of fuels, lubricants, and petrochemical feedstocks. Only three industry groups (e.g., petroleum refining; asphalt paving and roofing materials), and five industries (e.g., petroleum refining, lubricating oils and greases) make up this major group.

In 1991, this group:

- Employed 113,300 employees (2,000 less than in 1988 and 14,200 less than in 1985).

- Shipped $\$ 158.1$ billion of goods ( $\$ 26.7$ billion more than in 1988 and $\$ 21.1$ billion less than in 1985 ), about 6 percent of total manufacturing value of shipments.

- Spent approximately 3 percent of its total cost of materials for fuels and electrical energy.

\section{Use of Energy}

The Petroleum and Coal Products major group is the second most energy-intensive manufacturing group. In 1991, this major group:

- Consumed approximately 11 percent of the Offsite-Produced Energy and 20 percent of the Total Inputs of Energy for heat, power, and electricity in the manufacturing sector.

- Ranked a close second only to the Chemicals and Allied Products major group in consumption of Total Inputs of Energy for heat, power, and electricity.

- Satisfied approximately 60 percent of its energy requirements with byproduct energy sources.

- Used energy primarily for boiler fuel and process heating.

\section{Energy Management}

The 1991 MECS represents a first-time collection of manufacturers' participation in energy-management activities. To improve energy efficiency, manufacturing establishments participated in various demand-side management (DSM) and other energy-management programs. ${ }^{19}$ From 1989 through 1991, their activities and percent of participation, expressed in terms of Total Inputs of Energy used by participating establishments, were as follows: improving the efficiency of steam production (41 percent); improving the efficiency of process heating (41 percent); improving the efficiency of process refrigeration (14 percent); installing or retrofitting motors to achieve better energy efficiency ( 36 percent); improving the efficiency of facility HVAC systems (17 percent); and improving the efficiency of facility lighting (32 percent).

\section{Structural Shifts}

Since 1985, this major group has shifted slightly toward less energy-intensive products, as indicated by a structurally adjusted energy-intensity ratio that is more than the comparable unadjusted ratio. This type of shift occurred in both Offsite-Produced and Total Inputs of Energy (Figure 4.20).

\footnotetext{
${ }^{19}$ Energy Information Administration, Manufacturing Consumption of Energy 1991, DOE/EIA-0512(91), December 1994, Table A40, p. 304.
} 


\section{Impact of 1987 SIC Revision}

The 1987 SIC revision did not affect this group at any level. As with SIC 28 - Chemicals and Allied Products, differences in energy efficiency between this and earlier publications could be the result of reclassifications of petrochemical operations with collocated petroleum refining operations. Data collected on the 1987 Census of Manufactures were the basis for determining the primary product of the entire establishment.

\section{Historical Trends in Energy Consumption and Value of Shipments}

Between 1977 and 1991, the consumption of OffsiteProduced Energy by this group:

- Declined through 1978 with an increase in 1979. Energy consumption decreased steadily through 1985, the year of lowest consumption.

- Consumed approximately 87 percent of the 1977 consumption level in 1991.

Between 1977 and 1991, the value of shipments (output) for this group:

- Increased initially, then declined to its lowest point in 1982 and 1983. Consumption increased slightly when adjusted for reclassification of petrochemical plants in the Chemicals group.

- Was approximately 95 percent of the 1977 level in 1991.
Figure 4.19. Output and Offsite-Produced Energy Consumption Indices for SIC 29, 1977 Through 1991

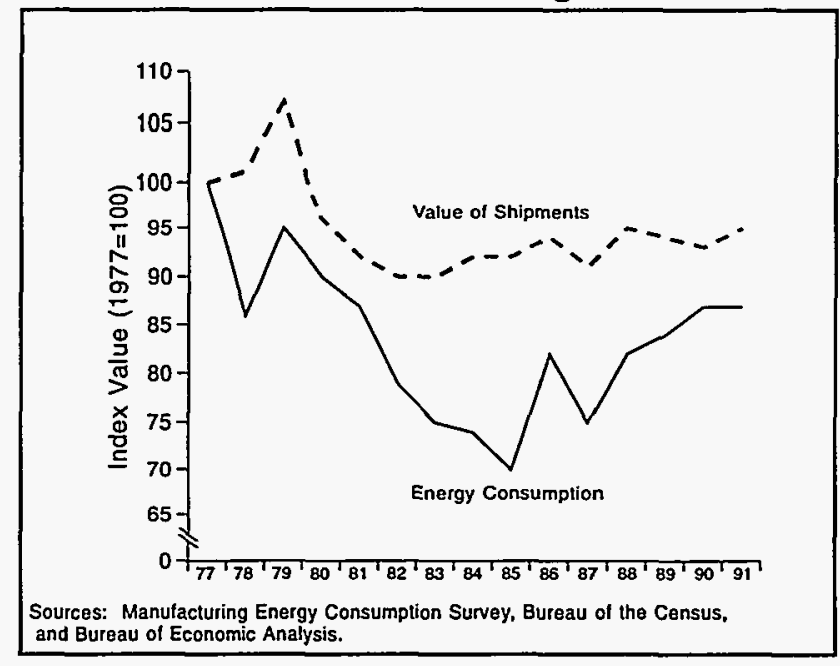

Energy efficiency increased most noticeably from 1981 to 1985 when consumption dropped sharply while value of shipments rebounded slightly (Figure 4.19).

\section{Energy Efficiency (Adjusted), 1985-1991}

In the petroleum industries, energy efficiency of OffsiteProduced Energy declined by 7 percent between 1988 and 1991, after a dip of 3 percent from 1985 to 1988 (Figure 4.20). However, energy efficiency for Total Inputs of Energy nudged upward by 3 percent from 1988 to 1991 , following a slide of 12 percent from 1985 to 1988. A possible cause of the 1991 upturn was decreased byproduct consumption of waste gas (1.3 quadrillion Btu in 1991, 1.5 quadrillion Btu in 1988).

In the manufacturing sector as a whole, OffsiteProduced Energy efficiency decreased by 4 percent between 1988 and 1991, but increased by 1 percent between 1985 and 1988. Similarly, energy efficiency for Total Inputs of Energy decreased by 3 percent between 1988 and 1991, following an increase of 1 percent between 1985 and 1988.
Figure 4.20. Site Energy Intensities for SIC 29, 1985-1991

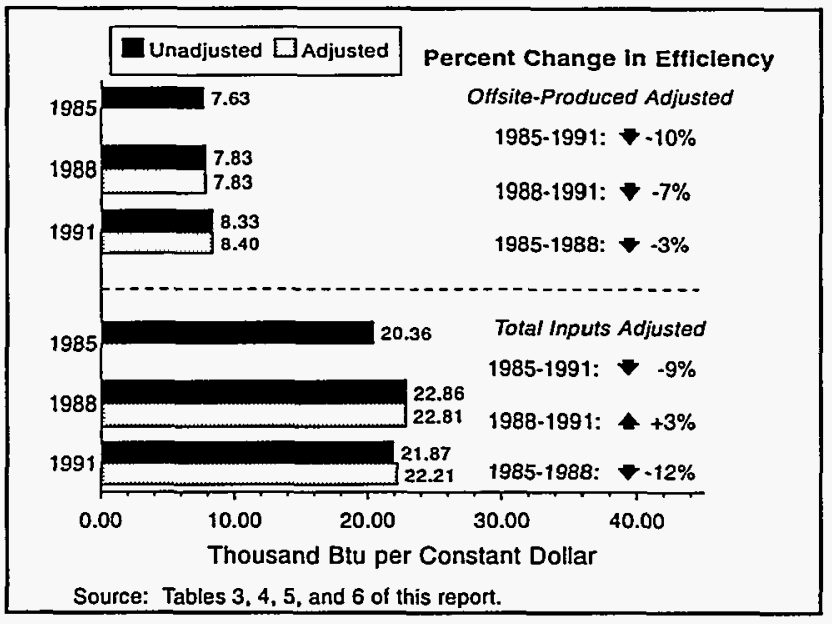




\section{Petroleum Refining, SIC 2911}

In 1991, the Petroleum Refining industry:

- Employed 73,900 employees in 1991 (700 more than in 1988 and 11,800 less than in 1985).

- Shipped $\$ 145.4$ billion of goods ( $\$ 26.6$ billion more than in 1988 and $\$ 22.1$ billion less than in 1985 ), about 10 percent of the Petroleum and Coal major group's value of shipments and 5 percent of total manufacturing value of shipments.

- Spent only 3 percent of its total cost of materials for fuels and electrical energy.

\section{Use of Energy}

The Petroleum Refining industry is extremely energy intensive. In 1991, this industry:

- Consumed such a quantity of energy that only the entire SIC 28 - Chemicals and Allied Products consumed more energy for heat, power, and electricity generation.

- Consumed 10 percent of the Offsite-Produced Energy and 19 percent of the Total Inputs of Energy for heat, power, and electricity generation in the manufacturing sector.

- Satisfied 63 percent of its energy requirements with Onsite-Produced Energy such as waste gas and petroleum coke.

\section{Energy Management}

The 1991 MECS represents a first-time collection of manufacturers' participation in energy-management activities. To improve energy efficiency, manufacturing establishments participated in various demand-side management (DSM) and other energy-management programs. ${ }^{20}$ From 1989 through 1991, their activities and percent of participation, expressed in terms of Total Inputs of Energy used by participating establishments, were as follows: improving the efficiency of steam production (42 percent); improving the efficiency of process heating (42 percent); improving the efficiency of process refrigeration (15 percent); installing or retrofitting motors to achieve better energy efficiency (37 percent); improving the efficiency of facility HVAC systems (17 percent); and improving the efficiency of facility lighting (33 percent).

\section{Structural Shifts}

Data are not available to determine whether structural shifts affected this industry group between 1985 and 1991 . Therefore, there is no adjusted energy-intensity ratio for this industry.

\section{Impact of 1987 SIC Revision}

The 1987 SIC revision did not affect this industry. 


\section{Energy Efficiency (Unadjusted), 1985-1991}

In the petroleum refining industries, energy efficiency of Offsite-Produced Energy faded by 10 percent from 1988 to 1991 , after slipping by 1 percent from 1985 to 1988 (Figure 4.21). However, energy efficiency for Total Inputs of Energy rose by 3 percent from 1988 to 1991 , after a plummet of 12 percent from 1985 to 1988 . A possible cause of the 1991 upturn was decreased byproduct consumption of waste gas (1.3 quadrillion Btu in 1991, 1.5 quadrillion Btu in 1988).

In the manufacturing sector as a whole, Offsite-Produced Energy efficiency decreased by 4 percent between 1988 and 1991, but increased by 2 percent between 1985 and 1988. Similarly, energy efficiency for Total Inputs of Energy decreased by 3 percent between 1988 and 1991, following an increase of 2 percent between 1985 and 1988.
Figure 4.21. Site Energy Intensities for SIC 2911, 1985-1991

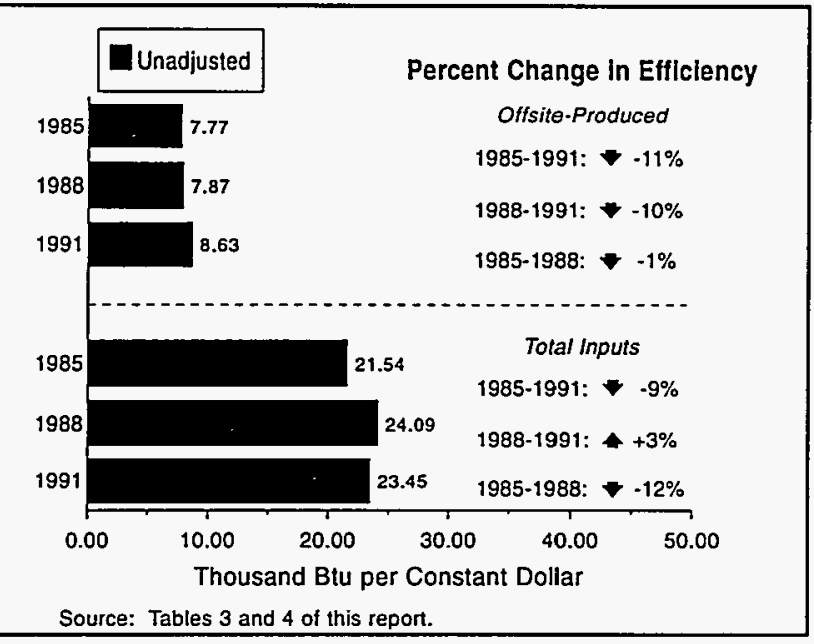




\section{Rubber and Miscellaneous Plastics Products, SIC 30}

Establishments in the Rubber Industry manufacture products from plastics resins and from natural, synthetic, or reclaimed rubber. This manufacturing category includes five industries groups (e.g., tires and inner tubes, rubber and plastics footwear) and 15 industries (e.g., rubber, plastics hose, and belting, and plastics pipe).

In 1991, this group:

- Employed 839,700 workers $(20,300$ less than in 1988 , and 97,200 more than in 1985$)$.

- Shipped $\$ 100.7$ billion of goods ( $\$ 6.5$ billion more than in 1988 , and $\$ 29.3$ billion more than in 1985) approximately 4 percent of total manufacturing value of shipments.

- Spent roughly 5 percent of its total cost of materials for fuels and electrical energy.

\section{Use of Energy}

Relative to the manufacturing sector, establishments in the Rubber and Miscellaneous Plastics Products major group consume a small amount of energy and are generally less energy intensive than the manufacturing sector as a whole. Specifically, this major group:

- Consumed about 2 percent of both Offsite-Produced Energy and Total Inputs of Energy for heat, power, and electricity generation in the manufacturing sector in 1991.

- Purchased nearly 100 percent of their fuel requirements from offsite energy suppliers, which results in nearly identical consumption estimates for Offsite-Produced Energy and Total Inputs of Energy.

- Used energy mainly for machine drive and as boiler fuel.

\section{Energy Management}

The 1991 MECS represents a first-time collection of manufacturers' participation in energy-management activities. To improve energy efficiency, manufacturing establishments in SIC 30 participated in various demand-side management (DSM) and other energy-management programs. ${ }^{21}$ From 1989 through 1991, their activities and percent of participation, expressed in terms of Total Inputs of Energy used by participating establishments, were as follows: improving the efficiency of steam production (19 percent); improving the efficiency of process heating (14 percent); improving the efficiency of process refrigeration (11 percent); installing or retrofitting motors to achieve better energy efficiency (23 percent); improving the efficiency of facility HVAC systems (24 percent); and, improving the efficiency of facility lighting (31 percent).

\section{Structural Shifts}

Since 1985, this major group has shifted slightly toward less energy-intensive industry group products, as indicated by a structurally adjusted energy-intensity ratio that is more than the comparable unadjusted ratio. This type of shift occurred in both Offsite-Produced and Total Inputs of Energy (Figure 4.23).

\section{Impact of 1987 SIC Revision}

The 1987 SIC revision affected this group. It added gaskets, packing, and sealing devices (1977 SIC 3293) to SIC 3053; added establishments primarily manufacturing fabricated rubber printing trades machinery (1977 SIC 3555); and removed part of plumbing fixture fittings and trim to 1987 SIC 34 (Fabricated Metal Products).

\footnotetext{
${ }^{21}$ Energy Information Administration, Manufacturing Consumption of Energy 1991, DOE/EIA-0512(91), December 1994, Table A40, p. 304.
} 


\section{Historical Trends in Energy Consumption and Value of Shipments}

Between 1977 and 1991, the consumption of OffsiteProduced Energy by establishments producing rubber products:

- Showed a general decline relative to 1977 consumption.

- Decreased to its lowest point in 1985 (77 percent of its 1977 consumption level) before increasing through 1990 and subsequently decreasing in 1991.

- Reached its highest point in 1989 , roughly 95 percent of the 1977 level.

- Ended 1991 at approximately 14 percent below the 1977 consumption level.

Between 1977 and 1991, the value of shipments (output) for this industry group:
Figure 4.22. Output and Offsite-Produced Energy Consumption Indices for SIC 30, 1977 Through 1991

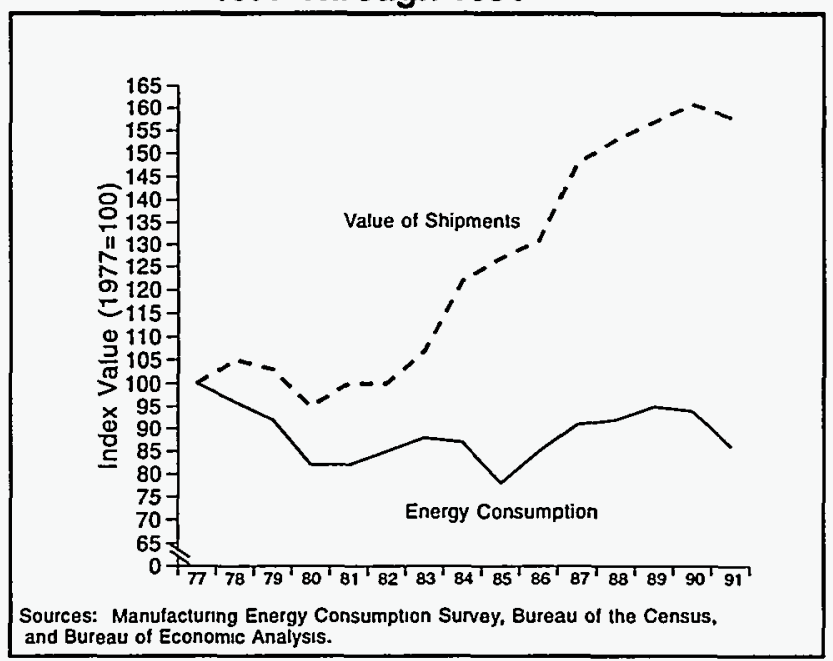

- Declined to its lowest point in 1980 (approximately 95 percent of the 1977 level) after experiencing an increase in 1978.

- Increased steadily from 1980 before declining slightly in 1991 .

- Ended 1991 at roughly 58 percent above the 1977 shipment level.

Energy efficiency increased gradually from 1977 through 1985, as shown by falling consumption and a corresponding increase in value of shipments (Figure 4.22). Although shipments declined from 1978 through 1980, energy efficiency increased because consumption declined at a far greater rate than shipments.

\section{Energy Efficiency (Adjusted), 1985-1991}

In the rubber industries, energy efficiency of OffsiteProduced rose by 15 percent, after a decline of 1 percent from 1985 to 1988 (Figure 4.23).

Total Inputs energy efficiency duplicated OffsiteProduced. In the case of Total Inputs of Energy, energy efficiency increased with an improvement of 14 percent between 1988 and 1991. That gain was preceded by a 1 percent decline from 1985 to 1988.

In the manufacturing sector as a whole, Offsite-Produced Energy efficiency decreased by 4 percent between 1988 and 1991, but increased by 1 percent between 1985 and 1988. Similarly, energy efficiency for Total Inputs of Energy decreased by 3 percent between 1988 and 1991, following an increase of 1 percent between 1985 and 1988.
Figure 4.23. Site Energy Intensities for SIC 30, 1985-1991

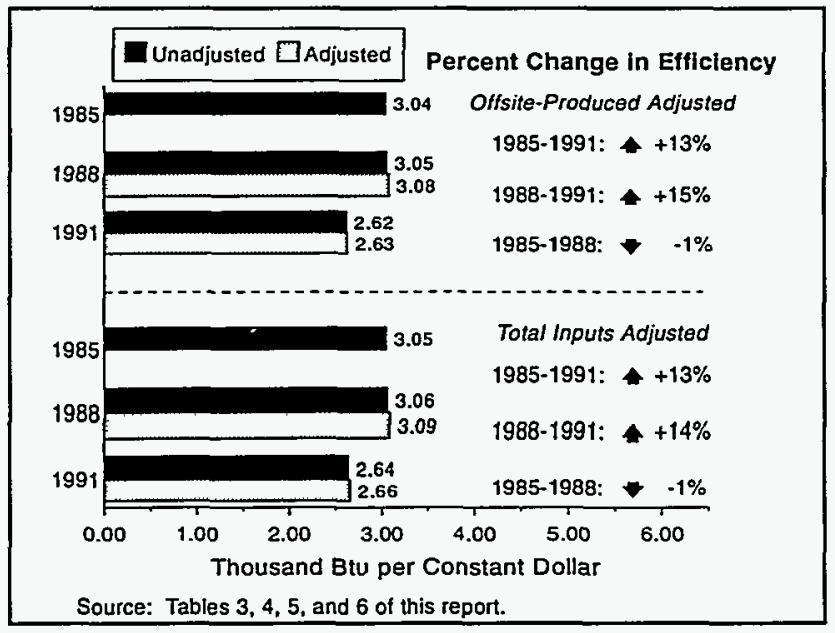




\section{Stone, Clay, and Glass Products, SIC 32}

Establishments in the Stone, Clay, and Glass major group produce end products such as flat glass, cement, pottery, and abrasives. This manufacturing category includes 9 industry groups (e.g., glass and glassware, structural clay products) and 26 industries (e.g., hydraulic cement, mineral wool).

In 1991, this group:

- Employed 475,700 workers (47,100 less than in 1988 , and 44,300 less than in 1985).

- Shipped $\$ 59.6$ billion of goods ( $\$ 3.4$ billion less than in 1988 , and $\$ 4.5$ billion less than in 1985 ) approximately 2 percent of total manufacturing value of shipments.

- Spent approximately 12 percent of its total cost of materials for fuels and electrical energy.

\section{Use of Energy}

Establishments in the Stone, Clay, and Glass major group rank as the sixth most energy-consuming major group in the manufacturing sector for heat, power, and electricity generation. Specifically, this major group:

- Consumed about 8 percent of Offsite-Produced Energy and 6 percent of Total Inputs of Energy for heat, power, and electricity generation in the manufacturing sector in 1991.

- Purchased roughly 98 percent of their fuel requirements from offsite energy suppliers in 1991 , continuing a purchasing trend of offsite purchases that accounted for 98 and 96 percent of fuel requirements in 1985 and 1988 , respectively.

- Used energy mainly for process heating and machine drive.

\section{Energy Management}

The 1991 MECS represents a first-time collection of manufacturers' participation in energy-management activities. To improve energy efficiency, manufacturing establishments in SIC 32 participated in various demand-side management (DSM) and other energy-management programs. ${ }^{22}$ From 1989 through 1991, their activities and percent of participation, expressed in terms of Total Inputs of Energy used by participating establishments, were as follows: improving the efficiency of steam production (4 percent); improving the efficiency of process heating ( 22 percent); improving the efficiency of process refrigeration (4 percent); installing or retrofitting motors to achieve better energy efficiency (35 percent); improving the efficiency of facility HVAC systems (12 percent); and, improving the efficiency of facility lighting (31 percent).

\section{Structural Shifts}

Since 1985, this major group has shifted slightly toward more energy-intensive industry group products, as indicated by a structurally adjusted energy-intensity ratio that is less than the comparable unadjusted ratio. This type of shift occurred in both Offsite-Produced and Total Inputs of Energy (Figure 4.25)

\section{Impact of 1987 SIC Revision}

The 1987 SIC revision affected this group. It reclassified part of 1977 SIC 3679 (electronic components) into porcelain electrical supplies (SIC 326) and removed gaskets, packing, and sealing devices from 1977 SIC 3293 and added it to 1987 SIC 30. 


\section{Historical Trends in Energy Consumption and Value of Shipments}

Between 1977 and 1991, energy consumption for this major group:

- Showed a steep decline relative to 1977 consumption.

- Increased to its highest point in 1978 (4 percent above the 1977 consumption level) before rapidly decreasing through 1985 and subsequently increasing in the next 4 years following 1985 .

- Reached its lowest point in both 1985 and 1991, roughly 70 percent of the 1977 level.

- Ended 1991 at roughly 30 percent below the 1977 consumption level.

Between 1977 and 1991, value of shipments (output) for this group:
Figure 4.24. Output and Offsite-Produced Energy Consumption Indices for SIC 32, 1977 Through 1991

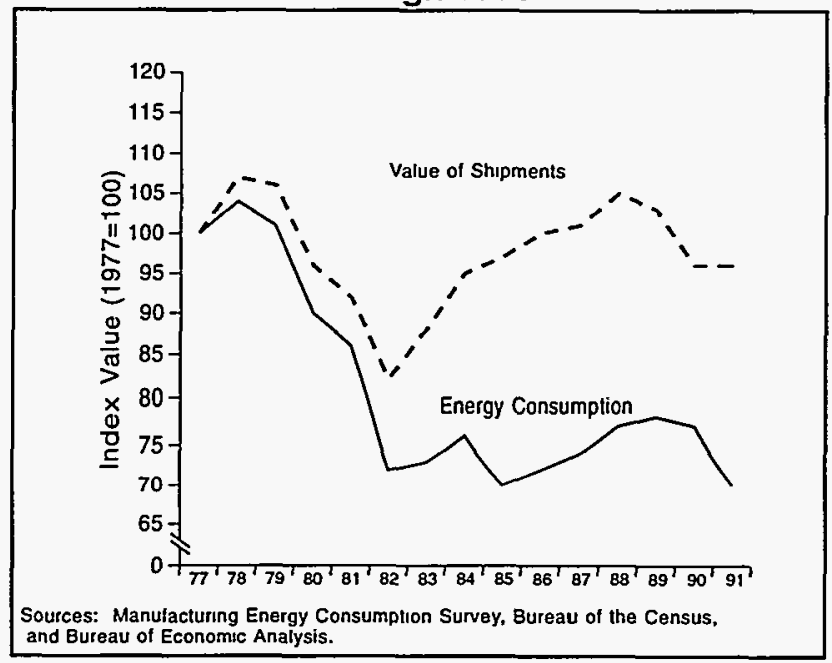

- Increased 7 percent to the industry high in 1978 before sharply declining to its lowest point in 1982.

- Increased steadily from 1982 before experiencing a decline between 1983 and 1991.

- Ended 1991 at approximately 4 percent below the 1977 shipment level.

Energy efficiency increased steadily from 1977 through 1985. Although both consumption and shipment declined from 1978 through 1982, the rate of decline for consumption was greater than shipments, which indicates an improvement in energy efficiency (Figure 4.24).

\section{Energy Efficiency (Adjusted), 1985-1991}

In the Stone, Clay, and Glass major group, energy efficiency of Offsite-Produced decreased by 6 percent from 1988 to 1991 (Figure 4.25). That decrease continued a trend of decreasing energy efficiency, where from 1985 to 1988 this major group also experienced a 5 percent decline in energy efficiency.

Total Inputs energy efficiency followed the efficiency trend given by Offsite-Produced Energy. Energy efficiency of Total Inputs of Energy decreased by 7 percent from 1988 to 1991, continuing the downward slide of energy efficiency, where from 1985 to 1988 efficiency declined by 4 percent.

In the manufacturing sector as a whole, Offsite-Produced Energy efficiency decreased by 4 percent between 1988 and 1991, but increased by 1 percent between 1985 and 1988. Similarly, energy efficiency for Total Inputs of Energy decreased by 3 percent between 1988 and 1991, following an increase of 1 percent between 1985 and 1988.
Figure 4.25. Site Energy Intensities for SIC 32, 1985-1991

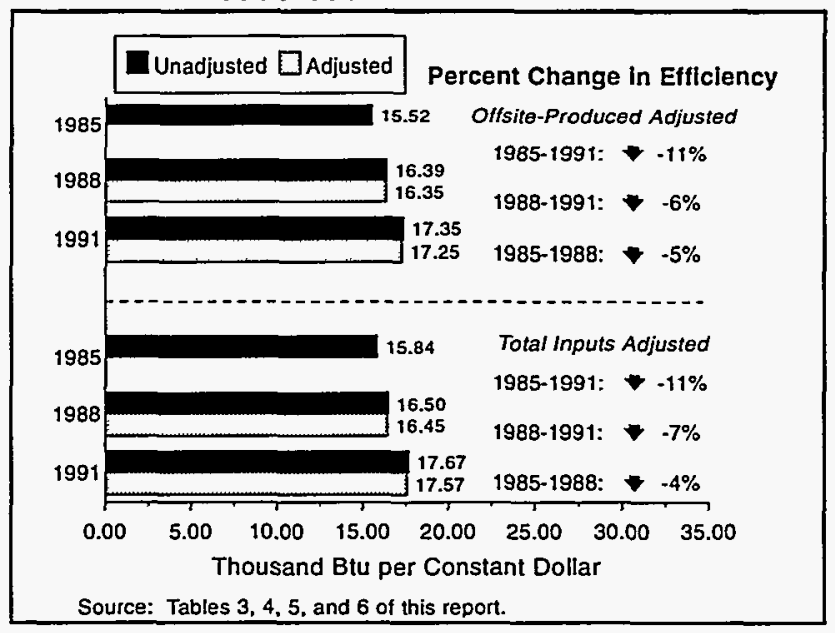




\section{Hydraulic Cement, SIC 3241}

Establishments that make up the Hydraulic Cement industry primarily produce portland cement, natural cement, hydraulic cement, masonry, and pozzolana cement.

In 1991, this industry:

- Employed 16,400 workers (2,200 less than in 1988, and 3,300 less than in 1985).

- Shipped $\$ 3.8$ billion of goods ( $\$ 0.5$ billion less than in 1988 and $\$ 0.4$ billion less than in 1985 ), less than 1 percent of total manufacturing but 6 percent of Stone, Clay, and Glass major group value of shipments.

- Spent approximately 41 percent of its total cost of materials for fuels and electrical energy.

\section{Use of Energy}

This industry consumes the most energy of any industry in the Stone, Clay, and Glass Products major group. Specifically, this industry:

- Consumed approximately 3 percent of the Offsite-Produced Energy and 2 percent of the Total Inputs of Energy consumed in the manufacturing sector in 1991.

- Consumed approximately 36 percent of the Total Inputs and Offsite-Produced Energy consumed for heat, power, and electricity generation by the Stone, Clay, and Glass major group.

- Purchased roughly 96,92 , and 95 percent of its fuel requirements from offsite energy suppliers in 1985, 1988, and 1991, respectively.

- Used energy mainly for process heating and machine drive.

\section{Energy Management}

The 1991 MECS represents a first-time collection of manufacturers' participation in energy-management activities. To improve energy efficiency, manufacturing establishments in SIC 3241 participated in various demand-side management (DSM) and other energy-management programs. ${ }^{23}$ From 1989 through 1991, their activities and percent of participation, expressed in terms of Total Inputs of Energy used by participating establishments, were as follows: improving the efficiency of steam production ( 5 percent); improving the efficiency of process heating (12 percent); installing or retrofitting motors to achieve better energy efficiency ( 47 percent); improving the efficiency of facility HVAC systems (16 percent); and, improving the efficiency of facility lighting ( 39 percent).

\section{Structural Shifts}

Structural shifts may be accounted for at any level of manufacturing aggregation. Ideally, structural adjustments would take place at the industry level. However, the samples of the MECS surveys, which are the sources of data used in this structural analysis, are not adequate for providing the needed estimates of shipments and consumption. For example, the structural adjustment of an industry's energy-intensity ratio must be calculated for the relative changes in output at the product level (5-digit SIC) within the industry. For this report, 83 groupings of industry groups are used to calculate adjusted energy-intensity ratios of major groups. 


\section{Impact of 1987 SIC Revision}

The 1987 SIC revision had no impact on the Hydraulic Cement industry.

\section{Energy Efficiency (Unadjusted), 1985-1991}

In the Hydraulic Cement industry, energy efficiency of Offsite-Produced Energy plummeted with a loss of 11 percent between 1988 and 1991, subsequent to a 4 percent improvement in efficiency from 1985 to 1988 (Figure 4.26).

For this industry, energy efficiency of Total Inputs of Energy roughly track those of Offsite-Produced. Specifically for the most recent three-year period, energy efficiency decreased by 15 percent, after improving 5 percent between 1985 and 1988.

In the manufacturing sector as a whole, Offsite-Produced Energy efficiency decreased by 4 percent between 1988 and 1991, but increased by 2 percent between 1985 and 1988. Similarly, energy efficiency for Total Inputs of Energy decreased by 3 percent between 1988 and 1991, following an increase of 2 percent between 1985 and 1988.
Figure 4.26. Site Energy Intensities for SIC 3241, 1985-1991

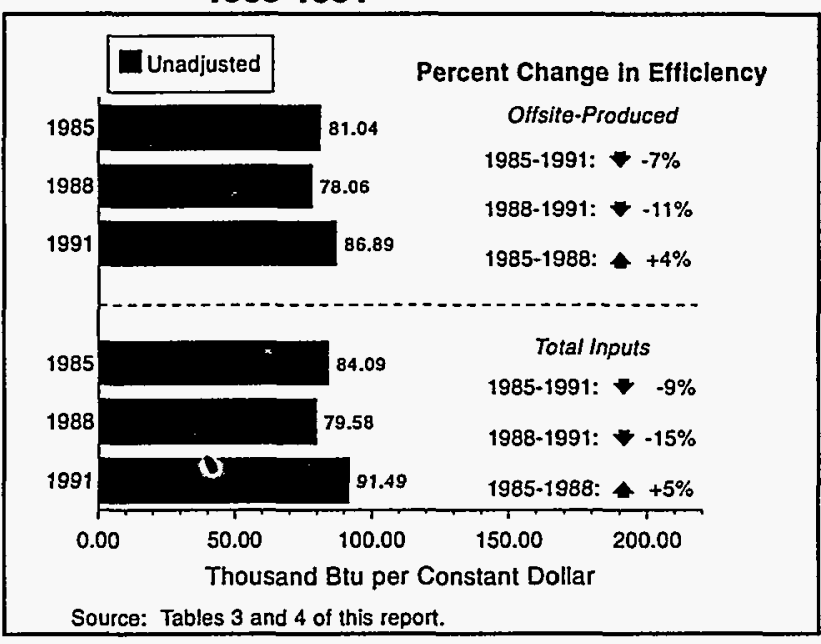




\section{Primary Metal Industries, SIC 33}

Establishments in the Primary Metals Industries group smelt, refine, and form basic metals from raw materials. This manufacturing category includes seven industry groups (e.g., steel works, blast furnaces, and rolling and finishing mills, iron and steel foundries). These groups are separated into 26 industries (e.g., steel works, blast furnaces, and rolling mills, primary smelting and refining of copper).

In 1991, the Primary Metals major group:

- Employed 677,000 workers $(49,300$ less than in 1988 , and 69,900 less than in 1985).

- Shipped $\$ 132.8$ billion of goods ( $\$ 16.2$ billion less than in 1988 , and $\$ 22.3$ billion more than in 1985 ), approximately 5 percent of total manufacturing value of shipments.

- Spent approximately 9 percent of its total cost of materials for fuels and electrical energy.

\section{Use of Energy}

The Primary Metals group is the fourth most energy-consuming manufacturing group. Establishments in this group:

- Accounted for approximately 14 percent of the Offsite-Produced Energy and 15 percent of the Total Inputs of Energy consumed by the manufacturing sector for heat, power, and electricity generation.

- Consumed approximately 36 percent of Total Inputs as Onsite-Produced Energy in 1985 and 32 percent in both 1988 and 1991.

- Used combustible energy sources primarily for process heating while electricity is concentrated in electrochemical processes.

\section{Energy Management}

The 1991 MECS represents a first-time collection of manufacturers' participation in energy-management activities. To improve energy efficiency, manufacturing establishments in SIC 33 participated in various demand-side management (DSM) and other energy-management programs. ${ }^{24}$ From 1989 through 1991, their activities and percent of participation, expressed in terms of Total Inputs of Energy used by participating establishments, were as follows: improving the efficiency of steam production (42 percent); improving the efficiency of process heating ( 56 percent); improving the efficiency of process refrigeration (12 percent); installing or retrofitting motors to achieve better energy efficiency (36 percent); improving the efficiency of facility HVAC systems (34 percent); and, improving the efficiency of facility lighting ( 60 percent).

\section{Structural Shifts}

Since 1985 , this major group has shifted dramatically toward more energy-intensive industry group products, as indicated by a structurally adjusted energy-intensity ratio that is less than the comparable unadjusted ratio. This type of shift occurred in both Offsite-Produced and Total Inputs of Energy (Figure 4.28) 


\section{Impact of the 1987 SIC Revision}

Revisions occurred in this major group. However, the analysis of energy efficiency is unaffected because any revision to this major group was limited to the industry level (4-digit) within this major group. Thus, both major and industry group estimates used to calculate efficiency changes are unaffected by this revision.

\section{Historical Trends in Energy Consumption and Value of Shipments}

Between 1977 and 1991, the consumption of OffsiteProduced Energy by this group:

- Increased by 7 percent from 1977 to 1978 , before decreasing sharply through 1982 .

- Increased slightly before falling to the lowest point in 1986, 56 percent of the 1977 level.

- Ended 1991 at roughly 38 percent below the 1977 consumption level.

Between 1977 and 1991, value of shipments (output) for this group closely tracked energy consumption, and it:

- Increased by 7 percent to an industry high in 1979 before sharply declining to its lowest point in 1982.

- Ended 1991 at approximately 23 percent below the 1977 shipment level.

\section{Figure 4.27. Output and Offsite-Produced Energy Consumption Indices for SIC 33, 1977 Through 1991}

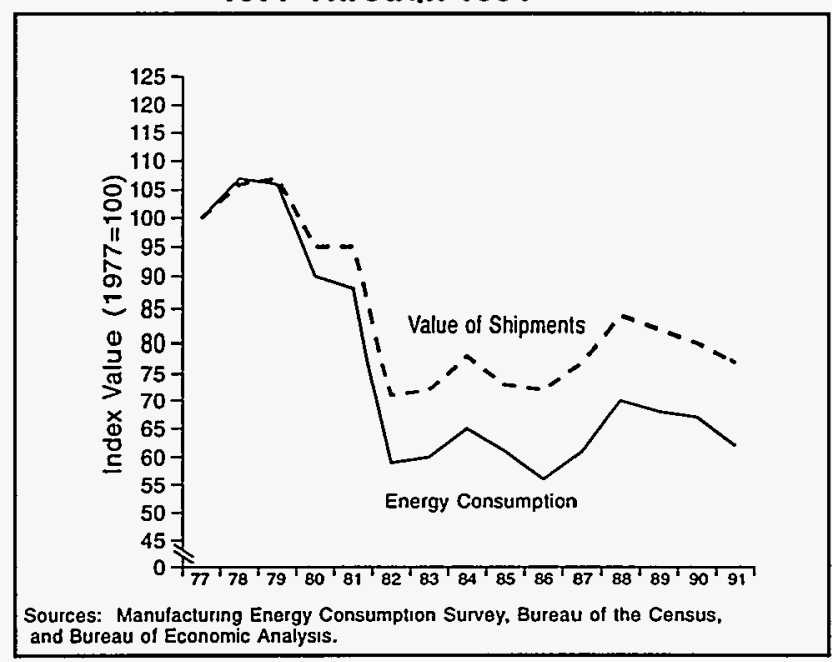

Energy efficiency increased steadily from 1978 through 1985. Although both consumption and shipment declined from 1978 through 1982, the rate of decline for consumption was greater than shipments, which indicates an improvement in energy efficiency. In the three-year period following 1982, there were small gains in efficiency relative to those that occurred from 1978 to 1982 (Figure 4.27).

\section{Energy Efficiency (Adjusted), 1985-1991}

Overall, improvements in energy efficiency continued from 1985 to 1991. In the Primary Metals major group, energy efficiency of Offsite-Produced climbed by an additional 2 percent from 1988 to 1991, after experiencing a 4 percent gain from 1985 to 1988 (Figure 4.28).

Total Inputs energy efficiency exceeded the efficiency trend given by Offsite-Produced Energy. Energy efficiency of Total Inputs of Energy increased by 4 percent from 1988 to 1991 , continuing the upward climb of energy efficiency gains, where from 1985 to 1988 efficiency increased by 10 percent.

In the manufacturing sector as a whole, Offsite-Produced Energy efficiency decreased by 4 percent between 1988 and 1991, but increased by 1 percent between 1985 and 1988. Similarly, energy efficiency for Total Inputs of Energy decreased by 3 percent between 1988 and 1991, following an increase of 1 percent between 1985 and 1988 .
Figure 4.28. Site Energy Intensities for SIC 33,

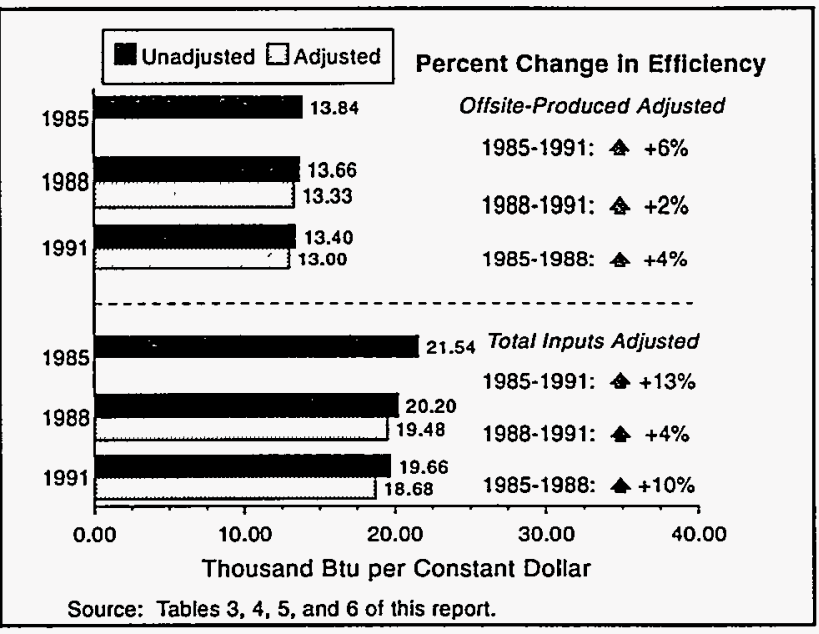
1985-1991 


\section{Blast Furnaces and Steel Mills, SIC 3312}

Establishments that manufacture hot metal, pig iron, and steel, or hot-roll iron and steel into basic shapes make up the Blast Furnace and Steel Mill industry. This industry also includes merchant blast furnaces and byproduct (beehive) coke ovens.

In 1991, this industry:

- Employed 177,300 workers (17,900 less than in 1988 , and 40,600 less than in 1985$)$.

- Shipped $\$ 40.8$ billion of goods ( $\$ 6.8$ billion less than in 1988 , and $\$ 2.7$ billion more than in 1985 ), approximately 1 percent of total manufacturing value of shipments and 31 percent of the Primary Metals value of shipments.

- Accounted for 10 percent of the Total Inputs and 8 percent of Offsite-Produced Energy consumed for heat, power, and electricity generation by the manufacturing sector.

- Spent approximately 12 percent of its total cost of materials for fuels and electrical energy.

\section{Use of Energy}

Blast furnaces and steel mills are extremely energy intensive, consuming more energy per unit of output than the entire Primary Metals major group. These establishments:

- Consumed 68 percent of the Total Inputs and 54 percent of the Offsite-Produced Energy consumed by the Primary Metals major group.

- Generated from onsite production processes approximately 51,46 , and 46 percent of their Total Inputs of Energy requirements in 1985, 1988, and 1991.

- Provided 74 percent of the onsite electricity generated by Primary Metals major group and 5 percent of manufacturing sector in 1991.

- Consumed energy primarily for process heating.

\section{Energy Management}

The 1991 MECS represents a first-time collection of manufacturers' participation in energy-management activities. To improve energy efficiency, manufacturing establishments in SIC 3312 participated in various demand-side management (DSM) and other energy-management programs..$^{25}$ From 1989 through 1991, their activities and percent of participation, expressed in terms of Total Inputs of Energy used by participating establishments, were as follows: improving the efficiency of steam production (58 percent); improving the efficiency of process heating (69 percent); installing or retrofitting motors to achieve better energy efficiency ( 43 percent); improving the efficiency of facility HVAC systems (46 percent); and, improving the efficiency of facility lighting ( 75 percent).

\section{Structural Shifts}

Structural shifts may be accounted for at any level of manufacturing aggregation. Ideally, structural adjustments would take place at the industry level. However, the samples of the MECS surveys, which are the sources of data used in this structural analysis, are not adequate for providing the needed estimates of shipments and consumption. For example,

${ }^{25}$ Energy Information Administration, Manufacturing Consumption of Energy 1991, DOE/EIA-0512(91), December 1994, Table A40, p. 304. 
the structural adjustment of an industry's energy-intensity ratio must be calculated for the relative changes in output at the product level (5-digit SIC) within the industry. For this report, 83 groupings of industry groups are used to calculate adjusted energy-intensity ratios of major groups.

\section{Impact of 1987 SIC Revision}

The 1987 SIC revision did not affect this industry.

\section{Energy Efficiency (Unadjusted), 1985-1991}

In the Blast Furnace and Steel Mills industry, energy efficiency of Offsite-Produced Energy rose by 5 percent between 1988 and 1991, rebounding from a 4 percent decline in efficiency that occurred during the previous 3 years, 1985 through 1988 (Figure 4.29).

For this industry, energy efficiency of Total Inputs of Energy increased steadily from 1988 to 1991 , rising energy efficiency by 4 percent. This rise continued a 6 percent improvement in efficiency over the previous threeyear period, 1985 through 1988.

In the manufacturing sector as a whole, Offsite-Produced Energy efficiency decreased by 4 percent between 1988 and 1991, but increased by 2 percent between 1985 and 1988. Similarly, energy efficiency for Total Inputs of Energy decreased by 3 percent between 1988 and 1991, following an increase of 2 percent between 1985 and 1988.
Figure 4.29. Site Energy Intensities for SIC 3312, 1985-1991

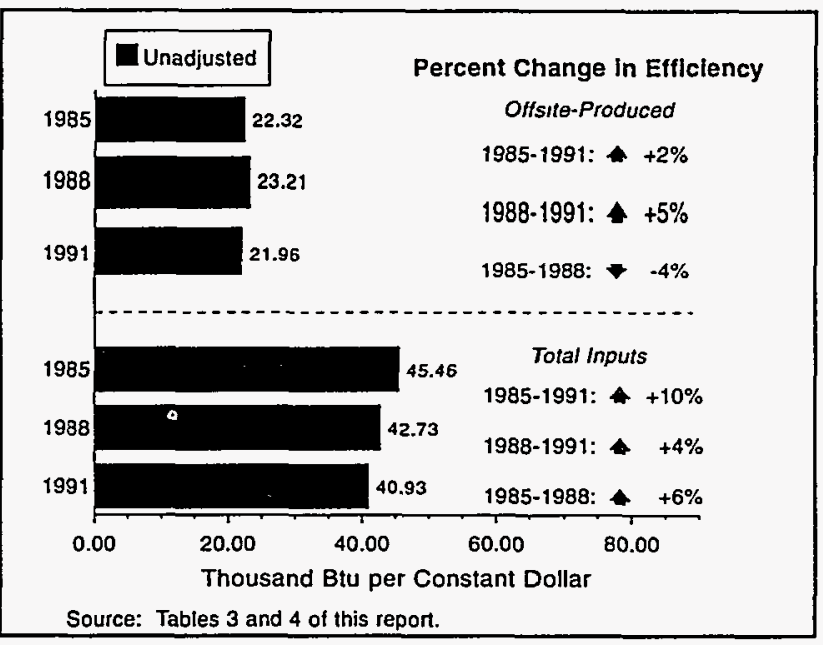




\section{Primary Aluminum, SIC 3334}

Establishments that produce aluminum from alumina or refine aluminum by any process are included in the Primary Aluminum industry.

In 1991, the Primary Aluminum industry:

- Employed 20,000 workers (1,100 more than in 1988 and 300 more than in 1985).

- Shipped $\$ 6.2$ billion of goods ( $\$ 1.6$ billion less than in 1988 and $\$ 1.7$ billion more than in 1985), 5 percent of the manufacturing major group but less than 1 percent of total manufacturing value of shipments.

- Spent approximately 31 percent of its total cost of materials for fuels and electrical energy.

\section{Use of Energy}

Establishments engaged in the production of aluminum are generally the most energy intensive in the Primary Metals major group. These establishments:

- Purchased nearly 100 percent of their fuel requirements from offsite energy suppliers, of which over 91 percent was electricity.

- Accounted for approximately 2 percent of Offsite-Produced and Total Inputs of Energy consumed for heat, power, and electricity generation by the manufacturing sector (11 percent of total and 16 percent of offsiteproduced consumed by the major group).

- Used energy mainly for electro-chemical processes, of which the most prevalent is the reduction process of alumina.

- Byproduct energy sources account for less than 1 percent of the Total Inputs of Energy consumed for heat, power, and electricity generation in 1991.

\section{Energy Management}

The 1991 MECS represents a first-time collection of manufacturers' participation in energy-management activities. To improve energy efficiency, manufacturing establishments in SIC 3334 participated in various demand-side management (DSM) and other energy-management programs. ${ }^{26}$ From 1989 through 1991, their activities and percent of participation, expressed in terms of Total Inputs of Energy used by participating establishments, were as follows: improving the efficiency of process heating (43 percent); installing or retrofitting motors to achieve better energy efficiency (17 percent); improving the efficiency of facility HVAC systems ( 0 percent); and, improving the efficiency of facility lighting (19 percent).

\section{Structural Shifts}

Structural shifts may be accounted for at any level of manufacturing aggregation. Ideally, structural adjustments would take place at the industry level. However, the samples of the MECS surveys, which are the sources of data used in this structural analysis, are not adequate for providing the needed estimates of shipments and consumption. For example, the structural adjustment of an industry's energy-intensity ratio must be calculated for the relative changes in output at the product level (5-digit SIC) within the industry. For this report, 83 groupings of industry groups are used to calculate adjusted energy-intensity ratios of major groups. 


\section{Impact of 1987 SIC Revision}

The 1987 SIC revision did not affect the Primary Aluminum industry.

\section{Energy Efficiency (Unadjusted), 1985-1991}

In the Primary Aluminum industry, energy efficiency of Offsite-Produced Energy rose by 8 percent between 1988 and 1991, continuing the gain of 9 percent in energy efficiency that occurred during the previous 3 years, 1985 through 1988 (Figure 4.30).

For this industry, Total Inputs of Energy are nearly identical with Offsite-Produced Energy. Therefore, energy efficiency of Total Inputs of Energy increased steadily from 1988 to 1991, climbing 8 percent. This rise continued a 9 percent improvement that had occurred over the previous three-year period, 1985 through 1988.

In the manufacturing sector as a whole, Offsite-Produced Energy efficiency decreased by 4 percent between 1988 and 1991, but increased by 2 percent between 1985 and 1988 . Similarly, energy efficiency for Total Inputs of Energy decreased by 3 percent between 1988 and 1991, following an increase of 2 percent between 1985 and 1988.
Figure 4.30. Site Energy Intensities for SIC 3334, 1985-1991

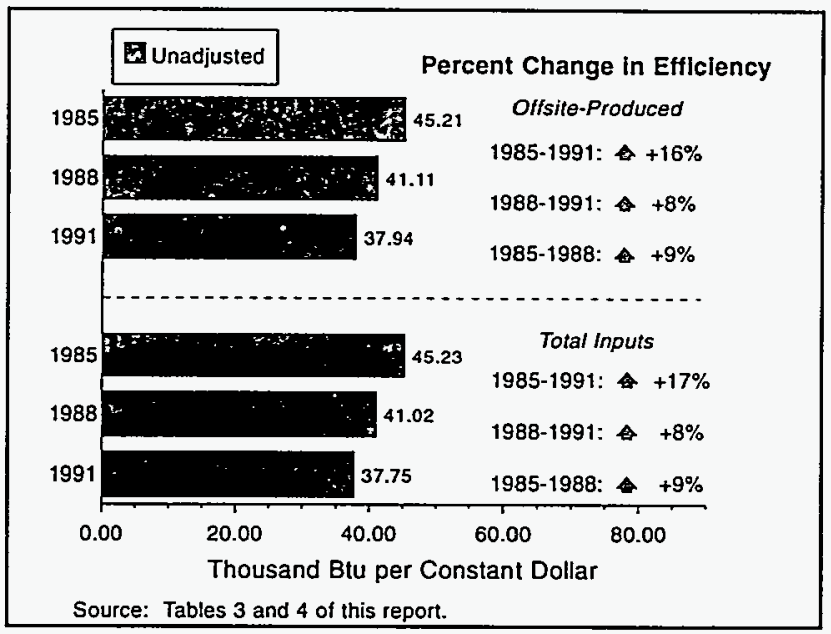




\section{Fabricated Metal Products, SIC 34}

The Fabricated Metals group contains establishments that fabricate ferrous and nonferrous metal products. Nine industry groups (e.g., metal cans and shipping containers, cutlery, hand tools, and general hardware) make up the major group. The industry groups are made up of 38 industries (e.g., saw blades and handsaws, metal doors, sash, frames, molding, and trim).

In 1991, Fabricated Metals:

- Employed 1,358,500 workers (129,000 less than in 1988 and 114,300 less than in 1985).

- Shipped $\$ 157.1$ billion of goods ( $\$ 1.8$ billion less than in 1988 and $\$ 17.5$ billion more than in 1985 ), approximately 6 percent of total manufacturing value of shipments.

- Spent about 3 percent of its total cost of materials for fuels and electricity.

\section{Use of Energy}

Relative to the manufacturing sector, the Fabricated Metals major group is not considered energy intensive. Establishments engaged in metals fabrication:

- Consumed approximately 2 percent of the Total Inputs of Energy consumed for heat, power and electricity in the manufacturing sector in 1991.

- Purchased nearly 100 percent of their fuel requirements from offsite energy suppliers, resulting in nearly identical estimates of Offsite-Produced and Total Inputs of Energy.

- Used energy mainly for machine drive and process heating.

\section{Energy Management}

The 1991 MECS represents a first-time collection of manufacturers' participation in energy-management activities. To improve energy efficiency, manufacturing establishments in SIC 34 participated in various demand-side management (DSM) and other energy-management programs. ${ }^{27}$ From 1989 through 1991, their activities and percent of participation, expressed in terms of Total Inputs of Energy used by participating establishments, were as follows: improving the efficiency of steam production (11 percent); improving the efficiency of process heating (12 percent); improving the efficiency of process refrigeration ( 6 percent); installing or retrofitting motors to achieve better energy efficiency (18 percent); improving the efficiency of facility HVAC systems (20 percent); and, improving the efficiency of facility lighting (30 percent).

\section{Structural Shifts}

Since 1985, this major group has shifted slightly toward more energy-intensive industry group products, as indicated by a structurally adjusted energy-intensity ratio that is less than the comparable unadjusted ratio. This type of shift occurred in both Offsite-Produced and Total Inputs of Energy (Figure 4.32)

\section{Impact of 1987 SIC Revision}

The 1987 SIC revision affected this group. It removed heating equipment (1977 SIC 3433) into the 1987 SIC 35, Industrial and Commercial Machinery and Computer Equipment major group; removed establishments that produce metal covered wooden doors, sash, and trim (1977 SIC 3442) into the 1987 SIC 24, Lumber and Wood Products group;

${ }^{27}$ Energy Information Administration, Manufacturing Consumption of Energy 1991, DOE/EIA-0512(91), December 1994, Table A40, p. 304. 
Included printing trades machinery (1977 SIC 3555) as part of hand and edge tools (1987 SIC 3423); included miscellaneous plastics products (1977 SIC 3079) as part of plumbing fixtures, fittings and trim (1987 SIC 3432); and, included part of aircraft equipment not classified elsewhere (1977 SIC 3728) into aircraft hydraulic and pneumatic valves (1987 SIC 3492).

It is unclear how much this reclassification of establishments affects the trends shown in Figure 4.31. Energy-intensity ratios, however, incorporate this revision, ensuring comparability among the 1985, 1988, and 1991 estimates shown in Figure 4.32.

\section{Historical Trends in Energy Consumption and Value of Shipments}

Between 1977 and 1991, the consumption of OffsiteProduced Energy by this group:

- Declined through 1983 when it reached the low of approximately 73 percent of the 1977 level.

- Increased through 1987 and 1988 before again dropping.

- Ended approximately 23 percent below the 1977 level of consumption in 1991.

Value of shipments (output) for this group:

- Increased slightly from 1977 through 1979 before decreasing to its lowest point in 1982

- Increased fairly steadily through 1988 , after which it again declined.
Figure 4.31. Output and Offsite-Produced Energy Consumption Indices for SIC 34, 1977 Through 1991

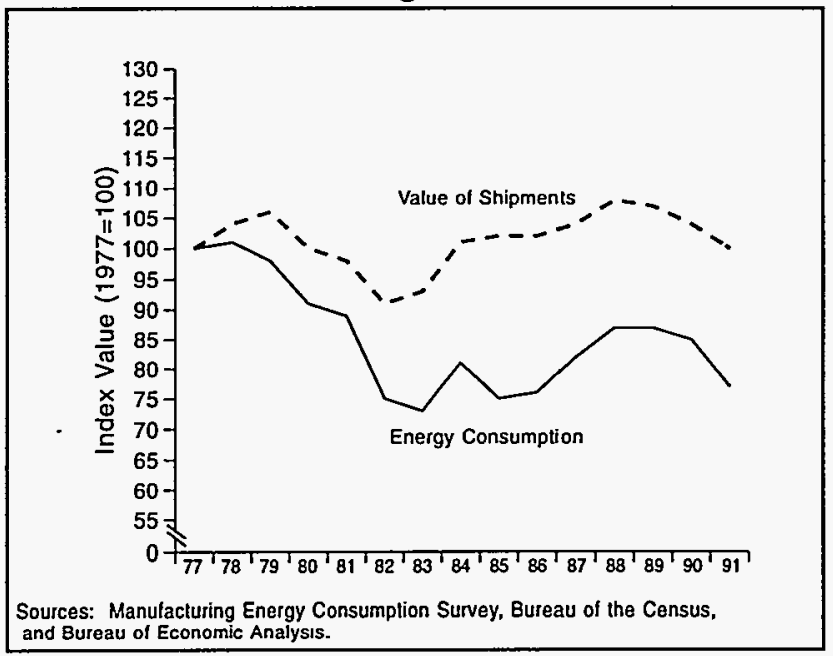

- Ended 1991 at the nearly identical amounts of 1977 shipments.

Energy efficiency increased gradually from 1977 through 1985, as shown by falling consumption and a corresponding decrease in value of shipments. Although shipments declined from 1979 through 1982, energy efficiency increased slightly because consumption declined at a far greater rate than shipments (Figure 4.31).

\section{Energy Efficiency (Adjusted), 1985-1991}

In the fabricated metals industries, energy efficiency of Offsite-Produced recovered with an improvement of 3 percent, after a decline in efficiency of 5 percent from 1985 to 1988 (Figure 4.32).

Total Inputs energy efficiency roughly duplicated OffsiteProduced. In the case of Total Inputs of Energy, energy efficiency increased with an improvement of 4 percent between 1988 and 1991. Similarly, that gain was preceded by a 5 percent decline from 1985 to 1988.

In the manufacturing sector as a whole, Offsite-Produced Energy efficiency decreased by 4 percent between 1988 and 1991, but increased by 1 percent between 1985 and 1988. Similarly, energy efficiency for Total Inputs of Energy decreased by 3 percent between 1988 and 1991, following an increase of 1 percent between 1985 and

Figure 4.32. Site Energy Intensities for SIC 34, 1985-1991

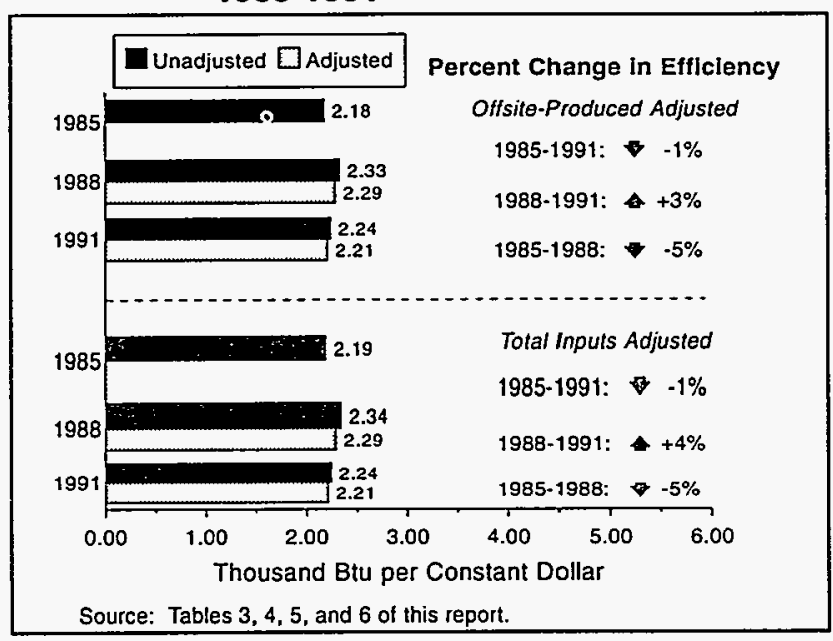




\section{Industrial Machinery and Equipment, SIC 35}

The Industrial Machinery and Equipment group consists of establishments that produce industrial and farm and garden machinery and equipment. The group also includes establishments that produce computer and office equipment. Nine industry groups (e.g., construction, mining, and materials handling machinery and equipment; metalworking machinery and equipment) make up this major group. These industry groups include 51 industries (e.g., power-driven hand tools, computer terminals).

In 1991, this group:

- Employed 1,773,700 workers (125,000 less than in 1988 and 217,400 less than in 1985).

- Shipped $\$ 243.5$ billion of goods ( $\$ 0.1$ billion more than in 1988 and $\$ 28.2$ billion more than in 1985), approximately 9 percent of total manufacturing value of shipments.

- Spent approximately 2 percent of its total cost of materials for fuels and electrical energy.

\section{Use of Energy}

Relative to the manufacturing sector, this major group is one of the least energy intensive. Establishments classified in this group:

- Purchased nearly 100 percent of their fuel requirements from offsite energy suppliers, resulting in nearly identical estimates of Offsite-Produced and Total Inputs of Energy.

- Consumed approximately 2 percent of the Total Inputs of Energy consumption for heat, power, and electricity generation in the manufacturing sector.

- Used process energy mainly for heating and machine drive, while nonprocess energy was consumed primarily for facility lighting and HVAC.

\section{Energy Management}

The 1991 MECS represents a first-time collection of manufacturers' participation in energy-management activities. To improve energy efficiency, manufacturing establishments in SIC 35 participated in various demand-side management (DSM) and other energy-management programs. ${ }^{28}$ From 1989 through 1991, their activities and percent of participation, expressed in terms of Total Inputs of Energy used by participating establishments, were as follows: improving the efficiency of steam production (15 percent); improving the efficiency of process heating (11 percent); improving the efficiency of process refrigeration ( 10 percent); installing or retrofitting motors to achieve better energy efficiency ( 25 percent); improving the efficiency of facility HVAC systems (33 percent); and, improving the efficiency of facility lighting (39 percent).

\section{Structural Shifts}

Since 1985, this major group has shifted toward less energy-intensive industry group products, as indicated by a structurally adjusted energy-intensity ratio that is more than the comparable unadjusted ratio. This type of shift occurred in both Offsite-Produced and Total Inputs of Energy (Figure 4.34)

\footnotetext{
${ }^{28}$ Energy Information Administration, Manufacturing Consumption of Energy 1991, DOE/EIA-0512(91), December 1994, Table A40, p. 304.
} 


\section{Impact of 1987 SIC Revision}

The 1987 SIC revision significantly affected this group. However, it is unclear how much the revision affected this group.

\section{Historical Trends in Energy Consumption and Value of Shipments}

Between 1977 and 1991, the consumption of OffsiteProduced Energy by this group:

- Increased initially through 1979 before decreasing to its second lowest point in both 1985 and 1986 (71 percent of its 1977 level).

- Increased through 1989 before again falling.

- Fell approximately 30 percent from the 1977 consumption level in 1991, representing its lowest consumption level from 1977 through 1991.

Between 1977 and 1991, value of shipments (output):

- Increased initially through 1979 before decreasing to its lowest point in 1983 , where shipments had declined to 89 percent of the 1977 level.

- Increased steadily from 1983 to 1990 before decreasing slightly in 1991.

- Ended 1991 at approximately 32 percent above the amount shipped in 1977.

Energy efficiency increased dramatically from 1977 through 1981, as shown by falling consumption and a corresponding increase in value of shipments. This trend of improved efficiency continued in subsequent years (Figure 4.33).

\section{Energy Efficiency (Adjusted), 1985-1991}

The machinery and computer major group extended their trend of efficiency gains of Offsite-Produced Energy by 4 percent from 1988 to 1991, after displaying a gain of 6 percent in the previous three-year period, 1985 through 1988 (Figure 4.34).

Total Inputs energy efficiency mimicked Offsite-Produced. In the case of Total Inputs of Energy, energy efficiency increased with an improvement of 4 percent between 1988 and 1991. Similarly, that gain was preceded by a 6 percent increase from 1985 to 1988.

In the manufacturing sector as a whole, Offsite-Produced Energy efficiency decreased by 4 percent between 1988 and 1991, but increased by 1 percent between 1985 and 1988. Similarly, energy efficiency for Total Inputs of Energy decreased by 3 percent between 1988 and 1991, following an increase of 1 percent between 1985 and 1988. 


\section{Electronic and Other Electric Equipment, SIC 36}

The Electronic and Other Electric Equipment major group produces machinery, equipment, and supplies for generating, storing, transmitting, transforming, and using electric energy. The manufacturing group includes eight industry groups (e.g., electric transmission and distribution equipment, household audio and video equipment) and 37 industries (e.g., motors and generators, phonographic records, and prerecorded audio tapes and disks).

In 1991, this industry group:

- Employed 1,427,400 workers (153,200 less than in 1988 and 579,700 less than in 1985).

- Shipped $\$ 197.9$ billion of goods ( $\$ 10.9$ billion more than in 1988 and $\$ 4.5$ billion more than in 1985 ), approximately 7 percent of total manufacturing value of shipments.

- Spent approximately 3 percent of its total cost of materials for fuels and electricity.

\section{Use of Energy}

Relative to the manufacturing sector, this major group is one of the least energy-intensive groups. Establishments classified in this major group:

- Consumed approximately 1 percent of the manufacturing sector's Total Inputs of Energy for heat, power, and electricity in 1991.

- Purchased 100 percent of their fuel requirements from offsite energy suppliers, resulting in identical estimates of Offsite-Produced and Total Inputs of Energy.

- Used process energy mainly for heating and machine drive, while nonprocess energy was consumed primarily for facility lighting and HVAC.

\section{Energy Management}

The 1991 MECS represents a first-time collection of manufacturers' participation in energy-management activities. To improve energy efficiency, manufacturing establishments in SIC 36 participated in various demand-side management (DSM) and other energy-management programs. ${ }^{29}$ From 1989 through 1991, their activities and percent of participation, expressed in terms of Total Inputs of Energy used by participating establishments, were as follows: improving the efficiency of steam production (17 percent); improving the efficiency of process heating (14 percent); improving the efficiency of process refrigeration (14 percent); installing or retrofitting motors to achieve better energy efficiency (28 percent); improving the efficiency of facility HVAC systems (43 percent); and, improving the efficiency of facility lighting (47 percent).

\section{Structural Shifts}

Since 1985, this major group has shifted negligibly toward less energy-intensive industry group products, as indicated by a structurally adjusted energy-intensity ratio that is marginally more than the comparable unadjusted ratio. This type of shift occurred in both Offsite-Produced and Total Inputs of Energy (Figure 4.36)

\section{Impact of 1987 SIC Revision}

The 1987 SIC revision affected this group. It is unclear how much any reclassification affected this group. 


\section{Historical Trends in Energy Consumption and Value of Shipments}

Between 1977 and 1991, the consumption of OffsiteProduced Energy by this group:

- Increased slightly in 1978 before decreasing steadily through 1991.

- Fell approximately 21 percent from the 1977 consumption level in 1991, representing its lowest consumption level from 1977 through 1991.

Between 1977 and 1991, value of shipments (output) for this group:

- Peaked in 1986 after experiencing a steady increase of shipments.

- Decreased sharply from 1985 to 1986 -possibly due to the SIC revision of 1987-before recovering in the following 5 years.
Figure 4.35. Output and Offsite-Produced Energy Consumption Indices for SIC 36, 1977 Through 1991

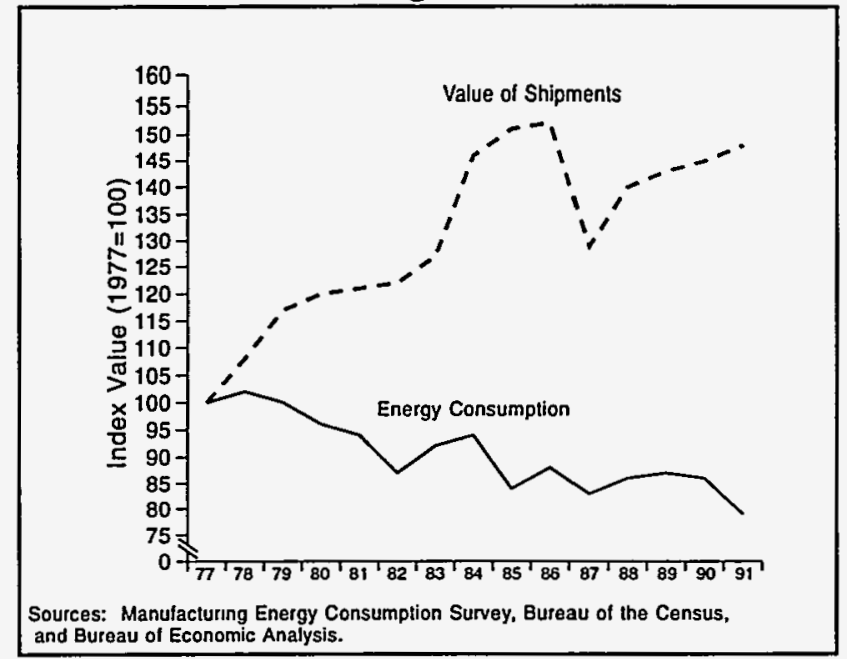

- Ended 1991 at approximately 48 percent greater than the 1977 level of output.

Energy efficiency increased dramatically from 1977 through 1985, as shown by falling consumption and a corresponding increase in value of shipments (Figure 4.35).

\section{Energy Efficiency (Adjusted), 1985-1991}

In the electronic major group, energy efficiency of Offsite-Produced recovered with a gain of 11 percent from 1988 to 1991, after experiencing an efficiency reduction of 3 percent in the previous three-year period, 1985 through 1988 (Figure 4.36).

Total Inputs energy efficiency matched Offsite-Produced because 100 percent of fuel requirements was satisfied by offsite energy suppliers. Thus, in the case of Total Inputs of Energy, energy efficiency increased with an improvement of 11 percent between 1988 and 1991 . Similarly, that gain was preceded by a 3 percent decrease in efficiency from 1985 to 1988.

In the manufacturing sector as a whole, Offsite-Produced Energy efficiency decreased by 4 percent between 1988 and 1991, but increased by 1 percent between 1985 and 1988. Similarly, energy efficiency for Total Inputs of Energy decreased by 3 percent between 1988 and 1991, following an increase of 1 percent between 1985 and 1988 .
Figure 4.36. Site Energy Intensities for SIC 36, 1985-1991

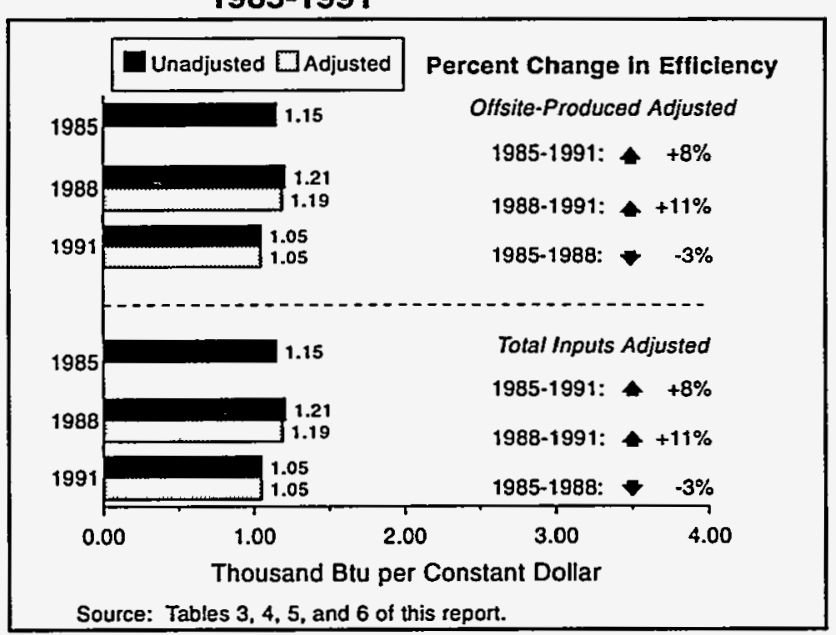




\section{Transportation Equipment, SIC 37}

Establishments in the Transportation Equipment group produce equipment to transport passengers and cargo by land, air, and water. Guided missiles and space craft are also produced by this group of establishments. The manufacturing group is made up of seven industry groups (e.g., aircraft and parts, ship and boat building and repairing) and 18 industries (e.g., motor vehicles and passenger car bodies, guided missiles and space vehicles).

In 1991, this group:

- Employed 1,633,500 workers (182,300 less than in 1988 and 123,500 less than in 1985).

- Shipped $\$ 364.0$ billion of goods ( $\$ 10.0$ billion more than in 1988 and $\$ 62.6$ billion more than in 1985), approximately 13 percent of total manufacturing value of shipments.

- Spent approximately 1 percent of its total cost of materials for fuels and electrical energy.

\section{Use of Energy}

Relative to the manufacturing sector, this major group is one of the least energy-intensive groups. Overall, this group:

- Consumed approximately 3 percent of the manufacturing sector's Offsite-Produced Energy and 2 percent of Total Inputs of Energy for heat, power, and electricity generation.

- Used energy mainly for process uses of heating and machine drive, and secondly for facility lighting and HVAC uses.

\section{Energy Management}

The 1991 MECS represents a first-time collection of manufacturers' participation in energy-management activities. To improve energy efficiency, manufacturing establishments in SIC 37 participated in various demand-side management (DSM) and other energy-management programs. ${ }^{30}$ From 1989 through 1991, their activities and percent of participation, expressed in terms of Total Inputs of Energy used by participating establishments, were as follows: improving the efficiency of steam production ( 31 percent); improving the efficiency of process heating ( 27 percent); improving the efficiency of process refrigeration (20 percent); installing or retrofitting motors to achieve better energy efficiency ( 36 percent); improving the efficiency of facility HVAC systems (48 percent); and, improving the efficiency of facility lighting (66 percent).

\section{Structural Shifts}

Since 1985 , this major group has shifted toward less energy-intensive industry group products, as indicated by a structurally adjusted energy-intensity ratio that is slightly more than the comparable unadjusted ratio. This type of shift occurred in both Offsite-Produced and Total Inputs of Energy (Figure 4.38)

\section{Impact of 1987 SIC Revision}

The 1987 SIC revision affected this group. It removed part of aircraft equipment (1977 SIC 3728) and included portions in 1987 SIC 3492 (fluid power valves and hose fittings), SIC 3594 (fluid power pumps and motors), and SIC 3593 (fluid power cylinders and actuators).

Because of this revision, disconnection of a comparable SIC basis occurs between the years preceding and subsequent to 1987 for both value of shipments and consumption estimates. It is unclear how much this reclassification of 
establishments affects the trends shown in Figure 4.37. Energy-intensity ratios, however, incorporate this revision, ensuring comparability among the 1985, 1988, and 1991 estimates shown in Figure 4.38.

\section{Historical Trends in Energy Consumption and Value of Shipments}

\author{
Between 1977 and 1991, Offsite-Produced Energy \\ consumption by this group:
}

- Increased slightly in 1978 before decreasing steadily through 1982 .

- Increased steadily from 1982 to 1989 before decreasing steadily through 1991 .

- Fell approximately 15 percent below its 1977 consumption level.

Between 1977 and 1991, value of shipments (output) for this industry group:

- Increased slightly in 1978 before decreasing steadily through 1982

- Rose rapidly from 1982 to 1989 before decreasing steadily through 1991 .
Figure 4.37. Output and Offsite-Produced Energy Consumption Indices for SIC 37, 1977 Through 1991

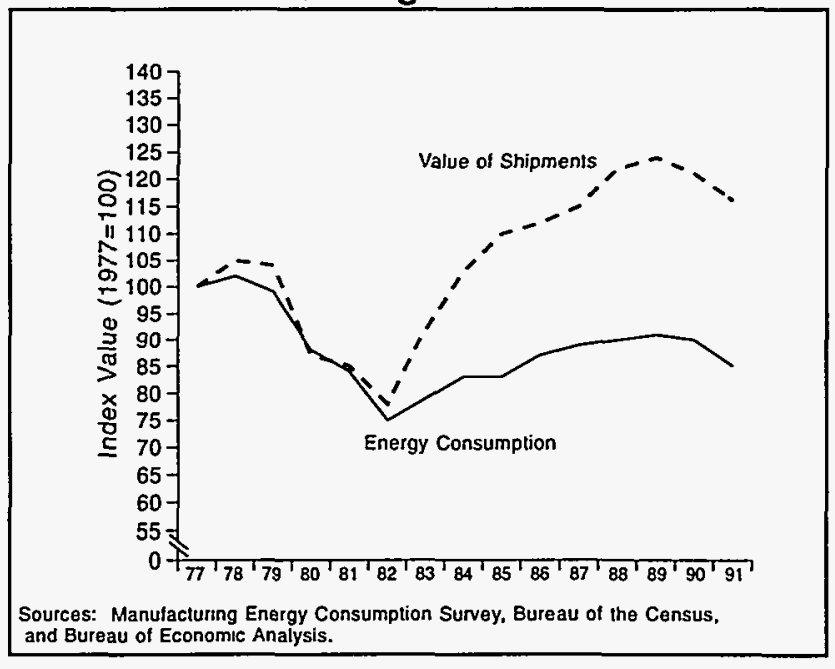

- Increased approximately 16 percent in 1991 above the 1977 output level.

Energy efficiency stagnated from 1977 through 1982, as shown by the paralleling of falling consumption and decreasing value of shipments (Figure 4.37). For the next 3 years, however, relative energy efficiency rose steadily, as evidenced by the rapid rise in shipments coupled with the gradual increase in consumption.

\section{Energy Efficiency (Adjusted), 1985-1991}

In the transportation group, energy efficiency of OffsiteProduced plummeted with a loss of 5 percent from 1988 to 1991, after experiencing an efficiency gain of 6 percent in the previous three-year period, 1985 through 1988 (Figure 4.38).

Total Inputs energy efficiency closely followed OffsiteProduced because nearly 100 percent of fuel requirements was satisfied by offsite energy suppliers. Thus, in the case of Total Inputs of Energy, energy efficiency decreased with a loss of 11 percent between 1988 and 1991. Similarly, that reduction was preceded by a 5 percent increase in efficiency from 1985 to 1988 .

In the manufacturing sector as a whole, Offsite-Produced Energy efficiency decreased by 4 percent between 1988 and 1991, but increased by 1 percent between 1985 and 1988. Similarly, energy efficiency for Total Inputs of Energy decreased by 3 percent between 1988 and 1991, following an increase of 1 percent between 1985 and 1988.
Figure 4.38. Site Energy Intensities for SIC 37, 1985-1991

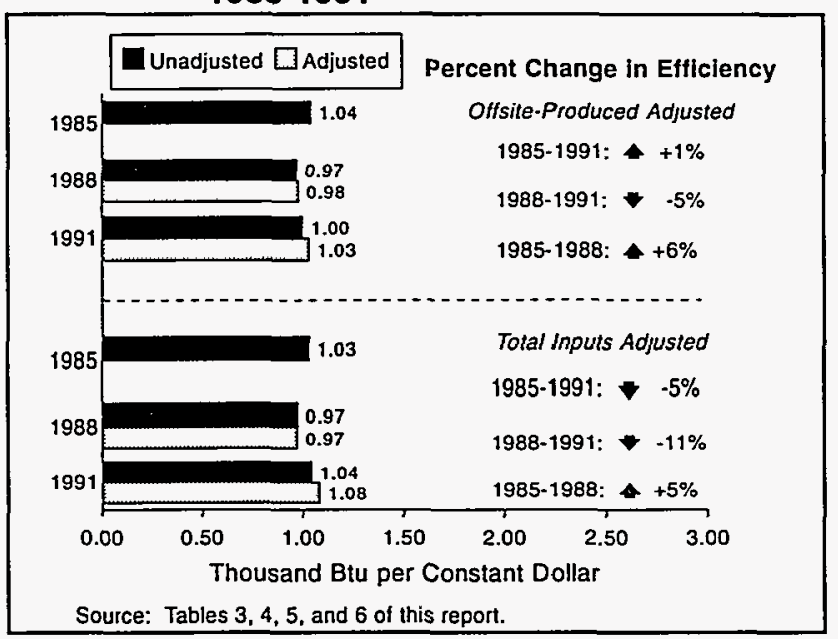




\section{Instruments and Related Products, SIC 38}

Establishments that manufacture instruments for measuring, testing, analyzing, and controlling, along with associated sensors and accessories make up the Instruments and Related Products major group. The manufacturing group is made up of six industry groups (e.g., laboratory apparatus, analytical, optical, measuring, and controlling instruments) and 17 industries (e.g., dental equipment and supplies, photographic equipment and supplies).

In 1991, this group:

- Employed 901,300 workers (84,800 less than in 1988 and 297,000 more than in 1985$)$.

- Shipped $\$ 127.2$ billion of goods ( $\$ 12.6$ billion more than in 1988 and $\$ 66.2$ billion more than in 1985 ), approximately 5 percent of total manufacturing value of shipments.

- Spent approximately 3 percent of its total cost of materials for fuels and electrical energy.

\section{Use of Energy}

Relative to the manufacturing sector, this major group is one of the least energy intensive. Establishments classified in this group:

- Purchased nearly 100 percent of their fuel requirements from offsite energy suppliers, which results in nearly identical consumption estimates for Offsite-Produced Energy and Total Inputs of Energy.

- Consumed less than 1 percent of Offsite-Produced and Total Inputs of Energy for heat, power, and electricity in the manufacturing sector.

- Used energy mainly for machine drive and facility HVAC.

\section{Energy Management}

The 1991 MECS represents a first-time collection of manufacturers' participation in energy-management activities. To improve energy efficiency, manufacturing establishments in SIC 38 participated in various demand-side management (DSM) and other energy-management programs. ${ }^{31}$ From 1989 through 1991, their activities and percent of participation, expressed in terms of Total Inputs of Energy used by participating establishments, were as follows: improving the efficiency of steam production ( 40 percent); improving the efficiency of process heating ( 34 percent); improving the efficiency of process refrigeration ( 39 percent); installing or retrofitting motors to achieve better energy efficiency ( 47 percent); improving the efficiency of facility HVAC systems (63 percent); and, improving the efficiency of facility lighting (68 percent).

\section{Structural Shifts}

Since 1985, this major group has shifted considerably toward less energy-intensive industry group products, as indicated by a structurally adjusted energy-intensity ratio that is more than the comparable unadjusted ratio. This type of shift occurred in both Offsite-Produced and Total Inputs of Energy (Figure 4.40)

\section{Impact of 1987 SIC Revision}

The 1987 SIC revision affected this group. It included part of 1977 SIC 3662 (radio and TV communications equipment) in 1987 SIC 3812 (search and navigation equipment) and part in 1987 SIC 3829 (measuring and controlling devices);

\footnotetext{
${ }^{31}$ Energy Information Administration, Manufacturing Consumption of Energy 1991, DOE/EIA-0512(91), December 1994, Table A40, p. 304.
} 
and included 1987 SIC 3693 (X-ray apparatus and tubes) in 1987 SIC 384 (surgical, medical, and dental instruments and supplies).

Because of this revision, disconnection of a comparable SIC basis occurs between the years preceding and subsequent to 1987 for both value of shipments and consumption estimates. Energy-intensity ratios, however, incorporate this revision, ensuring comparability among the 1985, 1988, and 1991 estimates shown in Figure 4.40.

\section{Historical Trends in Energy Consumption and Value of Shipments}

Between 1977 and 1991, the consumption of OffsiteProduced Energy by this group:

- Remained relatively stable through 1981 before declining through 1986.

- Reached its highest point in 1989, approximately 40 percent above the 1977 consumption level.

- Ended approximately 24 percent greater in 1991 than in 1977.

Between 1977 and 1991, value of shipments (output) for this group:

- Climbed steadily through $1986 . \quad$ Output increased dramatically between 1986 and 1987 , a result of the SIC revisions affecting this group.

- Climbed through 1991 , ending 147 percent greater than in 1977.

Energy efficiency steadily increased from 1977 through 1985 , as shown by stable consumption coupled with steadily increasing value of shipments (Figure 4.39).

\section{Energy Efficiency (Adjusted), 1985-1991}

In the instruments group, energy efficiency of OffsiteProduced Energy continued with a gain of 3 percent from 1988 to 1991 , after experiencing an efficiency gain of 5 percent in the previous three-year period, 1985 through 1988 (Figure 4.40).

Total Inputs energy efficiency closely followed Offsite-Produced because nearly 100 percent of fuel requirements was satisfied by offsite energy suppliers. Thus, in the case of Total Inputs of Energy, energy efficiency increased by 3 percent between 1988 and 1991. Similarly, that improvement in efficiency was preceded by a 3 percent increase in efficiency from 1985 to 1988 .

In the manufacturing sector as a whole, Offsite-Produced Energy efficiency decreased by 4 percent between 1988 and 1991 , but increased by 1 percent between 1985 and 1988. Similarly, energy efficiency for Total Inputs of Energy decreased by 3 percent between 1988 and 1991, following an increase of 1 percent between 1985 and 1988 . 


\section{Miscellaneous Manufacturing Industries, SIC 39}

Establishments whose primary products are not classified in any other manufacturing group make up the Miscellaneous Manufacturing Industries major group. This manufacturing group includes 6 industry groups (e.g., musical instruments; pens, pencils and other artists' materials) and 18 industries (e.g., dolls and stuffed toys, burial caskets).

In 1991, this group:

- Employed 363,100 workers (29,100 less than in 1988 and 35,100 more than in 1985).

- Shipped $\$ 37.1$ billion of goods ( $\$ 2.3$ billion more than in 1988 and $\$ 10.6$ billion more than in 1985 ), approximately 1 percent of total manufacturing value of shipments.

- Spent about 2 percent of its total cost of materials for fuels and electricity.

\section{Use of Energy}

This group is not energy intensive. Establishments included in this group:

- Purchased most of their fuel requirements from offsite energy suppliers, which results in nearly identical consumption estimates for Offsite-Produced Energy and Total Inputs of Energy.

- Consumed less than one percent of Offsite-Produced and Total Inputs of Energy consumed for heat, power, and electricity in the manufacturing sector.

- Consumed less energy for heat, power, and electricity generation than any other manufacturers except for the tobacco and leather major groups (SICs 21 and 31).

- Used energy mainly for process heating and machine drive.

\section{Energy Management}

The 1991 MECS represents a first-time collection of manufacturers' participation in energy-management activities. To improve energy efficiency, manufacturing establishments in SIC 39 participated in various demand-side management (DSM) and other energy-management programs..$^{32}$ From 1989 through 1991, their activities and percent of participation, expressed in terms of Total Inputs of Energy used by participating establishments, were as follows: improving the efficiency of steam production ( 9 percent); improving the efficiency of process heating ( 6 percent); improving the efficiency of process refrigeration (13 percent); installing or retrofitting motors to achieve better energy efficiency (13 percent); improving the efficiency of facility HVAC systems (26 percent); and, improving the efficiency of facility lighting (29 percent).

\section{Structural Shifts}

Two shifts are indicated in this major group over the past six years. During the 3 years following 1985, this major group had shifted considerably toward more energy-intensive industry group products, as indicated by a structurally adjusted energy-intensity ratio that is less than the comparable unadjusted ratio. Between 1988 and 1991, however, this major group reversed this trend and shifted toward less energy-intensive industry group products, as shown by a structurally adjusted energy-intensity ratio that is more that the comparable unadjusted ratio. These types of shifts occurred in both Offsite-Produced and Total Inputs of Energy (Figure 4.42) 


\section{Impact of the 1987 SIC Revision}

Revisions occurred in this major group. However, the analysis of energy efficiency is unaffected because any revision to this major group was limited to the industry and industry group levels (4-and 3-digits) within this major group. Thus, major group estimates used to calculate efficiency changes are unaffected by this revision. Specifically, energy-intensity ratios incorporate this revision, ensuring comparability among the 1985, 1988, and 1991 estimates shown in Figure 4.42.

\section{Historical Trends in Energy Consumption and Value of Shipments}

Between 1977 and 1991, the consumption of OffsiteProduced Energy by this group:

- Decreased steadily through 1985 , reaching a low of 61 percent of the 1977 consumption level.

- Increased through 1989 before again dropping.

- Ended 1991 at 63 percent of the 1977 level.

Between 1977 and 1991, the value of shipments (output) for this group:

- Dropped through 1983, reaching 83 percent of the 1977 value of shipments.

- Increased through 1988 before leveling off.

- Ended 1991 at approximately 3 percent above the 1977 level of output.

Energy efficiency widely fluctuated from 1977 through 1981, as shown by the rising and falling consumption and shipments indices (Figure 4.41). However, energy efficiency steadily increased from 1981 to 1985 due to the rapid rate of decline of energy consumption coupled with a generally increasing rate of output.

\section{Energy Intensity (Adjusted), 1985-1991}

In the Miscellaneous major group, energy efficiency of Offsite-Produced increased by 10 percent from 1988 to 1991 . That improvement in energy efficiency extended a trend of increasing efficiency, where from 1985 to 1988 this major group also experienced a 3 percent improvement in energy efficiency (Figure 4.42).

Total Inputs energy efficiency followed the efficiency trend given by Offsite-Produced Energy. Energy efficiency of Total Inputs of Energy increased by 8 percent from 1988 to 1991, continuing the upward climb of energy efficiency, where from 1985 to 1988 efficiency increased by 7 percent.

In the manufacturing sector as a whole, OffsiteFigure 4.42. Site Energy Intensities for SIC 39, 1985-1991

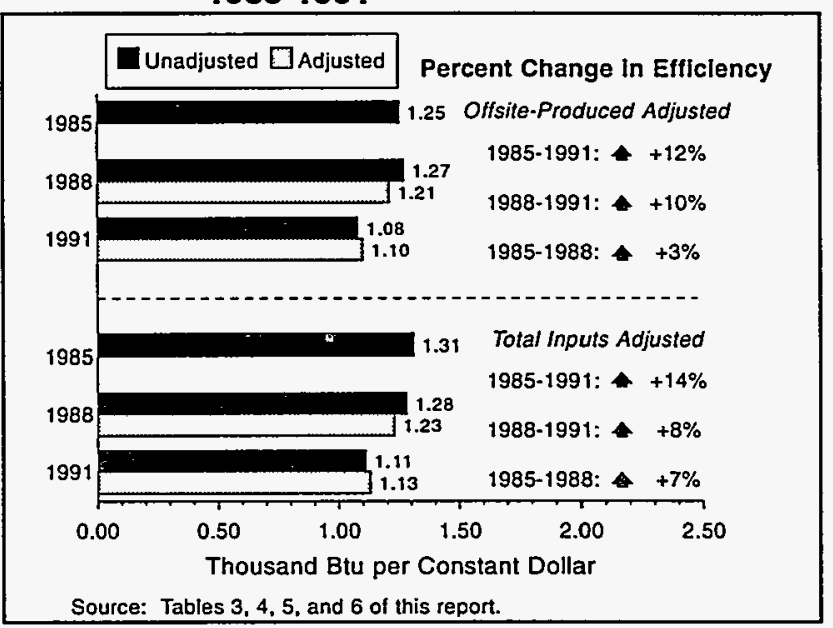

Produced Energy efficiency decreased by 4 percent between 1988 and 1991, but increased by 1 percent between 1985 and 1988. Similarly, energy efficiency for Total Inputs of Energy decreased by 3 percent between 1988 and 1991, following an increase of 1 percent between 1985 and 1988. 

Appendix A

Survey Design, Implementation, and Estimates 


\section{Appendix A}

\section{Survey Design, Implementation, and Estimates}

\section{Introduction}

The Energy Information Administration (EIA) designed the 1991 Manufacturing Energy Consumption Survey (MECS) to provide information on the consumption of energy by the manufacturing sector. For the first time, the survey also collected data on:

- the approximate size of buildings associated with manufacturing

- estimates of consumption by general end uses

- indications of advanced technologies already in use.

The MECS is a triennial survey, with the first survey collecting data for calendar year 1985. Federal energy legislation passed in 1992 revised the MECS collection schedule. Beginning in 1994, EIA will conduct the MECS every two rather than every 3 years.

This report on changes in energy intensity is the third report based on the 1991 MECS. Other publications include reports detailing the development of the 1991 survey $^{33}$ and the 1991 consumption of energy. ${ }^{34}$

In addition to new data for 1988 through 1991, this report includes estimates on changes in energy intensity from 1985 to 1988. Values used to calculate changes in intensities for those years differ from values used in earlier publications. For this report, changes in intensities data for 1985 and 1988 reflect changes in the Standard Industry Classification (SIC) system caused by the 1987 SIC revisions. For the first time, this report identifies changes in intensity based on Total Inputs of Energy consumed for heat, power, and electricity in addition to changes in Offsite-Produced Energy. Estimates of energy consumption in 1985, 1988, and 1991 are calculated using data from the MECS surveys. The Census Bureau provided economic data (e.g., value of shipments, value added) collected by the 1991 Annual Survey of Manufactures (ASM). The Bureau of Economic Analysis provided industry-specific price indices. These indices were applied to current dollar value of shipments to obtain value of shipments in 1987 constant dollars. Previous energy intensity reports used 1980 as the base year for calculating intensity changes. As explained in the section on the estimation process, 1985 is the base year for this report.

The basic unit of data collection for the MECS is the manufacturing establishment. A nationally representative sample of these establishments is selected to receive the questionnaire. The EIA provides survey specifications to the Census Bureau, which selects the MECS sample from the list of establishments responding to the ASM, conducts the fieldwork, and handles data processing. The Census Bureau performs these functions to ensure complete confidentiality of individual responses.

This appendix presents a brief overview of the survey, sample design, and estimation procedures for the 1991 MECS. A methodological report published in 1992 presents a nonstatistical description of sample selection issues for the 1991 survey. A methodological report published for the 1985 survey presents details relating to the background of the survey, original forms design, sample design, and estimation procedures. Appendix A of the Changes in Energy Intensity in the Manufacturing Sector, 1980-1988 details the methodological and statistical changes in the survey from 1985 to 1988. This appendix addresses changes from the 1988 survey and presents a brief overview of the survey, sample design, and estimation procedures.

\footnotetext{
${ }^{33}$ Energy Information Administration, Development of the 1991 Manufacturing Energy Consumption Survey, DOE/EIA-0555(92)/2 (Washington, DC, May 1992).

${ }^{3}$ Energy Information Administration, Manufacturing Energy Consumption Survey: Consumption of Energy 1991, DOE/EIA-0512(91) (Washington, DC, December 1994).
} 


\section{Description of the Manufacturing Sector}

The U.S. manufacturing sector consists of approximately 350,000 establishments in the 50 States and the District of Columbia. The Office of Management and Budget's SIC Manual provides the working definition of a manufacturing establishment:

[Manufacturing establishments are]... engaged in the mechanical or chemical transformation of materials or substances into new products. These establishments are usually described as plants, factories, or mills and characteristically use power driven machines and materials handling equipment. Establishments engaged in assembling component parts of manufactured products are also considered manufacturing if the new product is neither a structure nor other fixed improvement. Also included is the blending of materials such as lubricating oil, plastics, resins, or liquors. ${ }^{35}$

The SIC Manual contains a hierarchical classification system that groups establishments according to their primary economic activity. This system divides the manufacturing sector into 20 major groups. A two-digit code identifies each major group producing the same general output (e.g., textiles, primary metals). For manufacturing, these codes range from SIC 20, Food and Kindred Products, through SIC 39, Miscellaneous Manufacturing Industries. Four-digit industries and three-digit industry groups make up each two-digit major group. For example, SIC 20 includes the industry groups Meat Products (SIC 201), Dairy Products (SIC 202), and Preserved Fruits and Vegetables (SIC 203). SIC 202 includes the industries Creamery Butter (SIC 2021), Cheese, Natural and Processed (SIC 2022), and Dry, Condensed, and Evaporated Products (SIC 2023). Appendix D includes descriptions of the 20 major groups, as well as the three-digit industry groups and four-digit industries of interest to the 1991 MECS.

The SIC category is the most important classification variable in the MECS data system, both for selecting the sample and analyzing the data. In addition to the 20 two-digit major groups, the MECS pays special attention to four-digit industries that are large energy consumers. For the first time, the $1991 \mathrm{MECS}$ also targeted industries that have experienced rapid growth (for example, the computer industry) leading to increased energy consumption. For both the 1985 and 1988 surveys, the MECS collected data from the ten four-digit industries that consume the most energy , as well as from the 20 major groups. The 1991 survey also had an increased sample size, which permitted collection and publishing of data on 39 four-digit industries and two three-digit industry groups, in addition to the 20 major groups (61 sampling strata). The sample was selected such that estimates of energy consumption and fuel-switching capability for each of these industries would meet historical publication standards.

Both the 1991 and 1988 MECS samples were based on the classification scheme of the 1987 edition of the SIC manual. However, the 1985 MECS was based on the 1972 SIC classification. For ease in comparing 1988 and 1991 data with 1985, the 1985 estimates of energy consumption and value of shipment data were aggregated based on the 1987 SIC classifications. For most of the two-digit major groups, the 1987 change in industry definitions had no major effect on consumption estimates. For groups such as SIC 36 (Electronic and Other Electric Equipment) and SIC 38 (Instruments and Related Products), industry reclassification resulted in substantial effects on consumption matters and makes problematic some comparisons of 1985 estimates with 1988 and 1991.

Because of this revision, disconnection of a comparable SIC basis occurs between the years preceding and subsequent to 1987 for both value of shipments and consumption estimates. It is unclear how much this reclassification of establishments affects the trends shown in indice figures. Energy-intensity ratios, however, incorporate this revision, ensuring comparability among the 1985,1988 , and 1991 estimates.

\section{The MECS Sampling Frame and Sample Design}

The Census Bureau serves as the data collecting and compiling agent for the MECS so that confidentiality may be assured. The Census Bureau's role also permits the MECS sample to be drawn from establishments responding to the ASM. Establishments receiving the ASM also completed the Census of Manufactures (CM). Drawing the MECS sample

${ }^{35}$ Office of Management and Budget, Standard Industrial Classification Manual, 1987 (Washington, DC, 1987), p. 67. 
from the list of ASM respondents assures the estimates for each industry are representative, on a national level. It also permits matching MECS energy related data with previously collected economic data for the same establishments.

\section{The Census of Manufactures and Annual Survey of Manufactures}

The Census Bureau is responsible for conducting the CM and the ASM. The CM collects economic data for the entire universe of manufacturing establishments in the United States. The Census Bureau conducts the $\mathrm{CM}$ in years ending in "2" or "7" (e.g., 1987, 1992 and so on). For the CM, manufacturing establishments are separated into two categories:

- Small Single-Establishment Companies Not Sent a Report Form - In general, companies that employ fewer than five employees are exempt from participating in the CM, while establishments that employ more than 20 employees participate. Establishments that employ between five and 20 employees receive a report form if their annual payroll and value of shipments are large enough to meet SIC-specific requirements. The small establishment contribution to economic statistics published in the CM is estimated based on information collected by other Federal agencies. Approximately 160,000 manufacturing establishments do not participate in the CM due to their size.

- Establishments Sent a Report Form - All establishments in the manufacturing universe not excused due to size are sent a CM form. The Census Bureau mailed approximately 200,000 forms for the 1987 CM.

Like the CM, the ASM provides estimates of economic characteristics for the entire universe of manufacturing establishments. It is also separated into a mail and nonmail portion. The ASM provides yearly updates to the manufacturing universe to identify the birth or death of manufacturing establishments. The mail portion of the ASM is a weighted probability sample selected from the list of establishments sent the CM report form. Responses by these establishments represent the mail portion of the CM universe. The nonmail portion of the ASM is the same as the CM nonmail. As with the CM, published reports include the estimated nonmail contribution to economic statistics. The nonmail estimation procedure for the ASM is the same as that used for the nonmail portion of the CM.

\section{MECS Sample Design}

The EIA is responsible for MECS sample specifications. One requirement of the 1988 sample was to maximize 1985 "carry-over" establishments. This carry-over was designed to increase the precision of comparisons of estimates from the 1985 MECS with the 1988. There are two reasons for the smaller number of carry-over establishments in 1991.

- The 1991 ASM sample, from which the 1991 MECS sample is drawn, was based on a new sample frame created in 1989 from the $1987 \mathrm{CM}$. Hence, the 1989 and subsequent ASM samples did not automatically include establishments selected in the 1985 and 1988 MECS.

- The second reason for the smaller number of carry-over establishments is that the 1991 sample specifically targeted a larger number of fast growing or high energy-consuming four-digit SICs. Although the fast growth industries are not necessarily large consumers of energy, their growth rate results in a rapidly expanding pattern of energy consumption. Gathering more complete data on additional four-digit industries was considered relatively more important than continuing the longitudinal study begun in 1988 .

In 1991, the MECS sample size increased from roughly 12,000 to roughly 16,000 establishments. This increase was a result of the increased interest in energy consumption by specified three- and four-digit industries, and the desire to increase the precision of estimates reported. With five exceptions, the MECS sample included every establishment in the three- and four-digit SICs of interest included in the 1991 ASM sample. The five exceptions include beet sugar (SIC 2063), industrial gases (SIC 2813), miscellaneous plastic products (SIC 308), computer and office equipment (SIC 357), and motor vehicle parts and accessories (SIC 3714). The number of establishments in each of these SIC groups and industries was large enough to allow representative samples to be drawn. The total MECS sample would include enough establishments in these industries to produce estimates that had sampling errors within the pre-established bounds. Controls during sampling each of the 20 two-digit groups kept sampling errors within pre-established bounds. The 
procedures for subselecting ASM sample establishments into the MECS sample were such that overall probabilities of selection were proportional to an estimated energy-related measure of size.

For the $1985 \mathrm{MECS}$, the estimated sample size of 12,065 establishments resulted in a final sample of 11,684 establishments. In 1988, the initial sample of 12,400 resulted in a final sample of 12,065 establishments. The final 1991 sample included 16,054 establishments. Of these, 305 establishments were determined to be out-of-scope or no longer in business prior to the MECS mailing, leaving a mail sample of 15,749. At the final closing, 14,299 questionnaires were received, a response rate of 91 percent.

\section{Fieldwork, Editing, and Quality Control}

As in 1988, the 1991 MECS questionnaires were customized to minimize response burden by individual establishments. To accomplish this, the manufacturing sector was separated into three components. Each component received a slightly different version of the questionnaire. Each version required the same information on noncombustible energy sources (electricity, steam, and hot water) and fuel switching capability. In addition, all versions included the same questions on consumption by end use, estimated square footage of buildings, and energy management activities. The differences among questionnaires were in the information requested for combustible energy sources and technologies in use.

- EIA 846(A) - The majority of the MECS sample received this version of the questionnaire. This version collected the most basic combustible energy consumption data, along with data on expenditures for energy, fuel-switching capability, end-use consumption of energy, and information on technology adoption.

- EIA 846(B) - This version of the questionnaire was sent exclusively to establishments in the Petroleum Refining Industry (SIC 2911). The design of the questionnaire took advantage of the fact that other EIA surveys collect certain consumption and expenditure data from the refinery population. Because of this, the EIA-846(B) did not require respondents to report on particular data items.

- EIA 846(C) - This questionnaire was sent to establishments in SIC 24 (Lumber and Wood Products), SIC 26 (Paper and Allied Products), SIC 28 (Chemicals and Allied Products), the remaining three and four-digit SICs included in SIC 29 (Petroleum and Coal Products), and selected four-digit industries in SIC 32 (Primary Metals). This version was similar to the EIA-846(A) except it collects additional information on shipments of energy sources produced onsite and a different set of specific technologies related to energy efficiency.

\section{The Estimation Process}

The 1991 MECS represents the portion of manufactures in the manufacturing universe covered by the 1991 ASM mail sample. This portion, when sampled establishments are weighted up, accounts for approximately 98 percent of total manufacturing value of shipments and receipts. Weighing up inflates reported values from the sample to that portion of the population it represents. Multiplying a reported or derived value by an establishment-specific sample weight inflates the reported values to population values. Each establishment included in the MECS sample has an associated sampling weight with two components: sample weight and adjustment factor for nonresponse. The first component is the reciprocal of the establishment's overall probability of selection into the ASM and subsequent selection for the MECS.

The second component of the sampling weight addresses questionnaire nonresponse by establishments sent a MECS form but, for whatever reasons, did not respond. An establishment is selected into the MECS sample with a probability proportional to its energy measure of size. In effect, the estimated contribution each establishment makes to total manufacturing energy consumption is its measure of size. Adjustment factors for nonresponse are calculated using the known energy measures of size of the respondents and the entire sample. ASM data provide this information. Each of the 61 sampling strata has a separate adjustment factor: 


$$
a_{s}=\frac{\sum_{j \in s}^{\text {Sample }} \operatorname{MOS}_{s, j}}{\sum_{i \in s}^{\text {Resp. }} \operatorname{MOS}_{s, i}}
$$

where $M O S_{s,}$ is the measure of size for MECS sample establishment $j$ in stratum $s$. In this formula, $M O S_{s, l}$ is the measure of size for MECS respondent $I$ in stratum $s$. The MOS is determined using ASM reported cost of fuels and electrical energy.

This nonresponse adjustment is important for interpreting aggregate statistics such as consumption and fuel-switching capability; however, it does not affect energy intensity measures, as shown in the next section.

\section{The Concept of Energy Intensity}

\section{Technical Approach}

Previous MECS energy intensity reports identified the change in energy intensity resulting from more or less OffsiteProduced Energy. This report also presents the changes in energy intensity caused by either increased or decreased use of energy sources produced at manufacturing establishments. In addition, this report includes changes in intensity that result from the changes in relative output by industries (i.e., structural shifts). As in previous reports, output is defined as the constant dollar value of shipments and receipts. These were expressed in terms of constant 1982 dollars for the previous reports. This report uses constant 1987 dollars.

Comparing ratios of the amount of energy consumed per a common unit of output over a specified period identifies trends. The MECS reports trends for the 2-digit SIC codes in question and the entire manufacturing sector. These demand ratios, traditionally termed energy intensities, take the general form of:

$I=\frac{E}{Q}$,

where $E$ denotes energy consumption, and $Q$ represents output. Subsets of the manufacturing sector (e.g., 2-digit SIC categories) and the entire manufacturing sector had separate measures of energy intensity calculated. This was done because each subset had a common unit for consumption and output.

With energy intensities available for two periods, the raw change in the demand for energy between base year, $b$, and the $n^{\text {th }}$ subsequent year, $b+n$ can be expressed as:

$$
\begin{aligned}
\Delta I_{b: b+n} & =\frac{E_{b}}{Q_{b}}-\frac{E_{b+n}}{Q_{b+n}} \\
& =I_{b}-I_{b+n} .
\end{aligned}
$$

To streamline the display of the change in aggregate energy intensities, $\Delta I_{b: b+n}$ is generally presented with respect to the base year's energy intensity. This is written as:

$$
\begin{aligned}
\% \Delta I_{b: b+n} & =\frac{I_{b}-I_{b+n}}{I_{b}} \cdot 100 \\
& =\left[1-\frac{I_{b+n}}{I_{b}}\right] \cdot 100 .
\end{aligned}
$$




\section{Evaluation of the Effects on Energy Demand}

The manufacturing sector continually evolves. Evidence of this is the growth of some industries while other industries become less important. Examples include the decline of wagon makers when automobiles became available. A more current example is the growth of the compact disc industry with the subsequent decline of the LP record and eight-track tape industries. This evolution requires that any analytical approach for measuring changes in energy demand take two factors into account: The approach must cleanly attribute the effect on energy demand associated with structural shifts, as well as the effect of real efficiency changes. This approach produces both an estimated value of real efficiency improvements as well as an estimate of variations in manufacturing composition (structural shifts). Currently, there are two predominant approaches used to disentangle aggregate changes in energy demand: the Divisia ${ }^{36}$ and the Laspeyres ${ }^{37}$ indices approaches. Several energy analysts-Jenna $e t ~ a l,{ }^{38} \mathrm{Marlay}_{,}{ }^{39} \mathrm{EIA}_{,}{ }^{40}$ and most recently, Howarth $e t$ a ${ }^{41}$ - have used the Divisia approach to separate real energy efficiencies from structural shifts. However, for this report, EIA applied the Laspeyres technique, favoring the Laspeyres' ease of interpretation. This approach cleanly decomposes the aggregate change in energy intensity into three effects: structural shifts, real efficiency changes, and an interaction of structural shifts and real efficiency changes. In contrast, the Divisia approach identifies only main effects. ${ }^{42}$ In addition, EIA and Howarth $e t a l^{43}$ have shown that Laspeyres and Divisia derived estimates of the decomposed effects are remarkably similar. EIA has also derived a measure of reliability for decomposed effects under the Laspeyres approach. ${ }^{44}$

This report uses the Laspeyres approach to decompose the aggregate change in energy intensities. The decomposition results in real efficiency changes, structural shifts, and the interaction of real efficiency changes and structural shifts. To accomplish this, rewrite the energy intensity ratio given in Equation (3) as:

$I=\frac{E}{Q}=\sum_{s \in S} \frac{E_{s}}{Q_{s}} \cdot \frac{Q_{s}}{\sum_{j \in S} Q_{j}}$.

where the subscript $j$ represents an industry group of subsector $S . E_{s}$ and $Q_{s}$ denote the energy consumption and output of the $s^{\text {th }}$ industry group belonging in subsector $S$. Substituting Equation (5) into Equation (3) yields:

$$
\begin{aligned}
\Delta I_{b: b+n} & =\sum_{s \in S} \frac{E_{b, s}}{Q_{b, s}} \cdot \frac{Q_{b, s}}{\sum_{j \in S} Q_{b j}}-\sum_{s \in S} \frac{E_{b+n, s}}{Q_{b+n, s}} \cdot \frac{Q_{b+n, s}}{\sum_{j \in S} Q_{b+n, j}} \\
& =I_{b}-I_{b+n} .
\end{aligned}
$$

The Laspeyres approach reapportions $I_{b+n}$ to reflect the production shares, by industry group, that existed during the base year $b$. This is to separate the effect of structural shifts observed in manufacturing output, as measured by the difference in production shares of industry groups belonging to subsector $S$. For this report, SIC codes were aggregated into 83 groups of three-digit industries or combinations of three-digit industry groups to provide estimates of energy consumption sufficiently accurate for analysis (See page 79 for details).

\footnotetext{
${ }^{36} \mathrm{~F}$. Divisia, "L'indice Monetaire et la theorie de la monnaie." Revue d'Economie Politique Vol. 39, 1925.

${ }^{37}$ Laspeyres index, which is a common energy economic tool, is a based year weighted index.

${ }^{38} \mathrm{Jenna}, \mathrm{C}$. and R. Cattell, (1983). "Structural Change and Energy Efficiency in Industry." Energy Economics 5(2):114-123.

${ }^{39}$ Marlay, R. (1984). "Trends in Industrial Use of Energy." Science 226:1277-1283.

${ }^{40}$ Energy Information Administration, Short-Term Energy Outlook, DOE/EIA-0202(90/1Q) (Washington, DC, February 1990).

${ }^{41}$ Howarth, R. B., L. Schipper, P. A. Duerr, and S. Strom. "Manufacturing energy use in eight OECD countries, Energy Economics. (April 1991)

${ }^{42}$ For additional information concerning attributes of the Laspeyres index, see Howarth, R. B. et al, Op. Cit. (1991). For additional details comparing the Divisia index and other methods, see Boyd G. A., D. A. Hanson, and T. Sterner (October 1988), "Decomposition of Changes in Energy Intensity: A comparison of the Divisia Index and Other Methods." Energy Economics, pp. 309-12.

${ }^{43}$ Howarth, R. B., L. Schipper, P. A. Duerr, and S. Strom, Op. Cit. (1991).

"French, D. and M. Schipper (1991), "Variance Estimator for a Standardized Measure of Efficiency Change." An unpublished technical note in the Manufacturing Energy Consumption Technical Note Series.
} 
With the effect of structural shifts removed, the adjusted energy intensity $\mathrm{I}^{(\mathrm{int})}{ }_{b+\mathrm{n}}$ is expressed as:

$$
\sum_{s \in S} \frac{E_{b+n, s}}{Q_{b+n, s}} \cdot \frac{Q_{b, s}}{\sum_{j \in S} Q_{b j}} .
$$

The "pure" change in energy demand related to improvements in energy efficiency is expressed as:

$$
\begin{aligned}
\Delta \mathrm{I}_{b: b+n}^{(\mathrm{int})} & =\sum_{s \in S} \frac{E_{b, s}}{Q_{b, s}} \cdot \frac{Q_{b, s}}{\sum_{j \in S} Q_{b j}}-\sum_{s \in S} \frac{E_{b+n, s}}{Q_{b+n, s}} \cdot \frac{Q_{b, s}}{\sum_{j \in S} Q_{b j}} \\
& =I_{b}-I_{b+n}^{(i n t)} .
\end{aligned}
$$

The "pure" changes in energy demand associated with structural (production) shifts are given by reflecting the energy intensities, by industry group, that existed during the base year, $b$. This change is expressed as:

$$
\begin{aligned}
\Delta I_{b: b+n}^{\text {(prod) }} & =\sum_{s \in S} \frac{E_{b, s}}{Q_{b, s}} \cdot \frac{Q_{b, s}}{\sum_{j \in S} Q_{b j}}-\sum_{s \in S} \frac{E_{b, s}}{Q_{b, s}} \cdot \frac{Q_{b+n, s}}{\sum_{j \in S} Q_{b+n j}} \\
& =I_{b}-I_{b+n}^{\text {(prod) }} \cdot \\
\% \Delta I_{b: b+n} & =\left[\frac{\Delta I_{b: b+n}^{\text {(int) }}}{I_{b}}+\frac{\Delta I_{b: b+n}^{\text {(prod) }}}{I_{b}}+\frac{\Delta I_{b: b+n}^{\text {(int prod) }}}{I_{b}}\right] \cdot 100 \\
& =\% \Delta I_{b: b+n}^{\text {(int) }}+\% \Delta_{b: b+n}^{\text {(prod) }}+\% \Delta_{b: b+n}^{\text {(int x prod) }} .
\end{aligned}
$$

\section{Measures of Energy Consumption}

The MECS consumption of energy reports include, among others, tables identifying four different measures of energy consumption. These include:

- Total Primary Consumption of Energy for all purposes

- Total Primary Consumption of Energy for nonfuel (feedstock) purposes

- Total Inputs of Energy for heat, power, and electricity

- Total consumption of Offsite-Produced Energy for heat, power, and electricity.

This report identifies two measures of energy intensity by selected SIC codes. The first measure is Offsite-Produced Energy for heat, power, and electricity per constant 1987 dollar of products shipped. The second measure of intensity is Total Inputs of Energy for heat, power, and electricity per constant 1987 dollar of products shipped. 
For each SIC, the difference between the quantities reported as Total Inputs of Energy for heat, power, and electricity and the quantities reported as Offsite-Produced Energy consumed for those same purposes indicates the amount of energy produced and then consumed onsite. Comparing changes in energy intensity based on these two measures indicates the effect of Onsite-Produced Energy sources on intensity changes. Any difference between intensities based on the two measures would imply the increased (decreased) use of Onsite Produced Energy.

Energy efficiency cannot be inferred directly from changes in energy-intensity ratios. While improved energy efficiency does indicate reduced energy intensity, it is also true that a change in energy intensity can result from factors unrelated to energy efficiency. Energy produced onsite and structural shifts in production mix are two of those factors.

\section{Measures of Output}

In order to calculate an industry's change in energy intensity, it is necessary to have some measure of output to compare with energy consumption. Since the outputs of manufacturing establishments are physical units, these might appear to be the most appropriate measure. However, one major problem with using a physical measure of output is that it cannot be standardized within an industry or across industries. A single manufacturing establishment or industry may produce a wide variety of end products. These products would have to be aggregated to calculate the change in intensity. In SIC 22 (Textiles), for example, adding the quantity of cheesecloth produced in SIC 2211 to the quantity of fabric produced in SIC 2221 would not yield any meaningful measure of output. This difficulty with using a physical measure of output encourages the use of an economic measure as a proxy. The Census Bureau collects data on the value of shipments and receipts of manufacturers as well as the value added by manufactures. Because the MECS sample is drawn from the list of establishments covered by the CM and ASM, these economic data are available for establishments that respond to the MECS.

If the goal were to calculate the total output of the entire manufacturing sector, value added would be the appropriate economic measure to use. This measure represents the unique contribution of a manufacturer to the production of a finished good. Calculation of value added requires subtracting the cost of all materials from the value of shipments. This is then added to the net change in finished goods and work in progress inventory. Basically, value added consists of wages and employee supplements, net interest, indirect business taxes and adjustments, and income or corporate profits. $^{45}$

Value of shipments and receipts consists of the total receipts for products manufactured, services rendered, and the resales of products bought and sold without further manufacture. It is the dollar value received by the manufacture for the products it sells. For any industry group, this measure contains a large amount of duplication since the product outputs of one industry may be used as raw material inputs by others. For example, a manufacturer of copper wire may sell that wire to another manufacturer that builds electric motors. The electric motor manufacturer may, in turn, sell electric motors to a manufacturer that assembles refrigerators. Thus, the cost of the copper wire, which originated with the first manufacturer, appears in the value of shipments for all three. Summing the values of shipments for these three manufacturers would contain duplication of the cost of the copper wire. Because of this duplication, total manufacturing sector output is not the summation of individual industry groups' value of shipments. For the same reason, it is not accurate to compare changes in intensity across SIC codes but only between a single SIC grouping or the entire manufacturing sector.

The duplication inherent in the value of shipments measure is not an important consideration when calculating changes in intensity. The purpose is not to compare the efficiency ratios between industries, but rather, to compare energy consumption per unit of output at different points in time for each industry group. In most cases, whatever duplication existed in the base year will also be present in the comparison years. Value added as a percent of the value of shipments in this case is approximately equal for the base and comparison years. If industry groups have perfectly stable proportions of value added to value of shipments, the same estimate of energy intensity change will result regardless of whether the base is the value of shipments or value added.

\footnotetext{
${ }^{45}$ For more details on the value of shipments and value added, see U.S. Department of Commerce, Bureau of the Census, 1985 Annual Survey of Manufactures, "Statistics for Industry Groups and Industries," M85(AS)1 (Washington, DC, January 1987), Appendix A.
} 
If value added as a proportion of value of shipments differs between the base and comparison years, constant dollar value of shipments more closely approximates physical production than does constant dollar value added, according to previous studies. ${ }^{46}$ For this reason, the proxy measure of output for calculating energy intensity ratios included in this report is constant dollar value of shipments. This surrogate for physical output is fully consistent with the procedures adopted by other Federal agencies for estimating output. The Bureau of Labor Statistics (BLS) publishes a productivity measure known as "output per employee hour." Dividing an output index by an index of aggregate employee hours for a given industry produces this index. According to the BLS,

"...industry output indexes are based on quantifiable units of products or services of the industry.... Whenever possible, physical quantities are used as the unit of measurement. For those industries lacking quantity data, constant-dollar value of shipments, sales, or revenue data are used to develop the output series. ${ }^{47}$

This report investigates structural shifts as one reason energy intensity may have changed between the years in question. Calculation of these shifts was done at the lowest possible level (four-digit, then three-digit, then two-digit SIC). The sample size for the 1985 and 1988 MECS surveys was relatively small. Because of this, it was not possible to provide energy consumption estimates for any but the 10 largest four-digit industries. In addition, the samples were too small to produce accurate estimates of energy consumption for all of the three-digit industries. Letting both structural and intensity vary does not lend any additional significant interpretations. This interaction can be algebraically expressed as:

$$
\begin{aligned}
\Delta I_{b: b+n}^{\text {(prodxint) }} & =-\sum_{s \in S}\left[\left(\frac{E_{b, s}}{Q_{b, s}}-\frac{E_{b+n, s}}{Q_{b+n, s}}\right) \cdot\left(\frac{Q_{b, s}}{\sum_{j \in S} Q_{b j}}-\frac{Q_{b+n, s}}{\sum_{j \in S} Q_{b+n, j}}\right)\right] \\
& =-I_{b}+I_{b+n}^{\text {(int) }}+I_{b+n}^{\text {(prod) }}-I_{b+n} .
\end{aligned}
$$

The change in aggregate energy demand is now written as:

$$
\Delta \mathrm{I}_{\mathrm{b}: \mathrm{b}+\mathrm{n}}=\Delta \mathrm{I}_{\mathrm{b}: \mathrm{b}+\mathrm{n}}^{(\mathrm{int})}+\Delta \mathrm{I}_{\mathrm{b}: \mathrm{b}+\mathrm{n}}^{(\mathrm{prod})}+\Delta \mathrm{I}_{\mathrm{b}: \mathrm{b}+\mathrm{n}}^{\text {(int prod) }}
$$

With respect to the base year energy intensity, the percentage change of energy demand for each effect is expressed as:

$$
\begin{aligned}
\% \Delta I_{b: b+n} & =\left[\frac{\Delta I_{b: b+n}^{(i n t)}}{I_{b}}+\frac{\Delta I_{b: b+n}^{(\text {prod })}}{I_{b}}+\frac{\Delta I_{b: b+n}^{(\text {intx prod) }}}{I_{b}}\right] \cdot 100 \\
& =\% \Delta I_{b: b+n}^{(\text {int) }}+\% \Delta_{b: b+n}^{(\text {prod) }}+\% \Delta_{b: b+n}^{\text {(int x prod) }} .
\end{aligned}
$$

For this report, SICs were aggregated into 83 groups of three-digit industries or combinations of three-digit industry groups to provide estimates of energy consumption sufficiently accurate for analysis. The change in intensity for the entire manufacturing sector is adjusted based on the shipments-weighted contributions of these groups. For each of the two-digit major industry groups, changes in energy intensity are adjusted based on the shipments-weighted contributions of the 3-digit industries included in that major group.

\footnotetext{
${ }^{46} \mathrm{Appendix} \mathrm{C}$ of the Changes in Energy Intensity in the Manufacturing Sector 1980-1988, DOE/EIA-0552(80-88) (Washington, DC, December 1991), discusses a study performed to determine whether value added or value of shipments most closely mirrors physical output when value added is variable relative to value of shipments.

${ }^{47}$ U.S, Department of Labor, Bureau of Labor Statistics, BLS Handbook of Methods, Volume I, Bulletin 2134-1 (Washington DC, December 1983), p. 103.
} 

Appendix B

Quality of the Data 


\section{Appendix B}

\section{Quality of the Data}

\section{Introduction}

All data collection activities and the estimates produced from them are subject to a variety of errors. The two general types of errors are sampling and nonsampling errors.

Sampling error is the variability in a survey estimator that occurs because data are collected from a sample of units rather than from the entire population. A different estimate of population parameters is possible from each potential sample. Nonsampling errors are those associated with all aspects of the total survey design other than the sampling process. Nonsampling errors can include both random and systematic (biasing) errors. Commonly recognized sources of nonsampling error include undercoverage, random and systematic response errors, nonresponse, data processing errors, and tabulation errors. This appendix describes the effect of both sampling and nonsampling errors on the estimates of energy intensity change.

\section{Sampling Error}

Gathering data from samples of the population (survey) rather than the entire population (census) results in estimates that differ from true population estimates. The MECS is a survey, and as such, provides only one of a possible number of estimates. Estimates from other samples would differ depending on which establishments are in each sample.

One measure of the variability in estimates due to sampling is the average squared differences between the estimates by all possible samples and the mean value of those estimates. This type of measure is known as sampling error, and identifies the magnitude of sampling error. A single sample provides data to obtain the standard error of an estimate.

Tables B 1-B6 of this appendix present standard errors computed for the estimated energy efficiency changes. Using pre-existing data, the estimates are calculated as relative standard errors (RSE's), and converted to standard errors.

\section{Computation of Relative Standard Errors}

The relative variances and covariences of energy consumption are the primary information required for the development of RSE's. The constant dollar value of shipments and estimated change in energy intensity are additional information used in the calculations. To calculate RSE's, the standard error is multiplied by 100 , then divided by the estimate to which it refers. Approximate RSE's are computed using a specially-derived formula. The following paragraphs describe the derivation of the formula.

Ignoring the multiplier of 100 , the change in energy efficiency for an industry group given in Equation (4) of Appendix $A$ is:

$\Delta I_{s, b: t}=\left(1-\frac{I_{s, t}}{I_{s, b}}\right)$.

The object is to derive an approximate RSE for the change in energy intensity. The derivation begins:

$R S E\left(\Delta I_{b: b+n}\right)=R S E\left(1-\frac{I_{b+n}}{I_{b}}\right)=\sqrt{R S E^{2}\left(1-\frac{I_{b+n}}{I_{b}}\right)}$ 
where $\mathrm{RSE}^{2}$ is the relative variance, or rel-variance. By definition of the rel-variance,

$\operatorname{RSE}\left(\Delta I_{b: b+n}\right)=100 \sqrt{\frac{V A R\left(1-\frac{I_{b+n}}{I_{b}}\right)}{\Delta I_{b: b+n}^{2}}}$.

Equation (16) can be restated as:

$\operatorname{RSE}\left(\Delta I_{b: b+n}\right)=100 \sqrt{\frac{V \bar{A} R(1)+V A R\left(\frac{I_{b+n}}{I_{b}}\right)-2 \operatorname{COV}\left(1, \frac{I_{b+n}}{I_{b}}\right)}{\Delta l_{b: b+n}^{2}}}$

Since the variance of a constant and the covariance of a constant and a variable are equal to zero, Equation (17) reduces to:

$R S E\left(\Delta I_{b: b+n}\right)=100 \sqrt{\frac{V A R\left(\frac{I_{b+n}}{I_{b}}\right)}{\Delta I_{b: b+n}^{2}}}$

Expressing Equation (16) in terms of the rel-variance,

$R S E\left(\Delta I_{s, b: t}\right)=100 \sqrt{\frac{R S E^{2}\left(\frac{I_{s, t}}{I_{s, b}}\right) \times\left(\frac{I_{s, t}}{I_{s, b}}\right)^{2}}{\Delta I_{s, b: t}^{2}}}$

By Hansen, Hurwitz, and Madlow, ${ }^{48}$ the rel-variance of a ratio can be approximated using the rel-variances and the relcovariance of the components. Applying the approximation of Hansen et al., Equation (19) becomes:

$\operatorname{RSE}\left(\Delta I_{b: b+n}\right)=100 \sqrt{\frac{\left[\operatorname{RSE}^{2}\left(I_{b+n}\right)+R S E^{2}\left(I_{b}\right)-2 \operatorname{RELCOV}\left(I_{b+n}, I_{b}\right)\right] x\left[\frac{I_{b+n}}{I_{b}}\right]^{2}}{\Delta l_{b: b+n}^{2}}}$

Sample selections for the 1991, 1988, and 1985 MECS are independent of sample selection for the 1991 ASM. Because of this, the relative covariance in Equation (20) between the two ratios is assumed to be zero. Equation (18) reduces to: 
$R S E\left(\Delta I_{b: b+n}\right) \doteq 100 \sqrt{\frac{\left[R S E^{2}\left(I_{b+n}\right)+R S E^{2}\left(I_{b}\right)\right] x\left[\frac{I_{b+n}}{I_{b}}\right]^{2}}{\Delta I_{b: b+n}^{2}}}$

The two rel-variances in Equation (21) are the rel-variances of the energy intensity ratios for any industry group $s$ in periods $b$ and $b+n$ (b may equal 85 or 88). The approximation of Hansen et al. is used again. The rel-variances in Equation (19) may be approximated as:

$\operatorname{RSE}^{2}\left(I_{b+n}\right) \doteq \operatorname{RSE}^{2}\left(E_{b+n}\right)+\operatorname{RSE}^{2}\left(Q_{b+n}\right)-2 \operatorname{RELCOV}\left(E_{b+n}, Q_{b+n}\right)$

and,

$\operatorname{RSE}^{2}\left(I_{b}\right) \doteq \operatorname{RSE}^{2}\left(E_{b}\right)+\operatorname{RSE}^{2}\left(Q_{b}\right)-2 \operatorname{RELCOV}\left(E_{b}, Q_{b}\right)$

The 1985, 1988, and 1991 MECS provides the components of these rel-variances, as well as information provided by the Census Bureau. Estimates of the rel-variances are substituted into Equation (21) to derive the RSE's of the estimated changes in energy intensity. Standard errors for Tables B1-B6 are calculated by dividing these RSE's by 100 and multiplying by the corresporiding estimate of intensity change. 
Table B1. Relative Standard Errors for Primary Energy Intensity of Offsite-Produced Energy in Major Manufacturing Groups, 1985, 1988, and 1991 (Estimates in Percent)

\begin{tabular}{|c|c|c|c|c|}
\hline \multirow{2}{*}{$\begin{array}{l}\text { SIC } \\
\text { Code }\end{array}$} & \multirow[b]{2}{*}{ Major Group } & \multicolumn{3}{|c|}{ Energy-Intensity Ratios } \\
\hline & & 1985 & 1988 & 1991 \\
\hline 20 & Food and Kindred Products & 7 & 3 & 3 \\
\hline 21 & $\ldots \ldots \ldots \ldots \ldots \ldots \ldots \ldots \ldots \ldots \ldots$ & NA & NA & NA \\
\hline 22 & Textile Mill Products & 3 & 2 & 2 \\
\hline 23 & Apparel and Other Textile Products & NA & NA & NA \\
\hline 24 & Lumber and Wood Products & NA & NA & NA \\
\hline 25 & n...................... & 4 & 4 & 4 \\
\hline 26 & Paper and Allied Products & 5 & 6 & 3 \\
\hline 27 & Printing and Publishing & NA & NA & NA \\
\hline 28 & Chemicals and Allied Products & 5 & 6 & 4 \\
\hline 29 & Petroleum and Coal Products & 1 & 2 & 2 \\
\hline 30 & Rubber and Misc. Plastic Products & 5 & 5 & 5 \\
\hline 31 & Leather and Leather Products & NA & NA & NA \\
\hline 32 & Stone, Clay, and Glass Products & 7 & 6 & 5 \\
\hline 33 & Primary Metal Industries & 3 & 4 & 2 \\
\hline 34 & Fabricated Metal Products & 6 & 5 & 1 \\
\hline 35 & Industrial Machinery and Equipment & 4 & 4 & 2 \\
\hline 36 & Electronic and Other Electric Equipment & 2 & 3 & 6 \\
\hline 37 & Transportation Equipment & 1 & 1 & 1 \\
\hline 38 & Instruments and Related Products & 3 & 2 & 3 \\
\hline \multirow[t]{2}{*}{39} & Misc. Manufacturing Industries & 4 & 1 & 3 \\
\hline & Total $\ldots \ldots \ldots \ldots \ldots \ldots \ldots \ldots \ldots \ldots \ldots$ & 2 & 2 & 1 \\
\hline
\end{tabular}

$N A=$ Not available. Data are included in higher-level totals.

Source: Energy Information Administration, Manufacturing Consumption of Energy 1991, DOE/EIA-0512(91), Washington, DC, 1994, Manufacturing Energy Consumption Survey: Consumption of Energy, 1988, DOE/EIA-0512(88), Washington, DC, 1991, and Manufacturing Energy Consumption Survey: Consumption of Energy, 1985, DOE/EIA-0512(85), Washington, DC, 1988. 
Table B2. Relative Standard Errors for Primary Energy Intensity of Total Inputs of Energy in Major Manufacturing Groups, 1985, 1988, and 1991 (Estimates in Percent)

\begin{tabular}{|c|c|c|c|c|}
\hline \multirow{2}{*}{$\begin{array}{l}\text { SIC } \\
\text { Code }\end{array}$} & \multirow[b]{2}{*}{ Major Group } & \multicolumn{3}{|c|}{ Energy-Intensity Ratios } \\
\hline & & 1985 & 1988 & 1991 \\
\hline 20 & $\ldots \ldots \ldots \ldots \ldots \ldots \ldots \ldots$ & 8 & 4 & 4 \\
\hline 21 & $\ldots \ldots \ldots \ldots \ldots \ldots \ldots \ldots \ldots \ldots \ldots \ldots \ldots \ldots \ldots \ldots$ & NA & NA & NA \\
\hline 22 & Textlle Mill Products & 3 & 4 & 3 \\
\hline 23 & Apparel and Other Textile Products & NA & NA & NA \\
\hline 24 & Lumber and Wood Products & NA & NA & NA \\
\hline 25 & Fumiture and Fixtures & 8 & 6 & 11 \\
\hline 26 & Paper and Allied Products & 6 & 6 & 3 \\
\hline 27 & Printing and Publishing & NA & NA & NA \\
\hline 28 & Chemicals and Allied Products & 5 & 6 & 4 \\
\hline 29 & Petroleum and Coal Products & 1 & 2 & 2 \\
\hline 30 & Rubber and Misc. Plastic Products & 3 & 3 & 3 \\
\hline 31 & Leather and Leather Products & NA & NA & NA \\
\hline 32 & Stone, Clay, and Glass Products & 7 & 6 & 5 \\
\hline 33 & Primary Metal Industries & 4 & 5 & 3 \\
\hline 34 & Fabricated Metal Products & 6 & 6 & 3 \\
\hline 35 & Industrial Machinery and Equipment & 4 & 6 & 3 \\
\hline 36 & Electronic and Other Electric Equipment & 2 & 5 & 7 \\
\hline 37 & Transportation Equipment & 3 & 3 & 2 \\
\hline 38 & Instruments and Related Products & 3 & 6 & 4 \\
\hline \multirow[t]{2}{*}{39} & Mlsc. Manufacturing Industries & 5 & 6 & 5 \\
\hline & Total $\ldots \ldots \ldots \ldots \ldots \ldots \ldots \ldots \ldots \ldots \ldots$ & 2 & 2 & 2 \\
\hline
\end{tabular}

$\mathrm{NA}=$ Not available. Data are included in higher-level totals.

Source: Energy information Administration, Manufacturing Consumption of Energy 1991, DOE/EIA-0512(91), Washington, DC, 1994, Manufacturing Energy Consumption Survey: Consumption of Energy, 1988, DOE/EIA-0512(88), Washington, DC, 1991, and Manufacturing Energy Consumption Survey: Consumption of Energy, 1985, DOE/EIA-0512(85), Washington, DC, 1988. 
Table B3. Relative Standard Errors for Site Energy Intensity of Offsite-Produced Energy in Major Manufacturing Groups and Selected Industries, 1985, 1988, and 1991 (Estimates in Percent)

\begin{tabular}{|c|c|c|c|c|}
\hline \multirow[b]{2}{*}{ SIC Code } & \multirow[b]{2}{*}{ Major Group and Industry } & \multicolumn{3}{|c|}{ Energy-Intensity Ratios } \\
\hline & & 1985 & 1988 & 1991 \\
\hline 20 & Food and Kindred Products ......... & 8 & 4 & 4 \\
\hline 21 & Tobacco Products...$\ldots \ldots \ldots$. & NA & NA & NA \\
\hline 22 & Textile Mill Products $\ldots \ldots \ldots \ldots \ldots \ldots \ldots \ldots \ldots \ldots \ldots \ldots$ & 4 & 4 & 3 \\
\hline 23 & Apparel and Other Textile Products $\ldots \ldots \ldots \ldots \ldots \ldots \ldots$ & NA & NA & NA \\
\hline 24 & Lumber and Wood Products ......... & NA & NA & NA \\
\hline 25 & Fumiture and Fixtures $\ldots \ldots \ldots \ldots \ldots \ldots \ldots \ldots \ldots \ldots \ldots \ldots \ldots \ldots \ldots \ldots \ldots$ & 5 & 6 & 7 \\
\hline 26 & Paper and Allied Products $\ldots \ldots \ldots \ldots \ldots \ldots \ldots \ldots \ldots \ldots \ldots$ & 6 & 6 & 3 \\
\hline 27 & Printing and Publishing $\ldots \ldots \ldots$ & NA & NA & NA \\
\hline 28 & Chemicals and Allied Products . & 5 & 6 & 4 \\
\hline 29 & Petroleum and Coal Products ...... & 3 & 2 & 2 \\
\hline 30 & Rubber and Mlsc. Plastic Products .. & 3 & 4 & 3 \\
\hline 31 & Leather and Leather Products . ........... & NA & NA & NA \\
\hline 32 & 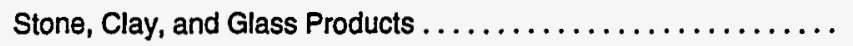 & 7 & 6 & 6 \\
\hline 33 & Primary Metal Industries $\ldots \ldots \ldots \ldots$ & 4 & 5 & 2 \\
\hline 34 & Fabricated Metal Products.$\ldots \ldots \ldots \ldots \ldots \ldots \ldots \ldots \ldots \ldots \ldots \ldots \ldots$ & 7 & 6 & 4 \\
\hline 35 & Industrial Machinery and Equipment $\ldots \ldots \ldots \ldots \ldots \ldots \ldots$ & 5 & 7 & 4 \\
\hline 36 & Electronic and Other Electric Equipment & 4 & 5 & 7 \\
\hline 37 & Transportation Equipment $\ldots \ldots \ldots \ldots \ldots \ldots \ldots \ldots \ldots$ & 2 & 3 & 2 \\
\hline 38 & Instruments and Related Products $\ldots \ldots \ldots \ldots \ldots \ldots$ & 7 & 9 & 7 \\
\hline \multirow[t]{2}{*}{39} & Misc. Manufacturing Industries $\ldots \ldots \ldots \ldots \ldots \ldots \ldots$ & 7 & 7 & 6 \\
\hline & 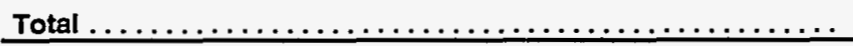 & 2 & 2 & 2 \\
\hline
\end{tabular}

$\mathrm{NA}=$ Not available. Data are included in higher-level totals.

Source: Energy Information Administration, Manufacturing Consumption of Energy 1991, DOE/EIA-0512(91), Washington, DC, 1994, Manufacturing Energy Consumption Survey: Consumption of Energy, 1988, DOE/EIA-0512(88), Washington, DC, 1991, and Manufacturing Energy Consumption Survey: Consumption of Energy, 1985, DOE/EIA-0512(85), Washington, DC, 1988. 
Table B4. Relative Standard Errors for Site Energy Intensity of Total Inputs of Energy in Major Manufacturing Groups and Selected Industries, 1985, 1988, and 1991 (Estimates in Percent)

\begin{tabular}{|c|c|c|c|c|}
\hline \multirow[b]{2}{*}{ SIC Code } & \multirow[b]{2}{*}{ Major Group and Industry } & \multicolumn{3}{|c|}{ Energy-Intensity Ratios } \\
\hline & & 1985 & 1988 & 1991 \\
\hline 20 & Food and Kindred Products $\ldots \ldots \ldots \ldots \ldots \ldots \ldots \ldots$ & 8 & 5 & 4 \\
\hline 21 & Tobacco Products $\ldots \ldots \ldots \ldots \ldots \ldots \ldots \ldots \ldots \ldots$ & NA & NA & NA \\
\hline 22 & Textile Mill Products $\ldots \ldots \ldots \ldots \ldots \ldots \ldots \ldots \ldots \ldots$ & 4 & 4 & 3 \\
\hline 23 & Apparel and Other Textile Products $\ldots \ldots \ldots \ldots \ldots \ldots$ & NA & NA & NA \\
\hline 24 & Lumber and Wood Products $\ldots \ldots \ldots \ldots \ldots \ldots \ldots$ & NA & NA & NA \\
\hline 25 & Furniture and Fixtures $\ldots \ldots \ldots \ldots \ldots \ldots \ldots \ldots \ldots \ldots$ & 6 & 6 & 15 \\
\hline 26 & Paper and Allied Products $\ldots \ldots \ldots \ldots \ldots \ldots \ldots \ldots$ & 6 & 6 & 3 \\
\hline 27 & Printing and Publishing $\ldots \ldots \ldots \ldots \ldots \ldots \ldots \ldots$ & NA & NA & NA \\
\hline 28 & Chemicals and Allied Products $\ldots \ldots \ldots \ldots \ldots \ldots \ldots$ & 5 & 6 & 4 \\
\hline 29 & Petroleum and Coal Products $\ldots \ldots \ldots \ldots \ldots \ldots \ldots$ & 2 & 2 & 2 \\
\hline 30 & Rubber and Misc. Plastic Products $\ldots \ldots \ldots \ldots \ldots \ldots$ & 3 & 4 & 4 \\
\hline 31 & Leather and Leather Products $\ldots \ldots \ldots \ldots \ldots \ldots \ldots$ & NA & NA & NA \\
\hline 32 & Stone, Clay, and Glass Products $\ldots \ldots \ldots \ldots \ldots \ldots \ldots$ & 7 & 6 & 6 \\
\hline 33 & Primary Metal Industries $\ldots \ldots \ldots \ldots$. & 4 & 5 & 3 \\
\hline 34 & Fabricated Metal Products . . . . . . . . . . . . & 7 & 6 & 4 \\
\hline 35 & Industrial Machinery and Equipment $\ldots \ldots \ldots \ldots \ldots \ldots$ & 5 & 7 & 4 \\
\hline 36 & Electronic and Other Electric Equipment & 4 & 5 & 7 \\
\hline 37 & Transportation Equipment $\ldots \ldots \ldots \ldots \ldots \ldots \ldots$ & 2 & 3 & 2 \\
\hline 38 & Instruments and Related Products $\ldots \ldots \ldots \ldots \ldots \ldots \ldots$ & 7 & 9 & 7 \\
\hline \multirow[t]{2}{*}{39} & Misc. Manufacturing Industries . . . . . . . . . . . . . . . & 9 & 8 & 6 \\
\hline & Total $\ldots \ldots \ldots \ldots \ldots \ldots \ldots \ldots \ldots \ldots \ldots \ldots \ldots$ & 2 & 2 & 2 \\
\hline
\end{tabular}

$N A=$ Not avallable. Data are included in higher-level totals.

Source: Energy information Administration, Manufacturing Consumption of Energy 1991, DOE/EIA-0512(91), Washington, DC, 1994, Manufacturing Energy Consumption Survey: Consumption of Energy, 1988, DOE/EIA-0512(88), Washington, DC, 1991, and Manufacturing Energy Consumption Survey: Consumption of Energy, 1985, DOE/EIA-0512(85), Washington, DC, 1988. 
Table B5. Relative Standard Errors for Site Energy Intensity of Offsite-Produced Energy (Structurally Adiusted) in Maior Manufacturing Groups, 1985, 1988, and 1991 (Estimates in Percent)

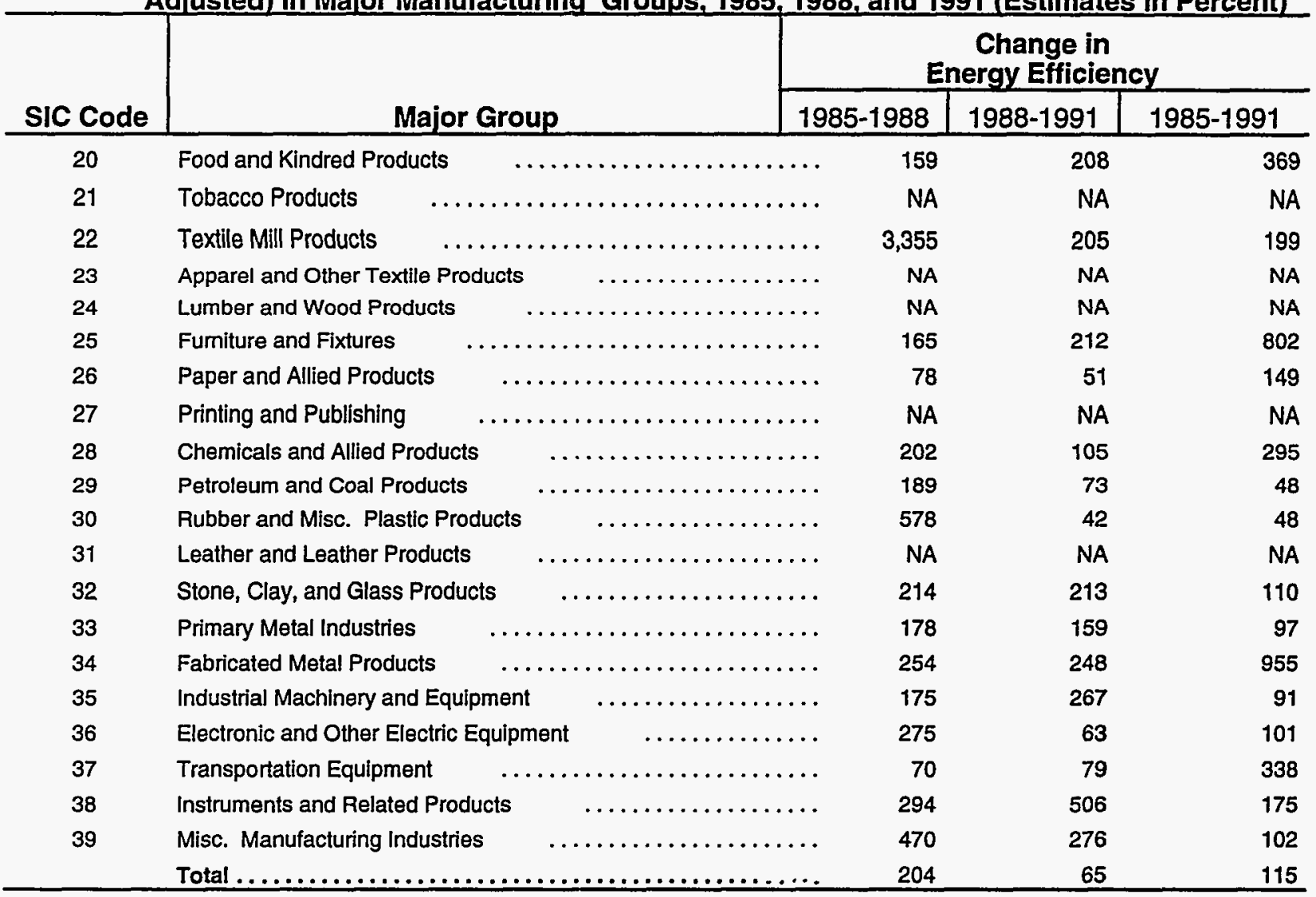

$N A=$ Not available. Data are included in higher-level totals.

Source: Energy Information Administration, Manufacturing Consumption of Energy 1991, DOE/EIA-0512(91), Washington, DC, 1994, Manufacturing Energy Consumption Survey: Consumption of Energy, 1988, DOE/EIA-0512(88), Washington, DC, 1991, and Manufacturing Energy Consumption Survey: Consumption of Energy, 1985, DOE/EIA-0512(85), Washington, DC, 1988. 
Table B6. Relative Standard Errors for Site Energy Intensity of Total Inputs of Energy (Structurally Adiusted) in Major Manufacturing Groups, 1985, 1988, and 1991 (Estimates in Percent)

\begin{tabular}{|c|c|c|c|c|}
\hline \multirow[b]{2}{*}{ SIC Code } & \multirow[b]{2}{*}{ Major Group } & \multicolumn{3}{|c|}{$\begin{array}{c}\text { Change in } \\
\text { Energy Efficiency }\end{array}$} \\
\hline & & $1985-1988$ & $1988-1991$ & 1985-1991 \\
\hline 20 & Food and Kindred Products & 245 & 302 & 1,243 \\
\hline 21 & Tobacco Products & NA & NA & NA \\
\hline 22 & Textile Mill Products & 3,448 & 204 & 183 \\
\hline 23 & Apparel and Other Textile Products & $\cdots$ & NA & NA \\
\hline 24 & Lumber and Wood Products & NA & NA & NA \\
\hline 25 & Furniture and Fixtures & 151 & 100 & 82 \\
\hline 26 & Paper and Allied Products & 89 & 72 & 237 \\
\hline 27 & Printing and Publishing & NA & NA & NA \\
\hline 28 & Chemicals and Allied Products & 186 & 150 & 186 \\
\hline 29 & Petroleum and Coal Products & ... & 76 & 49 \\
\hline 30 & Rubber and Misc. Plastic Products & 553 & 58 & 51 \\
\hline 31 & Leather and Leather Products & NA & NA & NA \\
\hline 32 & Stone, Clay, and Glass Products & 289 & 167 & 112 \\
\hline 33 & Primary Metal Industries & ... & 98 & 43 \\
\hline 34 & Fabricated Metal Products & 266 & 270 & 1,431 \\
\hline 35 & Industrial Machinery and Equipment & 174 & 190 & 95 \\
\hline 36 & Electronic and Other Electric Equipment & 250 & 69 & 102 \\
\hline 37 & Transportation Equipment & 82 & 57 & 86 \\
\hline 38 & Instruments and Related Products & 439 & 250 & 214 \\
\hline 39 & Misc. Manufacturing Industries & 211 & 121 & 94 \\
\hline & Total $\ldots \ldots \ldots \ldots \ldots \ldots \ldots$ & 254 & 108 & 172 \\
\hline
\end{tabular}

$N A=$ Not available. Data are included in higher-level totals.

Source: Energy Information Administration, Manufacturing Consumption of Energy 1991, DOE/EIA-0512(91), Washington, DC, 1994, Manufacturing Energy Consumption Survey: Consumption of Energy, 1988, DOE/EIA-0512(88), Washington, DC, 1991, and Manufacturing Energy Consumption Survey: Consumption of Energy, 1985, DOE/EIA-0512(85), Washington, DC, 1988. 


\section{Nonsampling Errors and Bias}

Nonsampling errors are not associated with obtaining data through a sample rather than a complete census. These errors can occur in any data gathering activity and fall into four general categories:

- Operational Errors include errors that result from inaccurate editing, coding and/or tabulating data.

- Errors of Measurement or respondent errors result from problems such as misunderstanding instructions or lack of precision in providing data.

- Estimation Errors are caused by inaccurate or incomplete assumptions underlying the values of the survey estimator.

- Errors of Nonobservation result from nonresponse or incomplete coverage.

\section{Minimizing Errors}

MECS uses several methods to ensure accurate estimates. These include:

- Data collection by the Census Bureau that minimizes the likelihood of operational errors. The quality control procedures carried out at each step of data check-in, editing, coding, and keying are standard Census Bureau procedures. These are the same procedures used for the ASM and the CM.

- Verification of data tabulations including comparing marginal totals in tables generated from files supplied to EIA with corresponding totals generated directly from microdata files held at the Census Bureau.

- Computer edits to identify measurement errors. These edits check both internal consistency as well as data consistency between MECS responses and ASM responses for the same establishment. An industry specialist reviews any response that fails an edit. This specialist is familiar with the manufacturing processes used by, and associated energy consumption of, the SIC in question. When necessary, the specialist contacts the individual(s) responsible for completing the questionnaire to verify questionable responses or provide data for any nonresponse items.

No editing procedure can identify all measurement errors, and it is reasonable to assume some small errors are not corrected. To the extent these errors are due to random rather than systematic misreporting, they are compensating in the aggregate totals calculated. Very few large systematic biases for the MECS result from unidentified measurement errors.

Estimation errors can result from any of the assumptions used to estimate the consumption of Offsite-Produced Energy or Total Inputs of Energy consumed for heat, power, or electricity generation. These are the two measures of consumption used in calculating the changes in energy intensity included in this report. Both Offsite-Produced Energy and Total Inputs of Energy are derived measures of consumption rather than reported values. They are both based on two primary assumptions:

- An establishment consumes all energy produced onsite.

- Offsite-Produced Energy is consumed onsite only if there is insufficient onsite production to meet the establishment's need for that particular energy source. The second assumption is that consumption of onsiteproduced energy sources will meet raw material or feedstock requirements first, with any remaining quantities consumed as a fuel. 
It is believed these assumptions accurately reflect the energy-use patterns of the most manufacturing establishments. Consumption estimates will be biased if the above assumptions are incorrect. For example, one assumption is that energy produced onsite meets feedstock requirements before fuel requirements. This could result in consistently underestimating the consumption of offsite-produced feedstocks and overestimating the consumption of offsite-produced fuels. If this were the case, an overestimation of the energy intensity ratios is the result.

If derived values are calculated using a consistent methodology from one survey cycle to the next, any bias due to estimation errors will be present to approximately the same degree in both cycles. Because the primary focus of this report is the change in energy intensity ratios from one period to another, persistent bias would eliminate itself. As such, it is believed that bias in the changes in energy intensity due to estimation errors is minimal.

Appendix A describes the MECS survey and explains that portion of the manufacturing sector it represents (i.e., the mail portion of the 1991 ASM). For this report, adjusted consumption values represent those three-digit industry groups, or combinations of three-digit industry groups, judged sufficiently accurate for the purposes of this analysis. Noncoverage errors could result from the procedures used to define these groups. Adjustments are made to account for nonresponses. These involve a ratio adjustment of the weighted data for respondents. Small establishments tend to have the highest nonresponse rate to the MECS. Because of this, the adjustment primarily affects the contribution of relatively small establishments. Without this adjustment, the MECS estimators produced from only the responding establishments would not have represented the target universe. Unadjusted estimators would also result in biased survey estimates. 
Appendix C

\author{
MECS Coverage \\ Related to EIA \\ Supplier Surveys
}





\section{Appendix C}

\section{MECS Coverage Related to EIA Supplier Surveys}

In addition to the MECS, the EIA also conducts a number of supplier surveys. These surveys are directed to the suppliers and marketers of specific energy sources. The purpose of these surveys is to provide estimates of the amounts of energy available for consumption. The EIA publishes results of these surveys in several energy-specific publications, as well as the Monthly Energy Review (MER). The MER identifies the quantities of each energy source available. It also identifies how much of each energy source is supplied to the various sectors (e.g., residential and commercial, industrial, and transportation). It is important to remember differences between the supply surveys and the MECS when using data from the two survey systems.

\section{Differences in Survey Systems}

- The MECS and supply surveys do not have the same coverage. The MECS addresses energy consumption by manufacturing establishments. These make up only part of the industrial sector. Supply surveys provide estimates for the total industrial sector. In addition to manufacturing (SIC codes 20 through 39), this includes agriculture, forestry, fishing, hunting and trapping, mining, and construction (SIC codes 01 through 17).

- The MECS is an establishment-based survey directed specifically to manufacturers. The supply surveys obtain data on deliveries to different customer categories. The determination of which category a customer falls into may be based on some threshold delivery quantity rather than the economic activity of that customer. Supply surveys obtain consumption information from utilities rather than from the individual consumers.

- Estimates of energy intensity are based on MECS measures of Offsite-Produced and Total Inputs of Energy consumed for heat, power, and electricity generation. There are differences between the estimates obtained from the MECS consumption and the EIA supply surveys. ${ }^{49}$ To reconcile these differences, it is necessary to compare MECS estimates of total primary energy consumed and supply survey estimates of quantities supplied to the industrial sector. Table $\mathrm{C} 1$ presents these estimates.

Explanations are available for differences between the quantities reported based on the MECS and those based on the supply surveys. One primary reason is that the MECS only addresses manufacturing establishments rather than the entire industrial sector. Possible explanations for the different estimates of energy consumption are as follows:

\footnotetext{
${ }^{49} \mathrm{For}$ further discussion of the discrepancy in supply and consumption data, see Energy Information Administration, Energy Consumption by EndUse Sector: A Comparison of Measures by Consumption and Supply Surveys, DOE/EIA-0533 (Washington, DC, April 6, 1990).
} 
Table C1. Comparison of EIA Energy Consumption Estimates, 1991

\begin{tabular}{|c|c|c|c|c|c|}
\hline \multirow[b]{2}{*}{ Type of Energy } & \multicolumn{2}{|c|}{ Manufacturing Only } & \multicolumn{3}{|c|}{ Total Industrial Sector ${ }^{\mathrm{a}}$} \\
\hline & MECS $^{b}$ & $\begin{array}{l}\text { Quarterly } \\
\text { Coal } \\
\text { Report }^{c} \\
\end{array}$ & $\begin{array}{l}\text { Monthly } \\
\text { Energy } \\
\text { Review }^{\text {d }} \\
\end{array}$ & $\begin{array}{l}\text { Electric } \\
\text { Power } \\
\text { Annual }^{\ominus} \\
\end{array}$ & $\begin{array}{c}\text { Natural Gas } \\
\text { Annual }^{\dagger}\end{array}$ \\
\hline $\begin{array}{l}\text { Electricity (billion } \\
\text { kilowatthours) }\end{array}$ & 695 & -- & 941 & 947 & -- \\
\hline $\begin{array}{l}\text { Natural Gas (billion } \\
\text { cubic feet) }\end{array}$ & 5,917 & -- & 8,381 & -- & 7,231 \\
\hline $\begin{array}{l}\text { Coal (thousand short } \\
\text { tons) }\end{array}$ & 83,860 & 109,259 & 115,698 & -- & -- \\
\hline $\begin{array}{l}\text { Petroleum Products } \\
\text { (thousand barrels per } \\
\text { day) }\end{array}$ & 1,491 & -. & 4,248 & -- & -- \\
\hline
\end{tabular}

"The industrial sector includes manufacturing, construction, mining, agriculture, and fishing and forestry.

'Energy Information Administration, Manufacturing Consumption of Energy, 1991, DOE/EIA-0512(91), Washington, DC, December 1994, Table A1.

'Energy Information Administration, Coal Industry Annual, 1993, DOE/EIA-0584(93), (Washington, DC, December 1994$),$ Table 71.

Table 2.1 of the 12/92 MER reports consumption in billions of British thermal units. These are converted here to physical units for comparative purposes only.

'Energy Information Administration, Electric Power Annual, 1992, DOE/EIA-0348(92), (Washington, DC, January 1994$)$, Table 55.

'Energy Information Administration, Natural Gas Annual, 1993, DOE/EIA-0131(93), (Washington, DC, October 1994), Table 15.

Source: Energy Information Administration.

Electricity - The Electric Power Annual ${ }^{50}$ provides the MER estimate of industrial sector electricity consumption. MECS estimates are based on different definitions of consumers, as well as different definitions of electricity consumed. Differences between the two systems include:

- Electric Power Annual presents sales by electric utilities to "industrial" customers. Utilities categorize customers into rate classes based on the quantity of sales rather than on the primary economic activity of the customer. It is likely that the industrial sales reported actually include commercial and residential sales.

- MECS includes "net electricity." This is the sum of purchases, transfers in, and generation onsite from noncombustible renewable energy sources (e.g., wind, hydroelectric). Removed from this are quantities of electricity sold or transferred offsite.

- MECS does not include that electricity generated or cogenerated from combustible fuels.

Natural Gas - The Natural Gas Annual ${ }^{51}$ supplies the MER reported estimates of natural gas consumed by the industrial sector. Differences between the MER and the MECS are:

- MER reports deliveries to industrial customers as well as those quantities of natural gas consumed in well, field, and lease operations. This includes gas used in drilling operations, heaters, dehydrators, and field compressors, as well as gas consumed in natural gas processing plants.

- MECS is based on the SIC classification of establishments. This includes natural gas processing plants and field operations as part of the mining sector (SIC 13). As such, the MECS does not include this consumption.

\footnotetext{
${ }^{50}$ Energy Information Administration, Manufacturing Energy Consumption Survey, Consumption of Energy 1991, DOE/EIA-0512(91) (Washington DC, DATE), Table A1.

${ }^{31}$ Energy Information Administration, Natural Gas Annual 1991, Volume 1, DOE/EIA (Washington, DC, DATE), Tables X.
} 
Coal - The MER publishes coal estimates provided by the Quarterly Coal Report. ${ }^{52}$ These estimates are from the only supply-side survey specifically addressing manufacturing establishments. Differences between the MECS and coal survey definitions include:

- The Quarterly Coal Report separately identifies quantities of coking coal from coal consumed at manufacturing establishments.

- MER estimates includes coal supplied to coal gasification projects. Electric generating facilities owned by manufacturing plants but not located on a manufacturing site are also included in the MER estimate.

- The SIC manual includes coal gasification projects in the mining sector (SIC 13), therefore they are not covered by MECS. Electric generating facilities owned by manufacturing plants but located offsite are considered "electrical services" (SIC 4911) are also not covered by the MECS. MECS estimates do include coal consumed as a raw material input at coke plants.

Petroleum Products - The estimates of petroleum products supplied to the industrial sector and reported in the MER are more inclusive than the estimates reported in the MECS consumption report.

- The quantity of petroleum products identified in the MER is the sum of the estimated individual petroleum products consumed. The Petroleum Supply Annual provides this data. The MER estimate includes the MECS reported energy sources of residual fuel oil, distillate fuel oil, diesel, and LPG. Also included in the estimate are all the various petroleum-based products consumed by the industrial sector (asphalt, jet fuel, lubricants, motor gasoline and aviation gasoline) not reported by MECS.

- The MER allocation to the industrial sector includes quantities supplied to oil companies and off-highway users (e.g., construction or mining transportation equipment). These and other portions of the sector are not covered by the MECS.

Fuels Consumed at Refineries - To compare the quantity of fuel supplied and consumed at petroleum refineries, it is necessary to use the MECS estimate of consumption for heat, power and electricity generation. The alternative measure is total primary energy. Total primary energy includes nonfuel (i.e., feedstock) consumption. Form EIA-820, the "Annual Refinery Report" provides estimates of "refinery fuel use" published in the Petroleum Supply Annual. ${ }^{53}$ The Annual Refinery Report collects data only for petroleum processing operations, which includes refiners and blenders. The MECS estimate covers the entire establishment site, which would include any co-located petrochemical operations. 


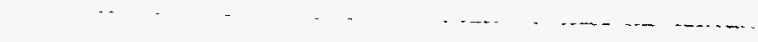


Appendix D

Description of

Manufacturing

Groups and Selected

Industries 



\section{Appendix D}

\section{Descriptions of Manufacturing Groups and Selected Industries}

This appendix contains descriptions of the industrial groups and industries of interest to the 1991 MECS. The 1987 Standard Industrial Classification Manual provides these descriptions. Descriptions cover each of the 61 sampling strata included in the MECS sample. This includes 20 major groups (2-digit SIC), two industry groups (3-digit SIC), and 39 industries (4-digit SIC). Appendix A discusses the SIC system of classifying establishments based on their primary economic activity.

SIC 20 - Food and Kindred Products: This major group includes establishments manufacturing foods and beverages for human consumption and certain related products such as manufactured ice, chewing gum, vegetable and animal fats and oils, and prepared feeds for animals and fowls.

SIC 2011 - Meat Packing Plants: Establishments primarily engaged in the slaughtering, for their own account or on a contract basis for the trade, of cattle, hogs, sheep, lambs, and calves for meat to be sold or to be used on the same premises in canning, cooking, curing, and freezing, and in making sausage, lard, and other products.

SIC 2033 - Canned Fruits and Vegetables: Establishments primarily engaged in canning fruits, vegetables, and fruit and vegetable juices: and in manufacturing catsup and similar tomato sauces or natural and imitation preserves, jams, and jellies.

SIC 2037 - Frozen Fruits and Vegetables: Establishments primarily engaged in freezing fruits, fruit juices, and vegetables. These establishments also produce important byproducts such as fresh or dried citrus pulp.

SIC 2046 - Wet Corn Milling: Establishments primarily engaged in milling corn or sorghum grain (milo) by the wet process, and producing starch, syrup, oil, sugar, and byproducts such as gluten feed and meal. Also included in this industry are establishments primarily engaged in manufacturing starch from other vegetable sources (e.g., potatoes, wheat).

SIC 2051 - Bread, Cake and Related Products: Establishments primarily engaged in manufacturing fresh or frozen bread and bread-type rolls and fresh cakes, pies, pastries and other similar "perishable" bakery products.

SIC 2062 - Cane Sugar Refining: Establishments primarily engaged in refining purchased raw cane sugar and sugar syrup.

SIC 2063 - Beet Sugar: Establishments primarily engaged in manufacturing sugar from sugar beets.

SIC 2075 - Soybean Oil Mills: Establishments primarily engaged in manufacturing soybean oil, cake, and meal and soybean protein isolates and concentrates or in processing purchased soybean oil other than into edible cooking oils.

SIC 21 - Tobacco Products: This major group includes establishments engaged in manufacturing cigarettes, cigars, smoking and chewing tobacco, snuff, and reconstituted tobacco and in stemming and redrying tobacco.

SIC 22 - Textile Mill Products: This major group includes establishments engaged in performing any of the following operations: (1) preparation of fiber and subsequently manufacturing of yarn, thread, braids, twine, or cordage; (2) manufacturing broadwoven fabrics, narrow woven fabrics, knit fabrics, and carpets and rugs from yarn; (3) dyeing and finishing fiber, yarn, fabrics, and knit apparel; (4) coating, waterproofing, or otherwise treating fabrics; (5) the integrated manufacture of knit apparel and other finished articles from yarn; (6) the manufacture of felt goods, lace goods, nonwoven fabrics, and miscellaneous textiles. 
SIC 23 - Apparel and Other Textile Products: This major group, known as the cutting-up and needle trades, includes establishments producing clothing and fabricating products by cutting and sewing purchased woven or knit textile fabrics and related materials, such as leather, rubberized fabrics, plastics, and furs.

SIC 24 - Lumber and Wood Products: This major group includes establishments engaged in cutting timber and pulpwood; merchant sawmills, lath mills, and shingle mills, cooperage stock mills, planing mills and plywood and veneer mills engaged in producing lumber and wood basic materials; and establishments engaged in manufacturing finished articles made entirely or mainly of wood or related materials.

SIC 25 - Furniture and Fixtures: This major group includes establishments engaged in manufacturing household, office, public building, and restaurant furniture; and office and store fixtures.

SIC 26 - Paper and Allied Products: This major group includes establishments primarily engaged in the manufacture of pulps from wood and other cellulose fibers, and from rags; the manufacture of paper and paperboard; and the manufacture of paper and paperboard into converted products, such as paper coated off the paper machine, paper bags, paper boxes, and envelopes.

SIC 2611 - Pulp Mills: Establishments primarily engaged in manufacturing pulp from wood or from other materials, such as rags, linters, wastepaper, and straw.

SIC 2621 - Paper Mills: Establishments primarily engaged in manufacturing paper from wood pulp and other fiber pulp, and which may also manufacture converted paper products.

SIC 2631 - Paperboard Mills: Establishments primarily engaged in manufacturing paperboard, including paperboard coated on the paperboard machine, from wood pulp and other fiber pulp.

SIC 27 - Printing and Publishing: This major group includes establishments engaged in printing by one or more common process such as letterpress, lithography (including offset), gravure, or screen; and those establishments which perform services for the printing trade, such as bookbinding and plate-making.

SIC 28 - Chemicals and Allied Products: This major group includes establishments producing basic chemicals, and establishments manufacturing products by predominately chemical processes. Establishments classified in this major group manufacture three general classes of products; (1) basic chemicals, such as acids, alkalies, salts, and organic chemicals; (2) chemical products to be used in further manufacture, such as synthetic fibers, plastics materials, dry colors, and pigments; and (3) finished chemical products used for ultimate consumption, such as drugs, cosmetics, and soaps; or to be used as materials or supplies in other industries, such as paints, fertilizers, and explosives.

SIC 2812 - Alkalies and Chlorine: Establishments primarily engaged in manufacturing alkalies and chlorine.

SIC 2813 - Industrial Gases: Establishments primarily engaged in manufacturing industrial gases (including organic) for sale in compressed, liquid, and solid forms.

SIC 2819 - Industrial Inorganic Chemicals, Not Elsewhere Classified: Establishments primarily engaged in manufacturing industrial inorganic chemicals, excluding alkalies and chlorine, industrial gases, and inorganic pigments.

SIC 2821 - Plastics Materials and Resins: Establishments primarily engaged in manufacturing synthetic resins, plastics materials, and nonvulcanizable elastomers.

SIC 2822 - Synthetic Rubber: Establishments primarily engaged in manufacturing synthetic rubber by polymerization or copolymerization. An elastomer, for the purpose of this classification, is a rubber-like material capable of vulcanization, such as copolymers of butadiene and styrene, or butadiene and acrylonitrile, polybutadienes, chloroprene rubbers, and isobutylene-isoprene copolymers. 
SIC 2823 - Cellulosic Manmade Fibers: Establishments primarily engaged in manufacturing cellulosic fibers (including cellulose acetate and regenerated cellulose such as rayon by the viscose or cuprammonium process) in the form of monofilament, yarn, staple, or tow suitable for further manufacturing on spindles, looms, knitting machines, or other textile processing equipment.

SIC 2824 - Organic Fibers, Noncellulosic: Establishments primarily engaged in manufacturing manmade organic fibers, except cellulosic (including those of regenerated proteins, and of polymers or copolymers of such components as vinyl chloride, vinylidene chloride, linear esters, vinyl alcohols, acrylonitrile, ethylenes, amides, and related polymeric materials), are in the form of monofilament, yarn, staple, or tow suitable for further manufacturing on spindles, looms, knitting machines, or other textile processing equipment.

SIC 2865 - Cyclic Crudes and Intermediates: Establishments primarily engaged in manufacturing cyclic organic crudes and intermediates, and organic dyes and pigments. Important products of this industry include; (1) aromatic chemicals, such as benzene, toluene, and mixed xylenes naphthalene; (2) synthetic organic dyes; and (3) synthetic organic pigments.

SIC 2869 - Industrial Organic Chemicals, Not Elsewhere Classified: Establishments primarily engaged in manufacturing industrial organic chemicals, excluding gum and wood chemicals, and cyclic organic crudes and intermediates, and organic dyes and pigments.

SIC 2873 - Nitrogenous Fertilizers: Establishments primarily engaged in manufacturing nitrogenous fertilizer materials or mixed fertilizers from nitrogenous materials produced in the same establishment.

SIC 2874 - Phosphatic Fertilizers: Establishments primarily engaged in manufacturing phosphatic fertilizer materials, or mixed fertilizers from phosphatic materials produced in the same establishment.

SIC 29 - Petroleum and Coal Products: This major group includes establishments primarily engaged in petroleum refining, manufacturing paving and roofing materials, and compounding lubricating oils and greases from purchased materials.

SIC 2911 - Petroleum Refining: Establishments primarily engaged in producing gasoline, kerosene, distillate and residual fuel oils, and lubricants, through fractionation or straight distillation of crude oil, redistillation of unfinished petroleum derivatives, cracking or other processes.

SIC 30 - Rubber and Miscellaneous Plastics Products: This major group includes establishments manufacturing products, not elsewhere classified, from plastics resins and from natural, synthetic, or reclaimed rubber, gutta percha, balata, or gutta siak.

SIC 3011 - Tires and Inner Tubes: Establishments primarily engaged in manufacturing pneumatic casings, inner tubes, and cushion tires for all types of vehicles, airplanes, farm equipment, and children's vehicle; tiring; camelback; and tire repair and retreading materials.

SIC 308 - Miscellaneous Plastics Products Not Elsewhere Classified: Establishments primarily engaged in manufacturing (1) unsupported plastics film and sheet from purchased resins or from resins produced in the same plant; (2) unsupported plastics profiles, rods, tubes, and other shapes; (3) laminated plastics plate, sheet, profiles, rods, and tubes; (4) plastic pipe; (5) plastics bottles; (6) custom compounding of purchased plastics resins; (7) plastics plumbing fixtures; and (8) plastics products not elsewhere classified.

SIC 31 - Leather and Leather Products: This major group includes establishments engaged in tanning, currying, and finishing hides and skins, leather converters, and establishments manufacturing finished leather and artificial leather products and some similar products made of other materials.

SIC 32 - Stone, Clay, Glass and Concrete Products: This major group includes establishments manufacturing flat glass and other glass products, cement, structural clay products, pottery, concrete and gypsum products, cut stone, abrasive and asbestos products, and other products from materials taken principally from the earth in the form of stone, clay, and sand. 
SIC 3211 - Flat Glass: Establishments primarily engaged in manufacturing flat glass. This industry also produces laminated glass, but establishments primarily engaged in manufacturing laminated glass from purchased flat glass are not included.

SIC 3221 - Class Containers: Establishments primarily engaged in manufacturing glass containers for commercial packing and bottling, and for use in home canning.

SIC 3229 - Pressed and Blown Glass and Glassware, Not Elsewhere Classified: Establishments primarily engaged in manufacturing glass and glassware, not elsewhere classified, pressed, blown, or shaped from glass produced in the same establishment. Establishments primarily engaged in manufacturing textile glass fibers are also included in this industry. Establishments primarily engaged in the production of pressed lenses for vehicular lighting, beacons, and lanterns are also included in this industry.

SIC 3241 - Cement, Hydraulic: Establishments primarily engaged in manufacturing hydraulic cement, including portland, natural, masonry, and pozzolana cements.

SIC 3274 - Lime: Establishments primarily engaged in manufacturing quicklime, hydrated lime, and "deadburned" dolomite from limestone, dolomite shells, or other substances.

SIC 3296 - Mineral Wool: Establishments primarily engaged in manufacturing mineral wool and mineral wool insulation products made of such siliceous materials as rock, slag, and glass, or combinations thereof.

SIC 33 - Primary Metals Industries: This major group includes establishments engaged in smelting and refining ferrous and nonferrous metals from ore, pig, or scrap; in rolling, drawing, and alloying metals; in manufacturing castings and other basic metal products; and in manufacturing nails, spikes, and insulated wire and cable.

SIC 3312 - Steel Works, blast furnaces (Including Coke Ovens), and Rolling Mills;: Establishments primarily engaged in manufacturing hot metal, pig iron, and silvery pig iron from iron ore and iron and steel scrap; converting pig iron, scrap iron, and scrap steel into steel; and in hot-rolling iron and steel into basic shapes, such as plates, sheets, strips, rods, bars, and tubing.

SIC 3313 - Electrometallurgical Products: Establishments primarily engaged in manufacturing ferrous and nonferrous metal additive alloys by electrometallurgical or metallothermic processes including high percentage ferroalloys and high percentage nonferrous additive alloys.

SIC 3321 - Gray and Ductile Iron Foundries: Establishments primarily engaged in manufacturing gray and ductile iron castings, including cast iron pressure and soil pipes and fittings.

SIC 3331 - Primary Copper: Establishments primarily engaged in smelting copper from the ore, and in refining copper by electrolytic or other processes.

SIC 3334 - Primary Production of Aluminum: Establishments primarily engaged in producing aluminum from alumina and in refining aluminum by any process.

SIC 3339 - Primary Nonferrous Metals, Not Elsewhere Classified: Establishments primarily engaged in smelting and refining nonferrous metals, except copper and aluminum.

SIC 3353 - Aluminum Sheet, Plate, and Foil: Establishments primarily engaged in flat rolling aluminum and aluminum-base alloy basic shapes, such as sheet, plate, and foil, including establishments producing welded tube.

SIC 34 - Fabricated Metal Products: This major group includes establishments engaged in fabricating ferrous and nonferrous metal products such as metal cans, tinware, hand tools, cutlery, and general hardware, nonelectric heating apparatus, fabricated structural metal products, metal forgings, and metal stampings. Ordnance (except vehicles and guided missiles), and a variety of metal and wire products not elsewhere classified. 
SIC 35 - Industrial Machinery and Equipment: This major group includes establishments engaged in manufacturing industrial and commercial machinery and equipment, and computers.

SIC 357 - Computer and Office Equipment: Establishments primarily engaged in manufacturing electronic computers; computer storage devices; computer terminals; point-of-sale devices; funds transfer devices and other calculating and accounting machines; and office machines and devices not elsewhere classified, including typewriters and word processing equipment.

SIC 36 - Electronic and Other Electric Equipment: This major group includes establishments engaged in manufacturing machinery, apparatus, and supplies for the generation, storage, transmission, transformation, and use of electrical energy.

SIC 37 - Transportation Equipment: This major group includes establishments engaged in manufacturing equipment for transportation of passengers and cargo by land, air, and water.

SIC 3711 - Motor Vehicles and Car Bodies: Establishments primarily engaged in manufacturing or assembling complete passenger automobiles, trucks, commercial cars and buses, and special purpose motor vehicles which are for highway use. This industry also includes establishments primarily engaged in manufacturing chassis and passenger car bodies.

SIC 3714 - Motor Vehicle Parts and Accessories: Establishments primarily engaged in manufacturing motor vehicle parts and accessories but not engaged in manufacturing complete motor vehicles or passenger car bodies.

SIC 38 - Instruments and Related Products: This major group includes establishments engaged in manufacturing instruments (including professional and scientific) for measuring, testing, analyzing, and controlling, and their associated sensors and accessories; optical instruments and lenses; surveying and drafting instruments; hydrological, hydrographic, meteorological, and geophysical equipment; search, detection, navigation, and guidance systems and equipment; surgical, medical, and dental instruments, equipment and supplies; ophthalmic goods; photographic equipment and supplies; and watches and clocks.

SIC 39 - Miscellaneous Manufacturing Industries: This major group includes establishments primarily engaged in manufacturing products not classified in any other manufacturing major group. 



\section{Appendix E}

Related EIA

Publications on

Energy Consumption 


\section{Appendix E}

\section{Related EIA Publications on Energy Consumption}

For information about how to obtain these publications, see the inside cover of this report. Please note that the prices quoted here are subject to change.

In addition to the reports listed below, public use data tapes and data diskettes for the residential, residential transportation, and commercial sectors are available from the National Technical Information Service (NTIS). To obtain information on how to order the tapes/diskettes, you may call NTIS at 703-487-4807, FAX number 703-321-8547. Data diskettes can also be obtained from the Office of Scientific and Technical Information (OSTI). For OSTI ordering information, call 615-576-8401.

\section{Industrial Sector}

Manufacturing Consumption of Energy 1991, December 1994, DOE/EIA-0512(91), GPO Stock No. 061-003-008709, $\$ 34.00$.

"Energy Preview: Manufacturing Energy Consumption Survey Preliminary Estimates, 1991," Monthly Energy Review, September 1993, DOE/EIA-0035(93/01).

"Energy Efficiency in the Manufacturing Sector," Monthly Energy Review (Article), p.1, December 1992.

Manufacturing Energy Consumption Survey: Changes in Energy Intensity in the Manufacturing Sector 1980-1988, December 1991, DOE/EIA-0552(80-88). GPO Stock No. 061-003-00734-1, \$4.75.

Manufacturing Energy Consumption Survey: Manufacturing Fuel-Switching Capability 1988; September 1991, DOE/EIA-0515(88), GPO Stock No. 061-003-00720-1, \$9.00.

Manufacturing Energy Consumption Survey: Consumption of Energy, 1988; May 1991, DOE/EIA- 0512(88), GPO Stock No. 061-003-00703-8, \$11.00.

Manufacturing Energy Consumption Survey: Energy Efficiency in Manufacturing, 1985; January 1990, DOE/EIA0516(85), GPO Stock No. 061-003-00650-7, \$4.25.

Manufacturing Energy Consumption Survey: Fuel-Switching Capability, 1985; December 1988, DOE/EIA-0515(85), GPO Stock No. 061-003-00601-9, \$3.50.

Manufacturing Energy Consumption Survey: Methodological Report, 1985; November 1988, DOE/EIA0514(85), GPO Stock No. 061-003-00595-1, \$6.00.

Manufacturing Energy Consumption Survey: Consumption of Energy, 1985; November 1988, DOE/EIA-0512(85), GPO Stock No. 061-003-00594-2, \$6.00.

"Manufacturing Sector Energy Consumption 1985 Provisional Estimates," Monthly Energy Review (Article), pp. vii-x, January 1987, DOE/ELA-0035(87/01).

Report on the 1980 Manufacturing Industries' Energy Consumption Study and Survey of Large Combustors; February 1983, DOE/EIA-0358, GPO Stock No. 061-003-00293-5, \$5.00.

Industrial Energy Consumption, Survey of Large Combustors: Report on Alternate Fuel-Burning Capabilities of Large Boilers in 1979; February 1982, DOE/ELA-0304, GPO Stock No. 061-003-0233-1, \$2.50. 
Methodological Report of the 1980 Manufacturing Industries Survey of Large Combustors (EIA-463); March 1982, DOE/EIA-0306 (no GPO Stock No.).

\section{Other Publications on the Industry Sector}

Energy Consumption Series--Derived Annual Estimates of Manufacturing Energy Consumption 1974-1988, August 1992, DOE/EIA-0555(92)/3, GPO Stock No. 061-003-00766-0, \$7.00.

Energy Consumption Series--Development of the 1991 Manufacturing Energy Consumption Survey, May 1992, DOE/EIA-0555(92)/2, GPO Stock No. 061-003-00757-1, \$5.50.

\section{Commercial Sector}

Note: The name of the Nonresidential Buildings Energy Consumption Survey was changed to the Commercial Buildings Energy Consumption Survey, beginning with the 1989 survey. The survey name was also dropped from the report title at that time and subsequently.

\section{Characteristics of Buildings}

Commercial Buildings Characteristics 1992; April 1994, DOE/EIA-0246(92), GPO Stock No. 061-003-00850-0, $\$ 28.00$.

"Commercial Buildings Characteristics 1992," Monthly Energy Review, January 1994, DOE/EIA-0035(94/01).

Commercial Buildings Characteristics 1989; June 1991, DOE/EIA-0246(89), GPO Stock No. 061-003-00699-0, \$18.00.

Nonresidential Buildings Energy Consumption Survey: Characteristics of Commercial Buildings, 1986; September 1988, DOE/EIA-0246(86), GPO Stock No. 061-003-00580-2, \$16.00.

Nonresidential Buildings Energy Consumption Survey: Characteristics of Commercial Buildings, 1983; A Supplemental Reference, DOE/EIA-M008, \$22.95. Available from the NTIS, Order No. DE-85015581.

Nonresidential Buildings Energy Consumption Survey: Characteristics of Commercial Buildings, 1983; July 1985, DOE/EIA-0246(83), GPO Stock No. 061-003-00439-3, \$7.50.

Nonresidential Buildings Energy Consumption Survey: Fuel Characteristics and Conservation Practices; June 1981, DOE/EIA-0278, GPO Stock No. 061-00300200-5, \$9.00.

Nonresidential Buildings Energy Consumption Survey: Building Characteristics; March 1981, DOE/EIA-0246, GPO Stock No. 061-003-00171-8, \$6.50.

\section{Consumption and Expenditures}

Commercial Buildings Consumption and Expenditures 1992; April 1995, DOE/EIA-0318(92), GPO Stock No. 061-00300904, \$31.00.

Commercial Buildings Consumption and Expenditures 1989; April 1992, DOE/EIA-0318(89), GPO Stock No. 061-00300753-8, \$25.00.

Nonresidential Buildings Energy Consumption Survey: Commercial Buildings Consumption and Expenditures 1986; May 1989, DOE/EIA-0318(86), GPO Stock No. 061-003-00613-2, \$19.00. 
Nonresidential Buildings Energy Consumption Survey: Commercial Buildings, Consumption and Expenditures 1983; September 1986, DOE/EIA-0318(83), GPO Stock No. 061-003-00496-2, \$13.00.

Nonresidential Buildings Energy Consumption Survey: 1979 Consumption and Expenditures, Part 1: Natural Gas and Electricity; March 1983, DOE/EIA-0318/1, GPO Stock No. 061-003-00298-6, \$9.50.

Nonresidential Buildings Energy Consumption Survey: 1979 Consumption and Expenditures, Part 2: Steam, Coal, Fuel Oil, LPG, and Total Fuels; December 1983, DOE/EIA-0318(79)/2, GPO Stock No. 061-003-00366-4, \$6.00.

\section{Other Publications on the Commercial Sector}

Energy Consumption Series-- Energy End-Use Intensities in Commercial Buildings, September 1994, DOE/EIA0555(94)/2, GPO Stock No. 061-003-0087-9, 9.00.

"Assessment of Energy Use in Multibuilding Facilities," Monthly Energy Review, December 1993, DOE/EIA0035(93/12).

Energy Consumption Series--Assessment of Energy Use in Multibuilding Facilities, August 1993, DOE/EIA-0555(93)/1, GPO Stock No. 061-003-00817-8, \$7.50.

Energy Consumption Series--User-Needs Study for the 1992 Commercial Buildings Energy Consumption Survey, September 1992, DOE/EIA-0555(92)/4, GPO Stock No. 061-003-00770-8, \$8.50.

Energy Consumption Series--Lighting in Commercial Buildings; March 1992, DOE/EIA-0555(92)/1, GPO Stock No. 061-003-00749-0, \$6.50.

\section{Residential Sector}

\section{Housing Characteristics}

Note: The survey name was dropped from the beginning of the report title starting with the 1987 data reports.

Housing Characteristics 1993; June 1995, DOE/EIA-0314(93), GPO Stock No. 061-003-00912-3, \$23.00.

Housing Characteristics 1990; May 1992, DOE/EIA-0314(90), GPO Stock No. 061-003-00754-6, \$23.00.

Housing Characteristics 1987; May 1989, DOE/EIA-0314(87), GPO Stock No. 061-003-00619-1, \$13.00.

Residential Energy Consumption Survey: Housing Characteristics 1984; October 1986, DOE/EIA-0314(84), GPO Stock No. 061-003-00499-7, \$12.00.

Residential Energy Consumption Survey: Housing Characteristics, 1982; August 1984, DOE/EIA-0314(82), GPO Stock No. 061-003-00393-1, \$7.00.

Residential Energy Consumption Survey Housing Characteristics, 1981; August 1983, DOE/EIA-0314(81), GPO Stock No. 061-003-00330-3, \$6.50.

Residential Energy Consumption Survey: Housing Characteristics, 1980; June 1982, DOE/EIA-0314, GPO Stock No. 061-003-00256-1, \$11.00.

Residential Energy Consumption Survey: Characteristics of the Housing Stock and Households, 1978; February 1980, DOE/EIA-0207/2, GPO Stock No. 061-003-00093-2, \$4.25. 
Residential Energy Consumption Survey: Conservation; February 1980, DOE/EIA-0207/3, GPO Stock No. 061-003-00087-8, \$6.00.

Preliminary Conservation Tables from the National Interim Energy Consumption Survey; August 1979, DOE/EIA-0193/P (no GPO Stock No.).

Characteristics of the Housing Stock and Households: Preliminary Findings from the National Interim Energy Consumption Survey; October 1979, DOE/EIA-0199/P (no GPO Stock No. available).

\section{Consumption and Expenditures}

Note: The survey name was dropped from the beginning of the report title starting with the 1987 data reports. The titles were changed to Household Energy Consumption and Expenditures 1987, Part 1: National and Part 2: Regional.

"Household Energy Consumption and Expenditures 1990," Monthly Energy Review, August 1993, DOE/EIA0035(93/08).

Household Energy Consumption and Expenditures 1990; February 1993, DOE/EIA-0321/1(90), GPO Stock No. 061003-00795-3, \$22.00.

Household Energy Consumption and Expenditures 1990S; DOE/EIA-0321/2(90), GPO Stock No. 061-003-00796-1, $\$ 21.00$.

Household Energy Consumption and Expenditures 1987, Part 1: National Data; October 1989, DOE/EIA-0321/1(87), GPO Stock No. 061-003-00635-3, \$15.00. Note: Energy end-use data are included in this report.

Household Energy Consumption and Expenditures 1987, Part 2: Regional Data; DOE/EIA-0321/2(87) (no GPO Stock No. available), $\$ 16.00$.

Residential Energy Consumption Survey: Consumption and Expenditures, April 1984 Through March 1985, Part 1: National Data; March 1987, DOE/EIA-0321/1(84), GPO Stock No. 061-003-00519-5, \$9.50.

Residential Energy Consumption Survey: Consumption and Expenditures, April 1984 Through March 1985, Part 2: Regional Data; May 1987, DOE/EIA-0321/2(84), GPO Stock No. 061-003-00528-4, \$17.00. Note: Energy end-use data are included in this report.

Residential Energy Consumption Survey: Consumption and Expenditures, April 1982 Through March 1983, Part 1: National Data; November 1984, DOE/EIA-0321/1(82), GPO Stock No. 061-003-00411-3, \$7.00.

Residential Energy Consumption Survey: Consumption and Expenditures, April 1982 Through March 1983, Part 2: Regional Data; December 1984, DOE/EIA-0321/2(82), GPO Stock No. 061-003-00414-8, \$9.50.

Residential Energy Consumption Survey: Consumption and Expenditures, April 1981 Through March 1982, Part 1: National Data; September 1983, DOE/EIA-0321/1(81), GPO Stock No. 061-003-00340-1, \$6.00.

Residential Energy Consumption Survey: Consumption and Expenditures, April 1981 Through March 1982, Part 2: Regional Data; October 1983, DOE/EIA-0321/2(81), GPO Stock No. 061-003-00357-5, \$8.00.

Residential Energy Consumption Survey: Consumption and Expenditures, April 1980 Through March 1981, Part 1: National Data; September 1982, DOE/EIA-0321/1(80), GPO Stock No. 061-003-00278-1, \$7.50.

Residential Energy Consumption Survey: Consumption and Expenditures, April 1980 Through March 1981, Part 2: Regional Data; June 1983, DOE/EIA-0321/2(80), GPO Stock No. 061-003-00319-2, \$7.00. 
Residential Energy Consumption Survey: 1979-1980 Consumption and Expenditures, Part 1: National Data (Including Conservation); April 1981, DOE/EIA-0262/1, GPO Stock No. 061-003-00191-2, \$6.50.

Residential Energy Consumption Survey: 1979-1980 Consumption and Expenditures, Part II: Regional Data; May 1981, DOE/EIA-0262/2, GPO Stock No. 061-003-00189-1, \$8.50.

Residential Energy Consumption Survey: Consumption and Expenditures, April 1978 Through March 1979; July 1980, DOE/EIA-0207/5, GPO Stock No. 061-003-00131-9, \$7.50.

Single-Family Households: Fuel Oil Inventories and Expenditures: National Interim Energy Consumption Survey; December 1979, DOE/ELA-0207/1, GPO Stock No. 061-003-00075-4, \$3.50.

\section{Other Publications on the Residential Sector}

Energy Consumption Series--Sample Design for the Residential Energy Consumption Survey, August 1994, DOE/EIA0555(94)/1, GPO Stock No. 061-003-00865-8, \$6.50.

Energy Consumption Series--User-Needs Study of the 1993 Residential Energy Consumption Survey, September 1993, DOE/EIA-0555(93)/2, GPO Stock No. 061-003-00819-4, \$13.00.

"End-Use Consumption of Residential Energy" Monthly Energy Review (Article), pp. vii-xiv, July 1987, DOE/EIA-0035(87/07).

Residential Energy Consumption Survey: Trends in Consumption and Expenditures 1978-1984 June 1987, DOE/EIA-0482, GPO Stock No. 061-003-00535-7, \$12.00.

Residential Conservation Measures; July 1986, SR/EEUD/86/01 (no GPO Stock No.).

An Economic Evaluation of Energy Conservation and Renewable Energy Tax Credits; October 1985, Service Report (no GPO Stock No.).

Residential Energy Consumption and Expenditures by End Use for 1978, 1980, and 1981; December 1984, DOE/EIA-0458, GPO Stock No. 061-003-00415-6, \$4.50.

Weatherization Program Evaluation, SR-EEUD- 84-1; August 1984 (available from the Office of the Assistant Secretary for Conservation and Renewable Energy, Department of Energy).

Residential Energy Consumption Survey: Regression Analysis of Energy Consumption by End Use; October 1983, DOE/EIA-0431, GPO Stock No. 061-00300-347-8, \$5.00.

National Interim Energy Consumption Survey: Exploring the Variability In Energy Consumption; July 1981, DOE/EIA-0272, GPO Stock No. 061-003-00205-6, \$5.00.

National Interim Energy Consumption Survey: Exploring the Variability in Energy Consumption--A Supplement; October 1981, DOE/EIA-0272/S, GPO Stock No. 061-003-00217-0, \$4.50.

Energy Use by U.S. Households; November 1980, DOE/EIA-0248 (brochure, no GPO Stock No.).

\section{Residential Transportation Sector}

Note: The survey name was dropped from the beginning of the report title starting with the 1988 data report, and the report title was changed to Household Vehicles Energy Consumption 1988. 
Household Vehicles Energy Consumption 1991; December 1993, DOE/EIA-0464(91), GPO Stock No. 061-003-00652$3, \$ 14.00$.

"Energy Preview: Residential Transportation Energy Consumption Survey Preliminary Estimates, 1991," Monthly Energy Review, January 1993, DOE/EIA-0035(93/01).

Household Vehicles Energy Consumption 1988; February 1990, DOE/ELA-0464(88), GPO Stock No. 061-003-00652-3, $\$ 11.00$.

Residential Transportation Energy Consumption Survey: Consumption Patterns of Household Vehicles 1985; April 1987, DOE/EIA-0464(85), GPO Stock No. 061-003-00521-7, \$8.50.

Residential Transportation Energy Consumption Survey: Consumption Patterns of Household Vehicles, 1983; January 1985, DOE/EIA-0464(83), GPO Stock No. 061-003-00420-2, \$4.50.

Residential Energy Consumption Survey: Consumption Patterns of Household Vehicles, Supplement:

January 1981 to September 1981; February 1983, DOE/EIA-0328, GPO Stock No. 061-003-00297-8, \$4.75.

Residential Energy Consumption Survey: Consumption Patterns of Household Vehicles, June 1979 to December 1980; April 1982, DOE/EIA-0319 (no GPO Stock No.).

\section{Cross-Sector}

Energy Consumption Series--Buildings and Energy in the 1980's, June 1995, DOE/EIA-0555(95)/1, GPO Stock No. 061-003-00914-0, \$6.50.

Energy Consumption by End-Use Sector: A Comparison of Measures by Consumption and Supply Surveys; April 6, 1990, DOE/EIA-0533 (no GPO Stock No. available), \$2.50.

Natural Gas: Use and Expenditures; April 1983, DOE/EIA-0382, GPO Stock No. 061-003-00307-9, \$5.50.

\section{Public Use Tapes}

Note: All tapes are available through the NTIS.

\section{Residential and Residential Transportation Sectors}

Residential Energy Consumption Survey: 1987 and Residential Transportation Energy Consumption Survey, 1988, Order No. PB90-501461, \$220.

Residential Energy Consumption Survey: 1984 and Residential Transportation Energy Consumption Survey, 1985; Order No. PB87-186540, \$220.

Residential Energy Consumption Survey: 1982 and Residential Transportation Energy Consumption Survey, 1983; Order No. PB85-221760, \$220.

Residential Energy Consumption Survey: Consumption and Expenditures, 1980-1981; Monthly Billing Data; Order No. PB84-166230, \$220.

Residential Energy Consumption Survey: Housing Characteristics, 1981; Consumption and Expenditures, 1981-1982; Monthly Billing Data; Order No. PB84-120476, \$220. 
Residential Energy Consumption Survey: Housing Characteristics, Annualized Consumption and Expenditures, 19801981; Order No. PB83-199554, \$220.

Residential Energy Consumption Survey: Household Transportation Panel Monthly Gas Purchases and Vehicle and Household Characteristics, 6/79-9/81; Order No. PB84-162452, \$220.

Residential Energy Consumption Survey: Household Screener Survey, 1979-1980; Order No. PB82-114877, \$220.

Residential Energy Consumption Survey: Household Monthly Energy Consumption and Expenditures, 1978-1979; Order No. PB82-114901, \$220.

National Interim Energy Consumption Survey (Residential), 1978; Order No. PB81-108714, \$220.

\section{Commercial Sector}

Nonresidential Buildings Energy Consumption Survey: 1986 Data; Order No. PB90-500034, \$220.

Nonresidential Buildings Energy Consumption Survey: 1979 and 1983 Data; Order No. PB88-245162, \$220.

\section{Public Use Diskettes}

Note: Diskettes are available through the Office of Scientific and Technical Information (OSTI).

Residential Energy Consumption Survey 1990 Data, OSTI - ASCII (3 diskettes) or dBASE (2 diskettes) format, order by title, $\$ 10$ per diskette. NTIS - ASCII format: Order No. PB-93-506103 and dBASE format: Order No. PB-93-506095.

Residential Energy Consumption Survey 1987 Data, OSTI - ASCII or dBASE format, order by title, $\$ 45$ for each set. NTIS - ASCII format: Order No. PB-91-505115, \$130, and DBASE format: Order No. PB-91-505107, \$130.

Commercial Buildings Energy Consumption Survey 1992 Data, OSTI - ASCII or dBASE format, order by title, $\$ 10$ per diskette, $\$ 40$ set of four. NTIS - ASCII or DBASE format, order by title, call for prices.

Commercial Buildings Characteristics 1992 Data, OSTI - ASCII or dBASE format, order by title, $\$ 10$ per diskette, $\$ 40$ set of four. NTIS - ASCII or dBASE format: Order No. PB-94-504305, call for prices.

Commercial Buildings Energy Consumption Survey 1989 Data, OSTI - ASCI format, order by title, $\$ 10$ per diskette, $\$ 40$ set of four. NTIS - ASCII or dBASE format: Order No. PB92-504232, \$140.

Nonresidential Buildings Energy Consumption Survey 1986 Data, NTIS - ASCII format: Order No. PB91-506808, $\$ 130$.

Residential Transportation Energy Consumption Survey 1991 Data, OSTI - ASCII or dBASE format, order by title, call for prices. NTIS - ASCII format: Order No. PB94-500824. dBASE format: Order No. PB94-500816, call for prices.

Residential Transportation Energy Consumption Survey 1988 Data, GPO - ASCII or dBASE format, order by title, $\$ 15$ for each set. NTIS - ASCII format: Order No. PB91-507269, dBASE format: Order No. PB91-507277, \$50 each.

\section{Planned Publications}

Household Energy Consumption and Expenditures 1993, planned for October 1995.

EPACT Section 407 Data System: Results from Atlanta Clean City Fleet Vehicle Survey, planned for November 1995. 
EPACT Section 407 Data Program: The Vehicle Stock and New Survey Findings, planned for December 1995.

Service Report: Federal Buildings Supplemental Survey Results, planned for October 1995.

Measuring Energy Efficiency in the U.S. Economy (Energy Consumption Series), planned for October 1995.

Note: The Energy Information Administration also publishes annually the State Energy Data Report, Consumption Estimates, DOE/EIA-0214, and the State Energy Price and Expenditures Report, DOE/EIA-0376; and the Monthly Energy Review, DOE/EIA-0035. These reports contain annual and monthly consumption information derived from EIA supply surveys. 
Appendix F

Metric Conversion

Factors 


\section{Appendix F \\ Metric Conversion Factors}

Data in the Energy Information Administration publications are expressed in units, such as British thermal units, barrels, cubic feet, and short tons, that historically have been used in the United States. However, because U.S. activities involve foreign nations, most of which use metric units of measure, the United States is committed to making the transition to the metric system. The metric conversion factors presented in Table F1 can be used to calculate the metric-unit equivalents of values expressed in U.S. units. For example, 500 short tons are the equivalent of 453.6 metric tons (500 short tons $\times 0.9071847$ metric tons/short tons $=453.6$ metric tons).

Table F1. Metric Conversion Factors

\begin{tabular}{|c|c|c|c|c|}
\hline Type of Unit & U.S. Unit & & Conversion Factor & Metric Unit \\
\hline Mass & $\begin{array}{l}\text { Short Tons } \\
\text { Short Tons Uranium Oxide }\left(\mathrm{U}_{3} \mathrm{O}_{8}\right) \\
\text { Short Tons Uranium Fluoride }\left(\mathrm{UF}_{6}\right) \\
\text { Long Tons } \\
\text { Pounds(lb) } \\
\text { Pounds Uranium Oxide }\left(\mathrm{lb} \mathrm{U}_{3} \mathrm{O}_{8}\right) \\
\text { Ounces, Avoirdupois }(\mathrm{Oz})\end{array}$ & $\begin{array}{l}x \\
x \\
x \\
x \\
x \\
x \\
x\end{array}$ & $\begin{array}{l}0.9071847 \\
0.769 \\
0.613 \\
1.016 \\
0.45359237^{a} \\
0.384645^{b} \\
28.34952\end{array}$ & $\begin{array}{l}=\text { Metric Tons }(t) \\
=\text { Metric Tons Uranium }(U) \\
=\text { Metric Tons Uranium }(U) \\
=\text { Metric Tons }(t) \\
=\text { Kilograms }(\mathrm{kg}) \\
=\text { Kilograms }(\mathrm{Kg}) \\
=\text { Grams }(\mathrm{g})\end{array}$ \\
\hline Volume & 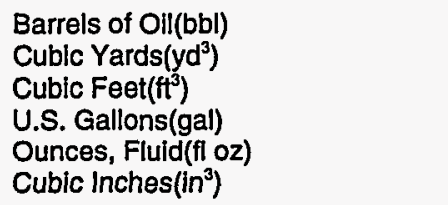 & $\begin{array}{l}x \\
x \\
x \\
x \\
x \\
x\end{array}$ & $\begin{array}{l}0.1589873 \\
0.765555 \\
0.02831685 \\
3.785412 \\
29.57353 \\
16.38706\end{array}$ & $\begin{array}{l}=\text { Cubic Meters }\left(\mathrm{m}^{3}\right) \\
=\text { Cubic Meters }\left(\mathrm{m}^{3}\right) \\
=\text { Cubic Meters }\left(\mathrm{m}^{3}\right) \\
=\text { Liter }(\mathrm{L}) \\
=\text { Milliliters }(\mathrm{ml}) \\
=\text { Milliliters }(\mathrm{ml})\end{array}$ \\
\hline Length & $\begin{array}{l}\text { Miles (mi) } \\
\text { Yards (yd) } \\
\text { Feet (ft) } \\
\text { Inches (in) }\end{array}$ & $\begin{array}{l}x \\
x \\
x \\
x\end{array}$ & $\begin{array}{l}1.609344^{\mathrm{a}} \\
0.9144^{\mathrm{a}} \\
0.3048^{\mathrm{a}} \\
2.54^{\mathrm{a}}\end{array}$ & $\begin{array}{l}=\text { Kilometers }(\mathrm{km}) \\
=\text { Meters }(\mathrm{m}) \\
=\text { Meters }(\mathrm{m}) \\
=\text { Centimeters }(\mathrm{cm})\end{array}$ \\
\hline Area & $\begin{array}{l}\text { Acres } \\
\text { Square Miles }\left(\mathrm{mi}^{2}\right) \\
\text { Square Yards }\left(\mathrm{yd}^{2}\right) \\
\text { Square Feet }\left(\mathrm{t}^{2}\right) \\
\text { Square Inches }\left(i \mathrm{n}^{2}\right)\end{array}$ & $\begin{array}{l}x \\
x \\
x \\
x \\
x\end{array}$ & $\begin{array}{l}0.40469 \\
2,589988 \\
0.8361274 \\
0.09290304^{a} \\
6.45616^{\mathrm{a}}\end{array}$ & $\begin{array}{l}=\text { Hectares (ha) } \\
=\text { Square Kilometers }\left(\mathrm{km}^{2}\right) \\
=\text { Square Meters }\left(\mathrm{m}^{2}\right) \\
=\text { Square Meters }\left(\mathrm{m}^{2}\right) \\
=\text { Square Centimeters }\left(\mathrm{cm}^{2}\right)\end{array}$ \\
\hline Temperalure & Degrees Fahrenheit' $\left.{ }^{\circ} \mathrm{F}\right)$ & $x$ & $5 / 9$ (after subtracting 32$)^{\mathrm{a}}$ & $=$ Degrees Celsius $\left({ }^{\circ} \mathrm{C}\right)$ \\
\hline Energy & $\begin{array}{l}\text { British thermal units (Btu) } \\
\text { Calories (cal) } \\
\text { Kilowatthours (kWh) }\end{array}$ & $\begin{array}{l}x \\
x \\
x \\
\end{array}$ & $\begin{array}{c}1,055.056 \\
4.1868 \\
3.6 \\
\end{array}$ & $\begin{array}{l}=\text { Joules }(\mathrm{J}) \\
=\text { Joules (J) } \\
=\text { Megajoules (MJ) }\end{array}$ \\
\hline
\end{tabular}

"Exact Conversion.

${ }^{b}$ Calculated by the Energy Information Administration.

'To convert degrees Celsius $\left({ }^{\circ} \mathrm{C}\right)$ to degrees Fahrenheit $\left({ }^{\circ} \mathrm{F}\right)$ multiply by $9 / 5$, then add 32.

Sources: -General Senices Administration, Federal Standard 376B, Preferred Metric Units for General Use by the Federal Government (Washington, DC, January 27, 1993), pp. 9-11, 13, and 16. - National Institute of Standards and Technology, Speclal Publications 330 , 811, and 814. - American Natlonal Standards Institute/Institute of Electrical and Electronic Engineers, ANS/EEE Std.268-1982, pp 28 and 29. Energy Information Administration, Monthly Energy Review August 1993, Appendix B, pp 161. 


\section{Glossary}

Anthracite: A hard, black, lustrous coal containing a high percentage of fixed carbon and a low percentage of volatile matter. It is often referred to as hard coal.

Barrel: A volumetric unit of measure equivalent to 42 U.S. gallons.

Biomass: Organic (animal waste), nonfossil plant material constituting an exploitable energy source.

Bituminous Coal: A soft coal (the most common solid fossil fuel), which is high in carbonaceous matter, with a volatility greater than anthracite.

Blast Furnace: A shaft furnace in which solid fuel is burned with an air blast to smelt ore in a continuous operation.

Blast Furnace Gas: The waste combustible gas generated in a blast furnace when iron ore is being reduced with coke to metallic iron. It is commonly used as a fuel within the steel works.

Breeze: The residue from the fine screenings of crushed coke.

British Thermal Unit (Btu): The amount of energy required to raise the temperature of one pound of water one degree Fahrenheit.

Butane $\left(\mathrm{C}_{44} \mathrm{H}_{10}\right)$ : A normally gaseous, parafinnic hydrocarbon extracted from natural gas or refinery gas streams. It includes isobutane (a branch-chain configuration) and normal butane (a straight-chain configuration). It is used primarily for blending into high-octane gasoline, for residential and commercial heating, and for industrial uses, especially the manufacture of chemicals and rubber.

Butylene $\left(\mathrm{C}_{4} \mathrm{H}_{8}\right)$ : A normally gaseous, olefinic hydrocarbon recovered from the refinery processes, and converted to alkylate, a high-octane gasoline blending component.

Byproduct: A secondary or additional product resulting from the feedstock use of energy or the processing of nonenergy materials. For example, the more common byproducts of coke ovens are coal as, tar, and a mixture of benzene, toluene, and xylenes (BTX).
Census Region: A geographic area defined by the Bureau of the Census, consisting of various States selected according to population size and physical location. The States are grouped into four regions:

1. Northeast: Connecticut, Maine, Massachusetts, New Hampshire, New Jersey, New York, Pennsylvania, Rhode Island, and Vermont.

2. South: Alabama, Arkansas, Delaware, District of Columbia, Florida, Georgia, Kentucky, Louisiana, Maryland, Mississippi, North Carolina, Oklahoma, South Carolina, Tennessee, Texas, Virginia, and West Virginia.

3. Midwest: Illinois, Indiana, Iowa, Kansas, Michigan, Minnesota, Missouri, Nebraska, North Dakota, Ohio, South Dakota, and Wisconsin.

4. West: Alaska, Arizona, California, Colorado, Hawaii, Idaho, Montana, Nevada, New Mexico, Oregon, Utah, Washington, and Wyoming.

Coal Coke: The strong, porous residue, consisting of carbon and mineral ash, which is formed when the volatile constituents of bituminous coal are driven off by heat in the absence of or with a limited supply of air. Coal coke is used primarily in blast furnaces.

Cogeneration: The production of electrical energy and another form of useful energy (such as heat or steam) through the sequential use of energy.

Coke Oven Gas: The mixture of permanent gases produced by the carbonization of coal in a coke oven at temperatures in excess of 1,000 degrees Celsius.

Consumption: The use of energy as a source of heat or power, or as an input to the manufacturing process.

Conversion Factor: A number that translates units of one system into corresponding values of another system. Conversion factors are used to translate physical units of measure for various energy sources into their Btu equivalents.

Cost of Materials: This term refers to direct charges actually paid or payable for items consumed or put into production during the year, including freight charges and other direct charges incurred by the establishment 
in acquiring these materials. It includes the cost of materials and fuel consumed, whether purchased by the individual establishment from other companies, transferred to it from other establishments of the same company, or withdrawn from inventory during the year.

The important components of this cost item are (1) all raw materials, semifinished goods, parts containers, scrap, and supplies put into production or used as operating supplies and for repair and maintenance during the year, (2) electric energy purchased, (3) fuels consumed for heat, power, and electricity generation, (4) work done by others on materials or parts furnished by manufacturing establishments (contract work), and (5) products bought and resold in the same condition.

Crude Oil: A mixture of hydrocarbons that exists in a liquid state in natural underground reservoirs and remains liquid at atmospheric pressure after passing through surface separating facilities. Crude oil is reported as liquid equivalents at the surface (excluding basic sediment and water), measured in terms of stock tank barrels of 42 U.S. gallons at atmospheric pressure, and corrected to 60 degrees Fahrenheit.

Distillate Fuel Oil: A general classification for light fuel oils distilled during the refining process. The classification includes products known as Nos. 1,2, and 4 fuel oils; and Nos. 1, 2, and 4 diesel fuels. Distillate fuel oil is used primarily for space heating, on-and-off highway engine fuel, and electric power generation.

Energy: The capacity for doing work as measured in the capability of doing work (potential energy) or the conversion of this capability to motion (kinetic energy).

Energy-Intensity Ratio: The ratio of energy consumption per manufacturing output.

Energy Source: A substance such as natural gas, coal, or electricity that supplies heat or power.

Establishment: As defined by the 1987 Standard Industrial Classification Manual, "...an economic unit, generally at a single physical location, where business is conducted or where services or industrial operations are performed." (See Manufacturing Establishment.)

Ethane $\left(\mathrm{C}_{2} \mathrm{H}_{6}\right)$ : A colorless, odorless, gaseous hydrocarbon extracted from natural gas or refinery gas streams. Ethane is used primarily as a petrochemical feedstock for the production of chemicals and plastic materials.
Ethylene $\left(\mathrm{C}_{2} \mathrm{H}_{4}\right)$ : A colorless, flammable, gaseous olefinic hydrocarbon recovered from natural gas and petroleum. Ethylene is used primarily as a petrochemical feedstock for numerous chemical applications and the production of consumer goods.

Expenditures: Funds spent for energy purchased and paid for, or delivered to a manufacturer during a calendar year. For the purposes of the MECS, the expenditure dollar includes State and local taxes and delivery charges.

Fossil Fuel: Any naturally occurring organic fuel, such as coal, crude oil, and natural gas.

Fuel: Any substance that can be burned to produce heat.

Fuel Use (of Energy): Use of energy in the production of heat, steam, power, or the generation of electricity.

Generation: The process of producing steam or electrical energy by transforming other forms of energy.

Geothermal Energy: Hot water or steam, extracted from reservoirs in the earth's crust, which is generally supplied to steam turbines that drive generators to produce electricity.

Hydroelectric Power: Electricity generated by a turbine driven by falling water.

Hydrogen $\left(\mathrm{H}_{2}\right)$ : A colorless, odorless, highly flammable gaseous element; the lightest of all gases and the most abundant element in the universe.

Industrial Sector: A subdivision of U.S. economic activity defined by the Energy Information Administration to include manufacturing, construction, mining, agriculture, fishing, and forestry establishments.

Kilowatthour (kWh): A unit of work or energy, measured as 1,000 watts ( 1 kilowatt) of power expended for one hour. Once generated, one $\mathrm{kWh}$ is equivalent to $3,412 \mathrm{Btu}$.

Liquefied Petroleum Gases (LPG): Ethane, ethylene, propane, propylene, butane, butylene, ethane-propane mixtures, propane-butane mixtures, and isobutane produced at refineries or natural gas processing plants, including plants that fractionate raw natural gas plant liquids.

Lease Condensate: A natural gas liquid recovered from gas-well gas (associated and nonassociated) in 
lease separators or field facilities. Lease condensate consists primarily of pentanes and heavier hydrocarbons. Volumes are reported in terms of barrels of 42 U.S. gallons, at atmospheric pressure, and corrected to 60 degrees Fahrenheit.

Lease Separator: A facility located at the surface for the purposes of (1) separating casinghead gas from produced crude oil and water at the temperature and pressure conditions of the separator; and (2) separating gas from that portion of associated gas and nonassociated gas which liquefies at temperature and pressure conditions of the separator.

Lignite: A brownish-black coal of low rank with a high percentage of inherent moisture and volatile matter content. It is also referred to as brown coal.

Manufacturing Establishment: An economic unit at a single physical location where mechanical or chemical transformation of materials or substances into new products are performed. These operations are generally conducted in facilities described as plants, factories, or mills, and characteristically use power-driven machines and materials-handling equipment. In addition, the assembly of components of manufactured products is considered manufacturing, as in the blending of materials such as lubricating oils, plastics, resins, or liquors. (See Establishment.)

Manufacturing Sector (Division): One of 10 fields of economic activity defined by the Standard Industrial Classification Manual. The manufacturing sector includes all establishments engaged in the mechanical or chemical transformation of materials or substances into new products. Other divisions of the U.S. Economy are agriculture; forestry; fishing, hunting, and trapping; mining; construction; transportation; communications; electric, gas, and sanitary services; wholesale trade; retail trade; finance, insurance, and real estate; personal, business, professional, repair, recreation, and other services; and public administration. The establishments in the manufacturing sector constitute the universe for the MECS.

Motor Gasoline: A complex mixture of relatively volatile hydrocarbons, with or without small quantities of additives, obtained by blending appropriate refinery streams to form a fuel suitable for use in spark-ignition engines. Motor gasoline includes both leaded and unleaded grades of finished motor gasoline, blending components, and gasohol.
Natural Gas: A mixture of hydrocarbon compounds and small quantities of various nonhydrocarbons existing in the gaseous phase or in solution with oil in natural underground reservoirs at reservoir conditions. Natural gas may be subclassified as:

1. Associated Gas: Free natural gas, commonly known as gas-cap gas, which overlies and is in contact with crude oil in the reservoir.

2. Dissolved Gas: Natural gas which is in solution with crude oil in the reservoir at reservoir conditions.

3. Nonassociated Gas: Free natural gas not in contact with crude oil in the reservoir.

All natural gas volumes are reported in cubic feet at a pressure base of 14.73 psi, at 60 degrees Fahrenheit.

Net Electricity: A value obtained by summing purchases, transfers in, and generation from noncombustible renewable resources, minus quantities sold and transferred out. This value does not include electricity produced from onsite cogeneration or generation from combustible fuels because that energy has already been included as generating fuel (e.g., coal).

Net Steam: A value obtained by summing purchases, generation from renewables, and net transfers.

Net Industrial Hot Water: A value obtained by summing purchases, generation from renewables, and net transfers.

Nonfuel Use (of Energy): Use of energy as a feedstock or raw material input.

Petroleum Coke: A solid residue, high in carbon content and low in hydrogen, which is the final product of thermal decomposition in the condensation process in cracking crude oil. Petroleum coke can yield almost pure carbon or artificial graphite suitable for the production of carbon or graphite electrodes, structural graphite, motor brushes, dry cells, and similar products.

Petrochemical Feedstock: Chemical feedstocks derived from petroleum, and used principally for the manufacture of chemicals, synthetic rubber, and a variety of plastics.

Plant: Commonly used as a synonym for an establishment. However, the term can also be used to refer to a particular process within an establishment. 
Propane $\left(\mathrm{C}_{3} \mathrm{H}_{8}\right)$ : A colorless, gaseous hydrocarbon extracted from natural gas or refinery gas streams. It is used primarily for residential and commercial heating and cooling, and also as a fuel for transportation. Industrial applications include use as a petrochemical feedstock.

Propylene $\left(\mathrm{C}_{3} \mathrm{H}_{6}\right)$ : A gaseous hydrocarbon recovered from refinery processes. Propylene is used primarily as a petrochemical feedstock.

Pulping Liquor (Black Liquor): The alkaline spent liquor removed from the digesters in the process of chemically pulping wood. After evaporation, the liquor is burned as a fuel in a recovery furnace that permits the recovery of certain basic chemicals.

Quadrillion Btu: Equivalent to $10^{15} \mathrm{Btu}$.

Refinery: A plant, device, or process which heats crude oil so that it separates into chemical components, which are then distilled off as more usable substances.

Relative Standard Error (RSE): A percentage measure of the precision of a survey statistic. The RSE is defined as the standard error of a survey estimate divided by the survey estimate and multiplied by 100 . The standard error is the square root of the variance.

Residual Fuel Oil: The general classification for the heavier oils that remain after the distillate fuel oils and lighter hydrocarbons are distilled away in refinery operations. The classification includes No. 5 (light and heavy), No. 6 including heavy-grade, so called Bunker $\mathrm{C}$ oil), and Navy Special fuel oil.

Roundwood: Wood cut specifically for use as a fuel.

Short Ton: A unit of weight equal to 2,000 pounds.

Solar Energy: The radiant energy of the sun, which can be converted into other forms of energy, such as heat or electricity.

Standard Industrial Classification (SIC): A classification scheme developed by the Office of Management and Budget, which categorizes establishments into groups with similar economic activities.

Still Gas (Refinery Gas): Any form or mixture of gas produced in refineries by distillation, cracking, reforming, and other processes, the principal constituents of which are methane, hydrogen, ethane, ethylene, propane, propylene, butanes, butylene, etc.
Still gas is used as a petrochemical feedstock and as a fuel in refineries.

Storage Capacity: For the purposes of the MECS, storage capacity includes any volumetric capacity (including tank tops and tank bottoms) that is on the establishment site even if it is dedicated to or leased for the storage of an energy source by other establishments.

Subbituminous Coal: A dull, black coal of intermediate rank between lignite and bituminous coal. Subbituminous coal, like bituminous coal, is used as a fuel.

Turbine: A machine for generating rotary mechanical power from an energy stream (such as water, steam, or hot gas). Turbines convert kinetic energy to mechanical energy through the principles of impulse and reaction, or a mixture of the two.

Value of Shipments: This item covers the received or receivable net selling values, f.o.b. plant (exclusive of freight and taxes), of all products shipped as well as all miscellaneous receipts, such as receipts for contract work performed for others, installation and repair, sales of scrap, and sales of products bought and resold without further processing. Included are all items made by or for the establishments from materials owned by it, whether sold, transferred to other plants of the same company, or shipped on consignment. The net selling value of products made in one plant on a contractual basis from materials owned by another was reported by the plant providing the materials.

In the case of multiunit companies, the manufacturer was requested to report the value of products transferred to other establishments of the same company at full economic or commercial value, including not only the direct cost of production but also a reasonable proportion of "all other costs" (including company overhead) and profit.

Value Added by Manufacture: This measure of manufacturing activity is derived by subtracting the cost of materials, supplies, containers, fuel, purchased electricity, and contract work from value of shipments. The result of this calculation is adjusted by the addition of value added by merchandising operations (i.e., the difference between the sales value and the cost of merchandise sold without further manufacture, processing, or assembly) plus the net change in finished goods and work-in-process between the beginning- and end-of-year inventories. 
"Value Added" avoids the duplication in the figure for value of shipments that results from the use of products of some establishments as materials by others. Value added is considered to be the best value measure available for comparing the relative economic importance of manufacturing among industries.

Waste Materials: Otherwise discarded combustible materials which, when burned, produce energy for such purposes as space heating and electric power generation. The size of the waste may be reduced by shredders, grinders, or hammer mills. Noncombustible materials, if any, may be removed. The waste may be dried and then burned, either alone or in combination with fossil fuels.
Waste Oils and Tar: Petroleum-based materials that are worthless for any purpose other than fuel use.

Wind Energy: Energy present in wind motion that can be converted to mechanical energy for driving pumps, mills, and electric power generators. Wind pushes against sails, vanes, or blades radiating from a central rotating shaft.

Wood Waste: Wood byproducts used as a fuel. Included are limb wood, wood chips, bark, sawdust, forest residues, charcoal, and pulp waste. 